\title{
Responsibly Engaged: \\ Ideology and Utopia along the Backpacker Trail
}

By

Sonja Bohn

Submitted to the Victoria University of Wellington in fulfilment of the requirements for the degree of Master of Arts in Sociology 


\section{Abstract}

By following the backpacker trail beyond the 'tourist bubble,' travellers invest in the ideals of freedom, engagement, and responsibility. Backpacker discourse foregrounds travellers' freedom to mobility as it constructs the world as 'tourable'; engagement is demonstrated in the search for 'authentic' connections with cultural Others, beyond the reach of globalised capitalism; responsibility is shouldered by yearning to improve the lives of these Others, through capitalist development. While backpackers frequently question the attainability of these ideals, aspiring to them reveals a desire for a world that is open, diverse, and egalitarian. My perspective is framed by Fredric Jameson's reading of the interrelated concepts of ideology and utopia. While backpacker discourse functions ideologically to reify and obscure global inequalities, to entrench free market capitalism, and to limit the imagining of alternatives, it also figures for a utopian world in which such ideology is not necessary. Using this approach, I attempt to undertake critique of backpacker ideology without invalidating its utopian content, while seeking to reveal its limits. Overall, I suggest that latecapitalism subsumes utopian desires for a better way of living by presenting itself as the solution. This leaves backpackers feeling stranded, seeking to escape the ills of capitalism, via capitalism. 


\section{Acknowledgements}

I am grateful to the backpackers who generously shared their travel stories and reflections for the purposes of this research, I wish you well on your future journeys.

To my supervisors, Dr Chamsy el-Ojeili and Dr Patricia Nickel, thank you for your intellectual guidance that continually challenged and inspired me. Your infectious enthusiasm encouraged me to persevere with the challenges I encountered and brought much joy to the process. I am grateful to have had the opportunity to work with you both.

I also am grateful to Victoria University of Wellington for granting me a postgraduate scholarship, which enabled me to undertake this work. Thank you to all the academic and administrative staff members of the SACS department who contribute to its warm working environment. To my fellow postgraduate students, thank you for much needed discussions and distractions throughout the year. Special thanks to Josh Barton, Hollie Doar, Michael Gilchrist, Garrity Hill, Owen Hughes, Ryan O'Brian, and Jared Walton, as well as Caleb Anderson, Vanessa Bowden, and Lillian Fougere, for your insightful feedback and comments at various stages of the process.

To Vicky Holben and Sophie Williams, thank you for talking me through my crises, and Vicky, for telling me to "just type faster." Nicola and Riley Kenneally, thank you for your friendship to Freja and me. To my far-away-but-close friends, thank you for being in my heart.

Mum and Dad, your travel stories first taught me to dream and then to question, and this thesis owes much to long and passionate discussions with you and with you too, Yvonne. Thank you all for your support and especially to Mum for the little and the big things you have helped with throughout the year.

Most of all to Tim, thank you for being beside me always. Your love, engaging and challenging conversation, patience, humour, and meals sustain me. This would not have been possible without your hard work. Freja, your words, giggles, and tears remind me what really matters. This is for you both. 


\section{Contents}

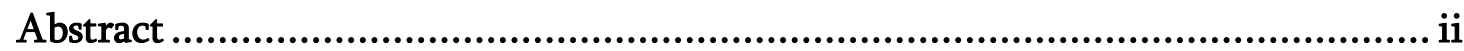

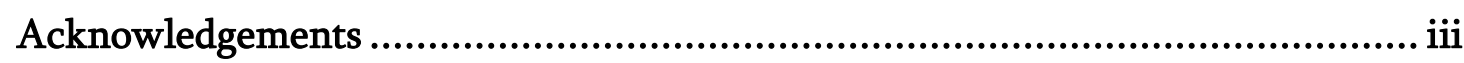

Introduction: Backpacker Dialectics ................................................................. 1

Backpacking and Globalisation................................................................

Theoretical Approach: Ideology and Utopia.................................................. 10

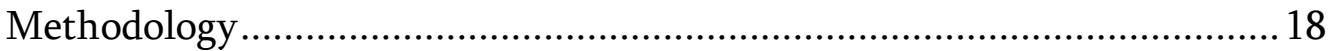

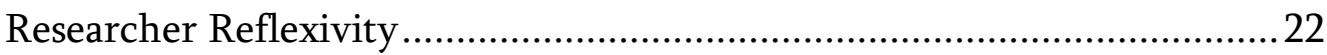

"Rough Guide" to the Thesis.......................................................................2

Chapter One: Freedom and Mobility in a 'Tourable' World ................................26

Catalogue of Destinations: a Counter-Culture Commercialised...................27

Discourse Cycles .......................................................................................... 32

Contested Label, Shared Ideals: Backpacker Identity ....................................36

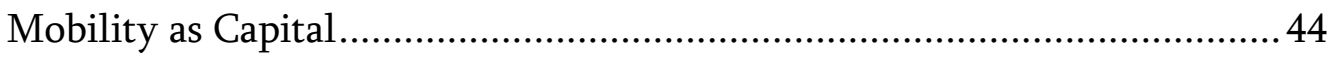

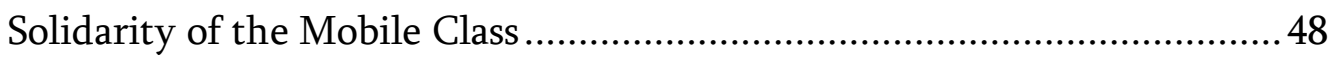

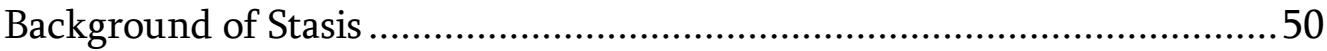

Conclusion: Guns and Cigarettes..............................................................52

Chapter Two: Engaging with the Real World ...................................................56

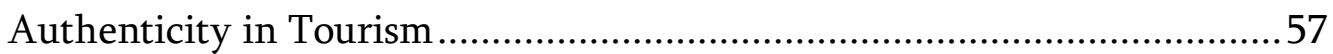

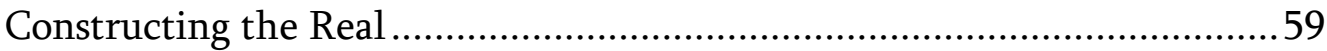

Utopia and Ideology in Guidebook Advice ..................................................63

Backpacker Ambivalence: The Abyss of Authenticity ..................................67 
Engaging With Difference: Fitting in With Utopia................................71

Utopia and Ideology: The Fragility of the Dream....................................74

Rupture: Confronted With the Self ..................................................... 78

Utopian Kernel in the Rupture.............................................................. 81

Conclusion: Back to the 'Bubble' .............................................................. 84

Chapter Three: Responsible Backpacking for a Better World ........................87

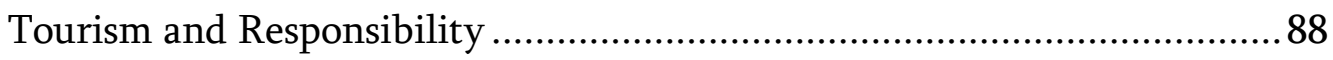

Dialectics of Development in Backpacker Discourse .............................. 93

Backpacking for a Better World ...................................................... 97

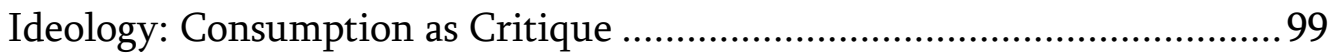

Utopia: Reflexivity and Limitations................................................ 102

Globalisation: Mapping the World through Travel................................. 108

Conclusion: Better Backpackers, a Better World.................................... 115

Conclusion: Ideology and Utopia along the Backpacker Trail .......................117

Appendix A: Participant Information Sheet ........................................... 124

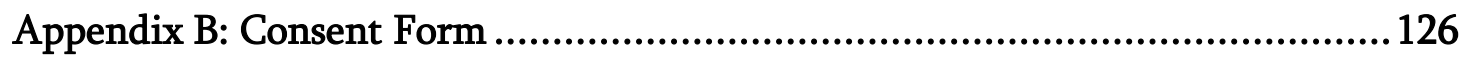

Appendix C: Interview Schedule ................................................... 128

References .............................................................................. 130 


\section{Introduction:}

\section{Backpacker Dialectics}

As they follow the backpacker trail beyond the tourist 'bubble,' travellers invest in the ideals of freedom, engagement, and responsibility. Although the achievement of these ideals is contested, aspiring to them is revealed as strongly in stories of failure as of success. This aspiration reveals a utopian desire for a world that is more open, diverse, and egalitarian: a world where individuals have a right to mobility, cultural diversity is celebrated, and equal opportunities are enjoyed by all. Backpackers attempt to realise this dream through two contradictory methods. The first is to strike out beyond the reach of 'globalised' modernity and corporate capitalism, to engage in authentic and equitable exchanges with cultural Others. The second is to take responsibility for the 'globalisation' of these Others through economic development and the spread of liberal values. The contradictory nature of these methods demonstrates the contradictory way in which globalisation itself is understood: as a force of cultural and economic homogenisation and domination, which backpackers seek to escape, as well as a driver of cultural diversity and economic opportunity for free and equal individuals. In their discourse and their practice, backpackers both celebrate and eschew these contradictory facets of globalisation, revealing their desire for a better way of living. 
Backpacker discourse can be read as both ideology and utopia. Although it potentially functions ideologically, by reifying and obscuring global inequalities, fortifying free market capitalism, and limiting the imagining of alternatives, it also figures for a utopian world in which such ideologies are not necessary. In this thesis, I draw on Jameson's $(2004 ; 2007 ; 2010)$ suggestion that ideology contains a utopian impulse, and attempt to undertake ideology critique without undermining these utopian contents. Instead, I explore how highlighting the traces of capitalism in backpacker discourse reveals both ideological limits and utopian possibilities (Jameson: 2010: 413). Overall, I suggest that late capitalism subsumes utopian desires for a better way of living by presenting itself as the solution. This leaves backpackers stranded, seeking to escape the ills of capitalism, via capitalism.

\section{Backpacking and Globalisation}

Theorists of contemporary globalised capitalism variously describe it as flexible, liquid, fast, disorganised, and mobile, as it becomes increasingly dominated by multinational corporations operating across state boundaries in the drive for lower production costs and more lucrative markets (Agger, 1989; Bauman, 2000; Lash and Urry, 1987). The complexity and mobility central to this 'free market' are a response to crises caused by capitalism's internal contradictions. As outlets for excess capital, temporal and spatial expansion temporarily fix crises of overaccumulation (Harvey, 1989). Thus, rather than representing a dramatic break from preceding forms of capital to a new post-industrial order, globalised freemarket (or late) capitalism is here understood as the 'purest' form yet, which has undergone "a prodigious expansion [...] into hitherto uncommodified areas" (Jameson, 2000: 217). This expansion, Jameson argues, is both geographic and substantive, incorporating the pre-industrial, the unconscious, nature, and importantly, culture, which has itself expanded throughout the social realm 
(Jameson, 2000: 226-227). Consequently, cultural shifts to postmodernism are more than stylistic, and approached from Jameson's Marxian perspective, can be seen as the ideological facet, or 'cultural logic,' of late capitalism (Jameson, 2000: 225; 1989; 1991).

In its vibrant, shiny pluralism and multiplicity, and its celebration of the signifier, postmodernism reflects the rapidity, fluidity, and diversity of third stage capitalism. It thus contains a "certain authenticity," in that its form "has genuine historical (and socioeconomic) reality as the third great original expansion of capitalism around the globe" (Jameson, 2000: 228). However, under postmodernism, the link between culture and capitalism is obscure, as the disorienting attributes of postmodern expression impede the capacity of individual subjects to 'cognitively map' their position in relation to the social structure to which they belong (Jameson, 1991). Consequently, the postmodern period appears to hail the end of totalising analyses and utopian visions, as the imagining of possible existences beyond capitalism are discredited (Jameson, 2000: 225). This postmodern culture functions ideologically, despite its potentially empowering emphasis on diversity (utopian contents). However, in this very failure of the utopian imagination, postmodernism highlights the structural limits to our thinking. As postmodernism distracts and blocks us from analysing the system as a totality, so it reveals a 'truth' about the system - that it is unknowable (Jameson, 1991: 49). As an attempt to represent our reality, postmodernism necessarily fails, and yet, in failing, somehow represents the totality's complexity and 'unmappability,' revealing our ideological constitution. Thus, Jameson argues, all attempts to supersede the system, to gain some distance for reflection, lead us straight back into it, but nonetheless represent a utopian desire for alternatives.

Jameson's positive and negative reading can also be applied to discourses of globalisation, by considering its economic and cultural facets. Prioritising 
globalisation's cultural effects, reveals a "postmodern celebration of difference and differentiation" where diverse cultures are in "tolerant contact with each other in a kind of immense cultural pluralism, which would be very difficult not to welcome" (Jameson, 2010: 437). However, economically, globalisation entails homogenisation rather than difference. This homogenisation occurs through the "rapid [and forced] assimilation of hitherto autonomous national markets and productive zones into a single sphere," from which 'delinking' is impossible and even unthinkable (Jameson, 2010: 437-438). But both these positions can be inverted. Cultural globalisation also entails homogeneity, "destruction of local differences, the massification of all the peoples on the planet" (Jameson, 2010: 438). Moreover, the free-market is often touted as a rich and exciting sphere in which human beings may grasp "their most fundamental human possibilities and the surest sources of freedom" (Jameson, 2010: 438). Thus, globalisation can be viewed as liberating and oppressive. The negative homogenising trends of globalisation, which operate both in its cultural and economic facets, are veiled by the free pluralistic utopian impulse, which also occurs in both facets. While this utopian vision legitimates and legitimises capitalist free market expansion, it is the functional link to domination and exploitation, rather than its 'contents,' which renders this particular utopia ideological.

As tourism is the second largest global industry (after oil), it significantly contributes to the expansion and persistence of capitalism (Fletcher, 2011). This industry can be linked to standardisation, exploitation, global inequality, and corporate dominance, or alternatively (especially in its sustainable or ethical variants), read as offering opportunities for economic development and freedom (Scheyvens, 2002; UNWTO, 2011b). Yet this economic development also leads to cultural homogeneity (Bauman, 1999; Bennett, 2008b), even while the industry relies on curiosity about cultural and geographic difference (Urry, 1995). Backpackers are caught between these contradictory sides of globalisation, and 
experience considerable ambivalence as to their effects. This thesis explores their imagining of this dialectic.

\section{Backpacking as 'Other Postmodern' Tourism}

Western tourism, within which backpacking is situated, is a modern phenomenon. Colonialism motivated, legitimised, and materially engendered travel; orientalism and romanticism continue to structure its discourses; and industrialised transportation and democratised leisure-time underlie its massification (Wang, 2000). Since World War Two, travel has become a marker of social status in the West, where democratic citizenship has come to include the 'right,' rather than merely the ability to travel (Urry, 1995: 165). ${ }^{1}$ In New Zealand, the 'overseas experience,' or 'OE,' an extended period of working and travelling overseas, is an "obligatory rite of cultural consumerism," central to many young peoples' transition to adulthood (Bell, 2002: 144), and a cultural institution (Haverig, 2007). ${ }^{2}$ In addition to the literal growth of tourism, mobility permeates contemporary lives in other ways. As Urry (1995: 148) argues, under disorganised capitalism, the incessant flow of information and finances means that people "are mobile most of the time, whether they are literally mobile or only experience simulated mobility through the incredible fluidity of multiple signs and electronic images." At the same time, many of the characteristics of tourism have flowed into the everyday; aesthetic consumption is not confined to tourism, and global diversity is conveniently available at the mall, the theme park, and in global cuisine. Despite these forms of 'virtual mobility,' the desire and need for physical

\footnotetext{
${ }^{1}$ Since the 1950s, international tourism arrivals have increased by 6.5 per cent annually. In 2010, 940 million international travellers were recorded, resulting in an estimated US\$919 billion of tourism receipts worldwide. In 2010 the growth was particularly strong in developing countries, which now make up to $47 \%$ of international arrivals (UNWTO, 2011b).

2 Because backpacker trips involve multiple and varied destinations and activities, the information the New Zealand government collects from departure and arrival cards, does not provide a clear quantitative picture New Zealanders backpacking in developing countries (Statistics New Zealand, 2011). This problem is not unique to New Zealand, as there is a derth of quantitative data on backpackers internationally (O'Reilly, 2006: 1001).
} 
proximity to places, people, or events remains, and exceeds tourism. Urry (2002a: 262) suggests:

The power to determine the corporeal mobility of oneself or of others is an important form of power in mobile societies, indeed it may well have become the most significant form of power with the emergence of awesomely mobile elites.

Thus, tourism is de-differentiated from the everyday, but certainly not dead. The postmodern tourist experience itself has become increasingly mediated: posttourists revel in the accelerated sensations of a "Disneyfied" world, without concern for discovering 'real' other cultures, treating tourism as pure aesthetic and sensual entertainment, without seeking deeper meanings (Urry, 2002b: 12; see also Bell and Lyall, 2002; and Frow, 1997).

However, not all tourism shares this postmodern light-heartedness. Uriely (1997) identifies an 'other postmodern' tourism, in which the search for the 'real' or the 'natural' remains a concern. This is evident in the post-Fordist niche marketing of individualised, flexible tours (as opposed to the modern market's standardised 'hordes'), which emphasise experiences with nature and 'other' cultures, while also being underpinned by a commitment to cultural sensitivity and sustainability (Munt, 1994). These combined ideals particularly encourage travel to the developing world, where cultural difference and environmental degradation are most visible. Munt draws on Bourdieu (1984) to argue that these interests satisfy the postmodern consumption tastes of the new middle class who struggle for distinction by participating in 'alternative' consumption practices. Although Munt primarily considers organised alternative tourism (such as eco-tours), I argue that most backpackers, or independent long-term travellers, also fit this category of 'other postmodern' tourist. ${ }^{3}$ Generally being young adults, and often students (aspiring members of the new middle class), they travel on a lower budget, but

\footnotetext{
${ }^{3}$ For an extended discussion on these distinctions, see chapter one.
} 
share concerns with individuality, flexibility, Otherness, and sustainability (Davidson, 2005; Cohen, 2004a; O'Reilly, 2006; Sørensen, 2003; Speed, 2008). Thus, I argue that backpackers distinguish themselves from mass tourists and posttourists by claiming to be freer (chapter one), more engaged (chapter two), and more responsible (chapter three).

\section{Perspectives on Backpacking}

The distinction between 'vulgar' tourists and 'noble' travellers has been in place since the industrialisation of mass tourism. This distinction rests upon the association of the traveller with the nineteenth century upper class, educational, 'grand tour;' and the tourist with middle class 'hordes,' considered vulgar consumers of 'pseudo-events' (Alneng, 2002; Boorstin, 1964; Wang, 2000). Despite MacCannell's (1976) seminal defence of the mass tourist as secular pilgrim, the distinction remains both in popular and academic discourse. In an early tourist typology, Cohen (1973: 89) identified the most un-institutionalised traveller as a 'drifter,' whom he characterised as "almost wholly immersed" in the host society, and alienated from the home culture. Despite the mainstreaming and commercialisation of backpacking since the 1970s, many travellers differentiate themselves from mainstream tourism by identifying with the drifter's ideals (Sørensen, 2003; O'Reilly, 2006; Kontogeorgopoulos, 2003; O'Reilly, 2005; Cohen, 2004a; Welk, 2004). The emergent literature on this sub-category of tourism generally falls into three categories. First, some are overtly connected to the tourism industry, and their concern is to count, categorise and ultimately improve backpacking. The second group pay particular attention to the understandings, experiences, and culture of backpackers themselves. The third, and rarer, critical perspective can be divided into those favouring a post-structural culturalist approach, usually focusing on the operation of discourse and power, and those (rarer still), offering a political economy perspective. 
A recent trilogy of books by the Backpacker Research Group is almost exclusively concerned with issues 'internal' to backpacker culture: behaviour, categorisation, identities, and experiences (Hannam and Ateljevic, 2008; Hannam and Diekmann, 2010; Richards and Wilson, 2004). Other, more ethnographic studies deal with the construction of identity, often drawing on Giddens' concept of self-reflexivity and Bourdieu's theory of distinction (Desforges, 2000; O'Reilly, 2006). Elsrud (2001) and Noy (2004) consider backpackers' narratives of risk and adventure as instrumental in identity creation, while Riley (1988), Sørensen (2003), Kontogeorgopoulos (2003), Muzaini (2006), and Molz (2006) explore backpacker culture 'on the road.' This literature is vital to understanding the experiences and perceptions of backpackers, and I draw on it throughout the thesis. But it does little to conceptualise the inequalities between backpackers and their hosts.

The critical perspectives on backpacking offer an important balance to analyses of backpacking culture, highlighting the power differentials that operate in the tourist-host relationship and examining the discourses that render the world asymmetrically 'tourable.' Many of these studies draw upon the Foucauldian concept of the 'tourist gaze,' developed by (Urry, 2002b), which suggests "the pure and innocent eye is a myth" (Urry and Larsen, 2011: 2):

Gazing at particular sights is conditioned by personal experiences and memories and framed by rules and styles, as well as by circulating images and texts of this and other places.

In this critical perspective, the power differentials entailed by this gaze are of interest. For example, Alneng (2002) examines the "pop-colonisation" of Vietnam by backpackers whose war movie-phantasms are indistinguishable from the country they travel in. Korpella (2010) explores colonial Othering by long-term sojourners in Varanasi, India, despite their professed post-colonial imaginations. Lozanski (2010: 745) treats the liberalism which underlies backpackers' interactions with the Other as "strategies of innocence," and examinations of 
guidebook texts reveal the reification of the Other as pre-modern and without agency (Bhattacharyya, 1997; Tegelberg, 2010). In general, these approaches treat backpacker ideals of engagement and responsibility towards the Other as false consciousness, dismissing the experiences that the first approach highlights as potentially life changing. As (Bennett, 2007: 28) put it, "McBackpackers" are a globalising force, and their liberal concerns for the Other are a "surface politics," the equivalent of salads at McDonalds (see also Hutnyk, 1996; and Phipps, 2004: for similar perspectives). In general, these studies also highlight, and sometimes attempt to redress, the absence of Other voices, both from popular tourism discourse and non-critical academic perspectives (Aitchison, 2001; Ateljevic and Doorne, 2005). The studies cited above are generally informed by poststructuralism and primarily treat tourism as a discursive and cultural phenomenon.

As Bianchi (2009), argues this 'critical turn' does little to examine the vast accumulation of capital and inequalities which underlie global tourism. Some theorists who provide a more material-structural perspective, are Britton (1982) from a political economy perspective, Duffy (2002) on ecotourism, and Fletcher (2011), who argues that tourism is one of the means by which capitalism seeks to 'fix' its inherent contradictions. However, the post-structural perspective views these political economy studies as essentialising and reductive, arguing that they contribute to the tourism industry's "Otherness machine," by further silencing subaltern voices and reducing complex power relations to economics (Aitchison, 2001: 143; see also Dann and Cohen, 1991). On the other hand, Bianchi (2009: 493) argues that concentrating on power at the expense of the economic means that:

At precisely the moment at which the nexus of economic and political forces has begun to promote an aggressive economic liberalism in tourism, the 'critical turn' appears to have retreated into a preoccupation with discourse and representation, leaving the study of the economic and political relations of power in tourism to those who whole-heartedly embrace neo-liberal globalisation and the free market. 
While there is considerable disagreement between these perspectives, this study is informed by all three, without necessarily resolving the tension between them. First, I am interested in backpackers' experiences and interpretations, but mainly of the outward-oriented aspects of their journey. As backpacking is a practice that transcends international borders and claims to broaden the mind, rather than focusing on self-reflexivity, I aim to make sense of backpackers' understanding of their position in the world. Second, I use critical discourse analysis to explore how backpacker narratives and experiences (the gaze) are structured by wider tourism and globalisation discourses. Thus mine is also a culture and discourse focused approach, which does not concretely analyse the material effects of backpacking. However, my understanding of discourse is that it is dialectically related to social and material structures in the 'real world' (Fairclough, 2006).

As a postmodern form of consumption, backpacking can also be theorised as a symptom of late capitalism. Positioned as it is, at the intersection of culture and economics, it offers an opportunity to analyse the relationship between these two, attempting to consider both the structural system of capitalism and people's experiences of and reflections about that system. I understand tourist gazes or experiences to be structured by discourses which are dialectically related to the broader social / economic structure of late capitalism. This reveals how their gaze may represent a quest for freedom, engagement, and responsibility - ideals that harbour a dream of, or desires for, a better world. Finally, I consider this dream in terms of ideology and utopia.

\section{Theoretical Approach: Ideology and Utopia}

In this thesis I understand ideology as "the ways in which meaning serves to establish and sustain relations of domination" (Thompson, 1990: 56). This 
definition emphasises ideology's functional relationship to power, and yet encourages engagement with the ideology's meaning or 'contents,' rather than simply dismissing these as false. Focusing on the meaning of ideology creates a space to understand the experience of ideology 'from within.' Ideologies may include a utopian impulse, understood as an "expression of the desire for a better way of being or living" (Levitas, 2005: 5). The purpose of my approach to ideology critique is to reveal, rather than dismiss and silence, such desires, so that their possibilities as well as their limitations may be discussed.

\section{Ideology Critique under Postmodern Suspicion}

Although nebulous and heterodox, post-Marxian critiques in general have argued that Marxist approaches to ideology constitute a positivist, totalising system that marginalises non-class-based political struggles, essentialises identities, is economically reductive, and is too closely associated with the memory of authoritarian communism (McLennan, 1996; el-Ojeili, 2010; Tormey and Townshend, 2006). To avoid these 'sins,' post-Marxists approach politics from a post-structural perspective, shifting their interest from class structure to the dynamic workings of power and agency, and favouring more localised identitybased struggles, over class antagonism (Tormey and Townshend, 2006; Reed, 2007). ${ }^{4}$ These perspectives, and the previously marginalised struggles they have brought into the centre of attention enrich critical theory, and I have no wish to undermine them. My argument with the post-Marxian project is only with its discrediting of attempts to analyse capitalism as a total system, because, although fragmented and complex, global capitalism is more, not less, pervasive today. I argue for a parallel (rather than replacement) return to analysing the effects of capitalism on social relations, on cultural life, and ideological constitution.

\footnotetext{
${ }^{4}$ However, Jameson (1989), McLennan (1996), Tormey and Townshend (2006) and Larrain (1994), all argue, that postmodern theory inadvertently and necessarily also commits some of these 'fallacies.'
} 
With late capitalism's global expansion, it seems the commodifying and stratifying effects of this singular division of labour and world market offer the one unifying system in a world which is otherwise plural and contingent. As Jameson insists, it is "capitalism which totalizes, which constitutes a total system, not its critics" (2010: 286). Considering capitalism's 'naturalistic' aura, produced both by market ideologies and by the lack of any actually existing alternatives, it is important to highlight the ways in which it shapes our social lives. However, Jameson's totalisation and historicism are not a replication of $19^{\text {th }}$ century orthodoxy, but more cultural and less essentialising or moralising than the post-Marxian critique implies. Rather than a fixed structure, Jameson's totality is an analytical concept that attempts to visualise the dominant mode of production, which is never completely homogenous or knowable (1989), and he interprets Marx's antihumanism as

perfectly consistent with contemporary existential, constructivist or anti-foundationalist and postmodern convictions which rule out presuppositions as to some pre-existing human nature or essence. If there have been not just one human nature but a whole series of them, this is because so-called human nature is historical: every society constructs its own. (Jameson, 2004: 37)

This is a process of historicising, or "showing how each cultural and social object is embedded in a complex web of dynamic social relations" (Hardt and Weeks, 2000: 11). Although this requires considering the influence of capital and the mode of production as a determinant, given the culturalisation of capitalism, this is not simple economic determinism; the mode of production is a system of social relations (which, it is true appear objectified) rather than mere economics (Hardt and Weeks, 2000: 11). The importance of historical materialism to ideological analysis is its ability to trace links between dominant ideology and the mode of production by which it is shaped. Thus, for Jameson, the final level of analysis is a text's relation to history, "conceived in its vastest sense, [as] the succession and 
destiny of the various human social formations, from prehistoric life to whatever far future history has in store for us" (Jameson, 1982: 75). As modes of production are human processes, I understand this as an argument of social construction, rather than crude economic determinism.

Post-Marxism emerged from the diversified social movements and post-structural revision of modernist positivism and Enlightenment epistemology of the 1960s (Tormey and Townshend, 2006). However, Jameson also links post-Marxism to the concurrent transformation in capitalism: if Marxism is the "science of the inherent contradictions of capitalism" it is small wonder that changes in the object of study have led to crises and eventual renewal of the accompanying theory (Jameson, 1996: 1). Postmodern anti-historicism, anti-totalisation, and anti-utopianism, are bound up with the fragmentation of class identities, the 'failure' of communism, the expansion, de-regulation, and acceleration of late capitalism, and neo-liberal ideology (Jameson, 1989: 34). This suggests that, rather than justifying the abandonment of ideological analysis, postmodern theory and culture function ideologically themselves, obscuring contradictions inherent to capitalism, strengthening global capitalism's aura of inevitability, and blocking the imagining of alternatives (1982; 2004). Thus Jameson (1991) historicises the post-Marxian critique, and constructs it as a "cultural dominant" or symptom of late capitalism. This operation clearly entails some reduction, but this is necessarily true of all theories that attempt to explain phenomena in terms of any system of meaning; in fact, some "regulative notion" is necessary to social explanation, and "remains close to the heart of what we mean by 'explanation' itself”' (McLennan, 1996: 58).

\section{The Problem of False Consciousness}

In addition to the post-Marxian suspicion of ideological analysis, many have challenged the idea of false consciousness, implied by the classical Marxian position that the ruling ideas are those of the ruling class. The problem with this 
perspective is that it treats agents as 'duped,' even to the point of abetting their own subjection, and implies that 'elitist' theorists have access to truths hidden from their subjects (Boltanski, 2011; Reed, 2007). Chiapello suggests a solution to this problem that combines the above meta-critical perspective with its polar opposite, a 'neutralised' understanding of ideology that refers to shared cultural knowledge and emphasises an integrative, rather than dominating social function. This can help to explain the attraction in ideology and the willingness of subjects to adhere to a system which they may know to be exploitative (Chiapello, 2003). Thus, ideology may at once legitimise power and be a legitimation of power (based on distortion or concealment) (2003: 161). These two aspects of ideology, suggest ideological analysis requires two steps. First, immanent analysis should examine "the meaning-world in which actions occur and the internal motivations of the actors themselves" (Reed, 2007: 7), this analysis 'from within,' recognises actors' understanding, critique, and contestations of ideology. Second, a process of historicising and totalisation should reveal how the ideology is determined by and functions to uphold the wider social and political context.

The Marxian understanding of ideology, however, includes a more materialist conception than the above focus on forms of knowledge: commodity fetishism and reification are more plainly a result of the dynamics of capital. Through the wage contract, capitalism reduces human relations to relations between objects, which conceal the real relations of production (Eagleton, 2007: 83). Apparently centred on inanimate objects, the social order appears neutral and inevitable, thereby forestalling critique, and values specific to capitalism present themselves as universal, 'natural,' and emancipatory. As Balibar puts it, commodity fetishism lets Marx recast the problem of objectivity; as fetishishised relations constitute the social world we live in and what we consider our very nature, these forms of thought are "socially valid and therefore objective" (2007: 66). Again, it is only by 
uncovering the workings of the system within them, that they are revealed as ideology (Jameson, 2010).

An example of this is the Marxian discussion of human rights (Balibar, 2007; Jameson, 2010). The concept of a universal human nature was subversive and emancipatory under the feudal system whose injustices were based on claims of inherent or natural inequality. However, under capitalism equality for individuals came simply to represent people's "equivalence as exchange value and commodified labour power" (Jameson, 2010: 327). This previously unknown conception of freedom through equality was presented as a "restoration of human nature" and yet it specifically functions through the market, where people are (only) as free as their purchasing (and labour) power permits (Balibar, 2007: 73). Human rights, in this context, are ideological in that they mask exploitation and claim to be natural. But they are also an expression of class struggle and emancipation. Thus, human rights appear universal, but in their current understanding are welded to market values. While not false, they function ideologically, and Balibar (2007: 75) argues a new emancipatory project must reveal this relationship, and dispute the fetishised nature of the rights, while preserving the rights themselves.

This discussion on human rights demonstrates the dual nature of ideology, and the two-fold nature of its analysis. While historicising reveals in whose interests ideology functions, and that this may change over time, we need also to detect the 'immanent truth,' or emancipatory utopian kernel of ideology. This involves describing, as Dowling (1984: 27) suggests Jameson does, "what reification might mean as experienced, so to speak from within - that is, not as an underlying economic process but as a mode of experiencing the world." I will attempt to address this by way of Jameson's concept of utopia within ideology and his method of reading both of these facets negatively as well as positively. 


\section{Utopia}

Popular definitions of utopia usually refer to Tomas More's (1516) Utopia, and stress that it is a 'good place,' which is simultaneously a 'non-place.' Defined in this way, utopia, like ideology, is popularly used to denigrate one's political opponents and their ideas: as naively unrealistic at best, or dangerously totalitarian at worst. Levitas (2005: 5) argues for a neutral and wide definition: "the expression of the desire for a better way of being or living." Following Ernst Bloch, she also argues that utopia is non-existent, in that it is not yet, and still not. On the other hand, she shows that as a desire, or impulse, it is both prevalent and important, in cultural and political forms (Levitas, 2007). Levitas' sensitivity to such impulses highlights that rather than having disappeared altogether, utopian thought persists, although socialist utopianism has largely been replaced by more fragmentary, individualised utopias (Bauman, 2003). In addition, contemporary utopias are often hidden by overt anti-utopianism. For example, dominant contemporary political discourse reserves the term utopianism as a charge to level at opponents (e.g. terrorists), while its own underlying utopianism is removed from debate. Unearthing visions of the 'good-life' that underlie ideology enables their evaluation and critique, and can reveal what is missing, but desired, in the present (Levitas, 2007).

Ideology and utopia are discussed as related but opposed by Manheim (1936); ideologies are the views by which the ruling class maintain their domination and utopias are the oppositional views of subordinated but rising groups. For Jameson, ideology and utopia are more dialectically interrelated. While he sees utopia and ideology as functionally opposed (ideology working in various ways to maintain the status-quo, utopia as progressive desires), he treats them as part of the same knowledge, discourse or practice; even those ideologies which serve to legitimise the most atrocious events include a utopian impulse (Jameson, 2004). At its most basic, he argues, ideology provides a sense of solidarity which he considers utopian 
because it "figures for the ultimate concrete collective life of an achieved Utopian or classless society" (1982: 291). This returns us to Chiapello's argument that ideology offers both cohesion and division, and is not necessarily false. In fact, it is precisely this "utopian moment" in ideology that lends it its power and appeal, and the ways it functions to perpetuate, instil, or conceal suffering renders it ideological in the negative sense (Žižek, 1997: 30).

Utopia can thus be identified by reading positively something that is in our time negative (dominant ideology) and seeing it as a 'seed' for a future change. The value of this lies as much in recognising the unfulfilled desires that are (mis)used by ideology, as in recognising their limits, or to show what cannot (yet) be grasped (Jameson, 2004). Because utopian dreams are tempered by the dreamer's class position and ideological formation, by looking at the limitations of utopia, we return to ideology critique. In fact, Jameson (2004: 46) suggests, utopia is

most authentic when we cannot imagine it. Its function lies not in helping us to imagine a better future but in demonstrating our utter incapacity to imagine such a future [...] is as to reveal the ideological closure of the system in which we are now trapped.

As the same time, elsewhere, he argues that although the utopian impulse is not political in itself, no politics is possible without it (Jameson, 2010: 433). Thus, ideology and utopia each exist in their negation of the other:

But the two terms must not cancel each other out; their disappearance would leave us back in that status quo that realm of current being which it was the function of the utopian fantasy to have negated in the first place. (Jameson, 2004: 50)

This demonstrates Jameson's dialectical method, in which he emphasises that resolving contradictions or arriving at synthesis is not the aim (Jameson 2010: 290). I am interested in the tension this creates. 
Jameson's understanding of utopia is clearly not the empty analytical category Levitas suggests, but is congruent with his own Marxian political project which underlies his analysis. Levitas argues that all critical sociology is motivated by some form of utopia itself, and that this needs to be laid bare rather than disguised through claims to scientific neutrality (Levitas, 2005). Thus, in this project I am aware that I am looking at backpackers' utopian imaginings through a theoretical framework that has its own utopian underpinnings. The extent to which these utopias merge and diverge will be discussed throughout.

\section{Methodology}

As a theoretically-driven project, my analytical strategy owes much to the preceding discussion of ideological and utopian analysis. However, my process has also been informed by critical discourse analysis (CDA), which has particularly enhanced my understanding of discourse as a part of wider social processes, while the tool-kit for linguistic analysis has been a more minor key (Fairclough, 2001: 121). This focus on discourse helps me to deal with the problem of representation and interpretation in interviews: to highlight how backpacker discourse is structured by and contributes to wider globalisation discourses (and globalisation itself), and to move the brunt of my critique from individuals to socially prevalent discourses.

A positivist approach to interviewing treats participants' responses as faithfully describing external reality or internal experience (Silverman 2005: 154). This approach then usually uses triangulation with another data source to attempt to 'test' the validity of what is said by the participants and how this is interpreted by the researcher. However, not only is this impractical (while participant observation may go some way to addressing this, I was unable to travel for this 
research), it is also epistemologically problematic as it disregards the multiple factors which mediate representation. Discourse analysis on the other hand is not concerned with the 'truth' of what is said, but considers texts as social processes. Despite its linguistic angle, the ultimate concern is with the social world, not language.

As opposed to post-structural approaches inspired by Foucault or Laclau and Mouffe, which see the social world as exclusively discursively constructed (Howarth, 2000: 4), Fairclough describes his approach as 'critical realism.' By this he means that while relations, structures, and practices are socially and discursively constructed, they nonetheless have a "material reality which is not conditional upon the fact or the nature of human knowledge of them" (Fairclough, 2006: 12). As such, "discourse is socially constitutive as well as socially shaped" (Fairclough and Wodak, 1997: 258). Discourse certainly operates in this way in tourism (see chapter one), ${ }^{5}$ where destinations and experiences are represented 'from above' in the form of advertising, guidebooks, policies, and more organically 'from below' in the form of diaries, letters blogs emails, slideshows and traveller stories (Fairclough and Wodak, 1997). These various genres overlap and influence each other, and are networked together in orders of discourse: they have differential relationships with power, and some function ideologically (Chiapello \& Fairclough, 2002: 194).

Focusing on discourse means my analysis of backpacker stories is not a comment on the narrators as individuals, but shows how broader discourses operate through travel stories (Lozanski, 2010: 742). CDA shifts the focus of ideological/utopian analysis from backpackers' consciousness or worldviews, which are difficult to access reliably, to discursive acts. This avoids "transforming the utopian impulse to inconsequential projections which carry no historical weight and imply no

\footnotetext{
${ }^{5}$ See also Dann (1996) for a sociolinguistic analysis of tourism.
} 
practical consequences for the social world as such" (Jameson, 2010: 416). Jameson's own solution to this is to focus primarily on material-structural analysis, suggesting that utopian impulses are glimpses of "higher relations of production" maturing "in the womb of the old society" (Marx, cited in Jameson 2010: 416). My study does, however, deal primarily with individual experiences, interpretations, and meaning-making. But analysing them as discourses that are dialectically related to the world of practices and real structures offers a link back to more structural analysis.

\section{Research Methods}

The empirical data for this thesis was collected from thirteen semi-structured interviews with fourteen individuals. Participants were recruited via notices put up at Victoria University of Wellington and the Wellington Public Library, as well as through the snowball technique. ${ }^{6}$ The posters requested people who had been 'backpacking' in 'developing countries'7 for a minimum of two months and I restricted partcipants to people currently living in New Zealand. Response to the notices was positive, and within one month six male participants had been recruited and interviewed. Due to this unexpected gender bias I made further posters requesting female participants, which quickly redressed the imbalance. Unfortuntately recordings of two interviews were lost before transcription. This was explained to the participants who were happy to read over and comment on my remembered notes. These notes were incorporated into the data. Due to this event I continued interviewing females, finally having full transcripts with six males and five females, and the additioinal notes from two interviews with three females. I have assigned all participants pseudonyms to protect their anonymity.

\footnotetext{
${ }^{6}$ The library was used to counteract the bias towards university students. However, high levels of tertiary education are characteristic of backpackers (O'Reilly, 2006)

${ }^{7}$ Both the terms 'backpacking' and 'developing country' are contested. I used them in the poster to target people who identify with them, and in the thesis I use them as socially constructed, popularly used, rather than objective terms.
} 
The average age of participants was 27.1 Five were completeing, or had, postgraduate degrees, six had completed undergraduate degrees, and three were current undergraduate students. This is similar to O'Reilly's research, where average age of backpackers was 26.4 and educational qualification levels relatively high (2006:1001; see also Sørensen, 2003, and Riley, 1988 for similar findings). Of the people I interviewed, all but two were New Zealanders, one was British and currently studying in New Zealand for several years, and one was Canadian, working in New Zealand as part of an ongoing world trip. Ethnically, nine identified as European or Pakeha, one as Maori/Euoropean, one as Maori, two as European/Asian and one as Sri Lankan. All had travelled in multiple countries, mainly in the Southeast Asian, South American, and African regions. Most had undertaken multiple overseas trips, but our conversation focused primarily on their most recent journey.

The interviews were conducted by loosely following a question guide (see Appendix $\mathrm{C}$ for an example), and as I gained experience and confidence interviewing, the format became even less rigid. This was beneficial as it allowed participants to tell their own stories in ways that made sense to them (May, 1997; Tolich and Davidson, 1999). I transcribed the interviews myself, which allowed close listenings and preliminary analysis of the data, which was then coded according to certain themes that seemed prelevant and relevant. Thus, the initial analyisis was content-based, and this was followed by closer readings of the selected excerpts, using some more technical features of CDA where appropriate. 


\section{Researcher Reflexivity}

As Levitas suggests, critical social science research is coloured by its own utopian underpinnings. This is also evident in much tourism literature, for example, the book dedication in Hannam and Anya's Beyond Backpacker Tourism reads: "To all our children, may they all be able to travel” (2010: iv). This reveals a two-fold wish on the behalf of the authors, first, that their particular children may be in a position to enjoy this privilege, and second, that the world remain or become more peaceful and 'open' to travellers. ${ }^{8}$ Even (or perhaps especially) the more critical accounts of travel often conclude with a statement that reveals the hope that tourism may somehow be practised more equitably or sustainably, not only transforming the industry itself, but also leading to wider positive effects. For example, Bennett (2007: 279), who sees backpackers as young neo-colonialists, advocates "listening literacy" and "political pedagogy" within tourism media to create a more sensitive industry that incorporates the voice of the Other. Although highly critical of backpacking in its current form, she sees backpacking as a “potential agent of global change" (p.279).

So what is my underlying utopian vision? At the outset of this research I very much hoped that backpackers, through their claimed difference and idealisation of the counter-cultural 'drifter,' were implicitly criticising capitalism, and seeking to imagine alternatives. I thought that travel to peripheral nations would help them cognitively map their positions in the world-system, leading to further critique of this very system. However, it appears their dreams of transcending capitalist relations frequently end in failure, and their investment in improving world is very much through capitalism. In addition, their reaction to witnessing global

\footnotetext{
${ }^{8}$ And also assumes that travel is inherently good!
} 
inequality occurs on a personal emotional level, resulting in a mixture of feeling lucky and guilty, rather than systemically critical; it seems the system is indeed too much to comprehend and map. Nonetheless, backpacker ideals add up to a desire for an open, democratic, and diverse world. This leads us back to the ideology/utopia of globalisation, in which these values sustain the contradictions of capitalism while also figuring for a better world.

My motivation for asking these questions originates in personally experiencing and struggling with these very dilemmas. So, although the dominant voice running through this thesis is one of critique, it is also an exercise in reflexivity; I have shared many of my participants' experiences, I am equally invested in their ideals, and my imagination of alternatives is equally limited. I am the daughter of Swiss migrants to New Zealand, who arrived here after two and a half years 'drifting' across Russia, Japan, and Southeast Asia in the mid-1970s. Throughout my childhood, my parents' travel stories and slideshows provided evenings of imagined and remembered adventure: it seemed to me that they knew and understood the world because they had seen it. And the traveller, in my mind, was indeed noble. However, my own travels in the 'developing world' threw up several troubling paradoxes, one example of I which can illustrate through the following excerpt from my travel notebook:

I think the link between travel and colonialism is very strong. We travel to relive the remembered and retold romance of colonialism and the dependency/money situation reproduces colonial relationships between Western travellers and locals. [...] Outwardly, it appears tourists are in control [...] but it doesn't actually feel like that does it? I mean we feel such awe and discomfort as we try to interact with another culture, and we are only accepted so far...

I realised from conversations with other travellers, I was not alone with these dilemmas, and my primary research question was how do (we) travellers reconcile our experiences with our ideals? How do we reflect upon our privileged position as 
consumers of poverty, when our ideal picture of the world is surely more egalitarian?

Often in writing about backpackers, I have been tempted to use the pronoun 'we' rather than 'they,' not only because I also belong to the 'mobile classes' (although during interviews I often had to bite back the temptation to interject with my own stories and participate in a demonstration of 'road status'), but also because I strongly identified with their broader worldviews. As mentioned earlier, this is not a critique of individuals and their practice or speech, but a critique of wider prevalent discourses, of which I am a part. Whence then comes my epistemological justification (distance) for critique? My attempts to uncover the traces of capitalism in backpacker discourse, through describing it as ideology and utopia are not meant as claims to 'higher knowledge.' Rather it is a theoretical lens I find useful. I am certainly not arguing that the backpackers could not also adopt this lens if they chose to: in fact, many do (just not fulltime for a year, as I have in writing this thesis). Where Bennett (2007) laments a lack of reflexivity in backpacker discourse, I identify plenty. However, I suggest that no amount of reflexivity about the contradictions between ideals and practice will change the world to match backpacker ideals. Only much broader ('total,' even) social change (whatever currently unimaginable form it may take), may one day resolve these contradictions, and realise the 'backpacker utopia.' This is why my method focuses on necessary failure and on underlining rather than resolving contradictions.

\section{"Rough Guide" to the Thesis}

Chapter one explores the ways in which backpacker discourse renders the world tourable, and how backpacking has become commercialised, mainstreamed, and is a form of 'other postmodern' tourism. The ideals backpackers invest in to 
distinguish themselves from mainstream tourists are defined as freedom, engagement and responsibility. I then discuss the first of these - freedom - in terms of backpackers' highly visible mobility. I consider the significance of this mobility under late capitalism and the dichotomy it creates with static Others. Although backpackers dream of a world where everyone has access to freedom, their own mobility relies on the (imagined) stasis of Others, and thus reinforces their subjugation.

Chapter two deals with the ways backpackers demonstrate their willingness to engage with the 'real world.' After a discussion of tourism literature around the concept of authenticity, I show how backpacking is predicated upon notions of authenticity constructed in relation to certain dreams. One dominant dream is the romantic notion of transcending modernity; however, for backpackers a more important dream is to achieve intimacy with Others. This is an attempt by backpackers to escape their status as colonial tourist-consumers, and to be accepted by the Other beyond the cash nexus. But this dream is notable for its fragility and frequent failure, which reveals certain limitations to the utopian imagination.

Chapter three focuses on backpacker investments in responsible travel. First, tourism discourses are analysed to reveal the common thread that tourism is linked to a utopian desire to improve the world in some way. Then I explore backpacker efforts to be 'responsible' travellers. Finally I explore whether travel engenders 'cognitive mapping' (Jameson, 1991), by looking at backpacker understandings of global inequality and their position in globalisation. I suggest that there is a tendency to focus on the positive aspects of globalisation and to view inequality in individualised terms. This results in backpackers seeming to individually shoulder a troubling sense of responsibility for the world, which they attempt to resolve by investing in ethical consumerism, charity, and discourses of 'luck.' 


\section{Chapter One:}

\section{Freedom and Mobility in a 'Tourable' World}

This chapter sets the scene: backpacking, once a marginal and counter-cultural practice is now mainstreamed and commercial, as backpackers consume a commodified world. The discourse reviewed in this chapter represents the global landscape as tourable and accessible, like objects in a catalogue. Nonetheless, backpackers distinguish themselves from mainstream tourists through their investment in the ideals of 'noble travel' by seeking depth through engagement and responsibility, beyond 'frivolous' consumerism. This subjectivity positions most participants in this study as 'other postmodern' tourists. I discuss backpackers' demonstration of freedom, in terms of their highly visible mobility, and suggest that under late capitalism this counts as cultural capital. To emphasise this, backpacker discourse depends on and reinforces the dichotomy between the mobility of the 'globalised' modern world and the (imagined) stasis of the Others backpackers travel past, reinforcing their subjugation. Throughout this chapter, I explore the tension apparent between the 'internal' understanding of backpackers' ideals, and the 'external' critique of their discourse as functioning ideologically. 


\section{Catalogue of Destinations: a Counter-Culture Commercialised}

Beyond your part of the planet lie mountain ranges with echo-bending canyons, tangled jungles, deserts that stretch into sanguine sunsets and yellow savannah veiling lions, wildbeast and springbok. There are retina-burning white beaches tapering off into gin-clear waters that serve as a playground for dolphins, turtles and manta rays. Not to mention over six-thousand languages, countless botanical wonders, architectural masterpieces and geological anomalies. All that is already out there. The decision to find it is yours. (The Rough Guide to First Time around the World, 2010: 4)

The drifter:

The type of [international] tourist [who] ventures furthest away from the beaten track [...] He [sic] shuns any kind of connection with the tourist establishment [...] He tries to live the way the people he visits live...The drifter has no fixed itinerary or timetable and no welldefined goals of travel. He is almost wholly immersed in his host culture (Cohen, 1972, cited in Cohen, 1973:89)

Erik Cohen originally wrote the above description of the 'drifter' in 1968 as part of a typology of tourists based on their engagement with cultural difference. As opposed to "organised mass tourists," travellers or 'drifters' were understood as an independent minority, venturing beyond the comforts of the tourist 'bubble,' and marginalised from their home societies (Cohen, 2004a). However, by 1973, drifting had become "one of the prevalent trends of contemporary tourism" (Cohen, 1973: 90). Even as it became more closely associated with counter-culture (the drugs, protests, and spiritual quests of the hippie-generation), it also became more institutionalised, as,

paradoxically it came to sudden prominence when established economic interests - e.g. the airlines - realized they could capitalize on the very alienation of this youths [sic], by providing them with cheap opportunities to escape. (Cohen, 1973: 94) 
If drifting was considered "both a symptom and an expression of broader alienative forces current among contemporary youth" (Cohen, 2004a: 44) of 1970s, few could argue that backpacking is an act of rebellion now. Taking time out from work-life to travel is an accepted 'rite of passage' for young Westerners. ${ }^{9}$ It represents youthfulness, freedom, and fulfilment, while also seen as leading to maturity, selfreliance, and enhanced career prospects back home (O'Reilly, 2006; Simpson, 2005; Desforges, 2000; Cremin, 2007; Bell, 2002). Although backpackers are difficult to quantify, the proliferation of services catering to them is testimony to their prevalence. In destination countries, well-trodden trails link 'backpacker enclaves' or 'bubbles' catering specifically to global youth culture. Khao San Road in Bangkok, backpacker gateway to Southeast Asia, had two guesthouses in the early 1980s: in 2003 there were several hundred, accompanied by travel agents, shops, fast-food outlets, souvenir stalls, restaurants and bars (Sørensen, 2003). In between home and destination, a plethora of commercial travel corporations and communication technologies organise, mediate, and regulate backpacker experiences. Guidebook publishers like the Rough Guide (cited above) or the Lonely Planet are major corporations, with the latter, commonly described as 'the backpacker bible,' selling about seven million books annually (Tegelberg, 2010). These are supplemented by websites such as Lonely Planet's Thorn Tree ${ }^{10}$ or the TripAdvisor $^{11}$, which offer opportunities for travellers to co-construct advice. Air travel companies sell flexible round-the-world tickets and, at the more preorganised end of the scale, companies such as Gapyear.com offer structured trips involving periods of volunteering and travel in developing countries for up to 10,000 British people annually (Simpson, 2005: 448). Thus, the backpacker

\footnotetext{
${ }^{9}$ Although globalisation and postcolonial scholarship reject the notion of a Western subject, the idea of this persists: and it is often used in backpacker discourse (Lozanski, 2010: 761). It is in this constructed and imagined sense that I use it.

${ }^{10}$ See: www.lonelyplanet.com/thorntree/index.jspa

${ }^{11}$ See: www.tripadvisor.co.uk
} 
experience is now commercialised and routinized, while also being flexible and individualised.

The quotation from The Rough Guide (Lansky, 2010: 4) at the start of this chapter is typical of the opening paragraphs of many travel guides: essentially its aim is to sell travellers the world. This illustrates Alneng's (2002: 485) argument that tourism "does not begin with the act of touring, but with the construction of a world picture that renders the world 'tourable.' " My reading of this 'sales-pitch' paragraph is that it achieves this by emphasising the world's appeal and accessibility. Appeal is created through the dichotomy between 'exotic' and 'normal' worlds. The text clearly addresses a reader from the latter, for whom the interesting destinations are "beyond your part of the planet." These destinations are constructed as Other (which qualifies them for tourist attention in the first place) and turned into objects to be gazed at, experienced, and consumed. Accessibility is constructed by the collapsing of geographical distance in this twosentence summary of the planet's 'natural wonders.' In the second half of this extract, Lansky turns to cultural attractions: multiple diverse languages, "botanical wonders," and "architectural masterpieces," are the traces of humanity considered worthwhile. The author introduces this sentence with the phrase "not to mention"; what he really fails to mention is the presence of living people for whom the 'exotic' is home. Many scholars, who argue that such silencing of local voices, agency, and potential resistance has political consequences, have identified this omission in guidebook discourse (Bennett, 2008b; Bhattacharyya, 1997; Tegelberg, 2010). The final two sentences ("All that is already out there. The decision to find it is yours."), reduce the structural privilege that enables travellers to enjoy the world's wonders to a simple, freely taken, individual consumer decision. Cremin (2007: 532) calls this "the injunction to enjoy," where questions about the processes which enable this enjoyment are obscured, by implying backpackers are people, "simply doing what it is they want to." Thus, I interpret 
this list of destinations and activities as presenting the world the way a catalogue presents products, at once encouraging and enabling travellers to claim it as their oyster.

Participants in the interviews for this thesis echoed such passages when summarising their itinerary. For example, Adam listed the following experiences:

Diving and snorkelling, and doing cycle touring in the Himalayas on a drop of a hat $[\ldots]$, bloody bus trips in the Himalayas were adrenaline sport enough, and yoga in Rishikesh, white water rafting the Ganges, camel riding in Egypt, camping out with the Bedouin for two weeks in the Western Desert, going between oasis and oasis...

To my reading, this itinerary again collapses vast geographic distances, cultures, and peoples, and constructs the world as a playground. Adam continued; "[Egypt] was one of the safest countries that we could find in the Middle East that we thought was going to be what we wanted." This weighing up of destinations, in terms of offering a pleasing mix of adventure and safety for the customer's satisfaction, demonstrates how tourism commodifies the world: it is backpackers' purchasing power and favourably viewed passports which allow such selectivity.

Although not all these backpacker experiences carry a price-tag, commodification in tourism is more ephemeral than the tickets and souvenirs which are literally purchased (Urry, 2002b). It includes the whole experience, the 'flavour' of a place, which is nonetheless 'sold' by guidebooks and in backpacker discourse. The process of commodification depends upon objectification and the subsequent ascription of value (even if not always strictly monetary) and suggests equivalence and exchangeability between objects (Jameson, 2010: Chapter 9). Even for backpackers who design a unique and serendipitous itinerary, the world as they experience it is packaged into an individually tailored combination of exoticism, risk, adventure, safety, and entertainment (Munt, 1994). In backpacker discourse, cycling in the Himalayas, yoga classes in India, the Ganges, Egyptian camels and 
the Bedouin 'way of life,' become things to be incorporated into this exchange system.

The backpacking industry promises access to an open, colourful, diverse world, and along its trails, it delivers on this promise to backpackers. Whenever they share their itinerary or travel story, they discursively reproduce this world. Backpackers really can, and frequently do, select their itinerary from a cataloguelike guidebook. Thus, at first glance, the backpacker travels in a 'tourable' world of consumable objects: a world that could suggest utopia is superfluous for the globalised citizen, for whom consumerism is "an end in itself," which is:

[...] transforming the daily life of the advanced countries in such a way as to suggest the Utopianism of multiple desires and consumption is already here and needs no further supplement. (Jameson, 2010: 413)

If this were the complete picture, there would be no need for ideological or utopian thinking. However, the world is a playground to some, only through the subjugation of Others. Quite apart from the discursive silencing of Others mentioned above, backpacker touring requires global economic inequality to render the 'world' affordable and exotic. Thus, while the picture of the world as 'tourable' is not ideological for its factual falsity, it is ideological insofar as it disguises the exploitation, inequality, and commodification at its centre. However, I will soon return to complicate this picture by looking at the ideals in which backpackers invest. These ideals suggest that backpackers strive to overcome this commodification and inequality, and when they are unable to, their dream may rupture, allowing unsettling awareness of their own position of privilege to seep into the backpacker experience. 


\section{Discourse Cycles}

Backpacker discourse is a particular representation of the world, which has real effects and real power. In this section, I explore the dialectical relationship between the wider orientalising 'order of discourse,' backpacker practice (the gaze), and real-world tourism development. Adam's catalogue or itinerary, above, was produced during the interview, but would likely occur in most situations where his story is shared with travellers and non-travellers alike. Each time it is told, the route taken becomes discursively solidified in listeners' imaginations, potentially influencing further travellers. This is how tourism discourse is circulatory: word of mouth, guidebooks, and other travel media provide anticipation and advice, affecting backpacker decisions of where to go and how to behave (Bhattacharyya, 1997). Combined with more institutional facets such as policy, infrastructure, and regulators such as UNESCO, this affects the physical and social world along the tourist trail, as destinations become more or less popular. These changes in the real world must then also feed back into the discourse, as travellers themselves retell their experience of these places, sharing photos, writing blogs, and giving advice, thus luring new potential travellers. ${ }^{12}$ This is an overt illustration of the dialectical relationship between discourse and practice, and of the statement that "discourse is socially constitutive as well as socially shaped" (Fairclough and Wodak, 1997: 258).

In turn, discourse structures the tourist gaze, and the anticipation of gazing:

[...] such anticipation is constructed and sustained through a variety of non-tourist practices, such as film [and other media], which construct that gaze. Such practices provide the signs in terms of which the

\footnotetext{
${ }^{12}$ For more on the linguistic character of tourism, see (Dann, 1996).
} 
holiday experiences are understood, so what is then seen is interpreted in terms of those pre-given categories. (Urry, 1995: 133)

The discourses through which experiences are interpreted, are neither neutral nor free-floating, but draw on and influence other discourses, that together make up an "order of discourse" (Fairclough, 2003: 31). Thus, tourism discourse is influenced by the dominant Orientalising discourses the West produces about the Rest. As Said argues (2003: 6), representation of the Other (discursive inequality) is enabled by, and further entrenches, real power imbalance; the West discursively constructed the Orient "because it could be - that is, submitted to being - made Oriental." The romantic and orientalist tropes from earlier European travellers' stories, such as the Grand Tour and colonial exploration, live on in contemporary tourist imaginations and discourses (Aitchison, 2001; Tegelberg, 2010; O'Reilly, 2006; Korpela, 2010; Bennett, 2008a). Guidebooks are particularly powerful as they offer an authoritative voice that directs and frames the tourist gaze. By careful editing and omission, they select worthwhile sights for travellers. Generally this is framed by the romanticist gaze, stressing "past glory and present exoticism" (Bhattacharyya, 1997: 378) This results in the omission of contemporary everyday lives and politics, and the silencing of local voices (Bennett, 2008b). Although I will discuss how backpackers actively seek to supersede this guidebook vision, for now I focus on the way dominant tropes nonetheless structure experiences. I suggest that the dominance of such discourses means that the experiences which (can be made to) fit them, are recognised as stories worth re-telling, and perpetuate the discourse.

Storytelling is an integral part of backpacking. Although intangible, stories are important souvenirs to bring home. Many travellers mentioned struggling to find enough willing listeners, and several explained this partly motivated their participation in my research. Through the following quotation, I hope to illustrate how the most successful travel stories conform to the dominant romantic 
discourse. Francis told me he was writing a book about his travels, and at the time of his interview, had already written several episodes into stories, including one about a rafting adventure on a tributary of the Amazon, which he retold in the interview:

We were just sort of bobbing along admiring the scenery [...] kind of like naively romantic scenes of life in Amazonia, like you know, flocks of screeching parrots flying overhead and an old canoe pulled up on a sandbank, and Quechua women doing their washing in the river with their children. [Emphasis added]

Francis went on to tell me how he and his friend were subsequently thrown from their raft by rapids, and trapped on the wrong side of the river. At the time of the interview, this was an already-crafted story that fits into the romantic trope, with indigenous life presented as a simple, peaceful idyll set in the sublime beauty of nature, where danger lurks just beneath the surface. Francis' use of the term "naively romantic" suggests he is quite consciously recreating this trope. He may have even already been using this set of symbols to frame his gaze at the time of the experience. Francis later explained why this is the story he tells the most often:

Because that's, that's like the most classic kind of adventure because like, fearing for my life on the river, climbing around the side of a cliff [...]. At parties when I meet new people it's always good, when you're breaking ice you can bust out these insane travel stories [...]. Like, a lot of people kind of find it really interesting or sort of impressive.

For Francis this is a story worth telling because it conforms to popular expectations of the travel adventure. Constructing the landscape according to this trope also allows the traveller to present himself as the brave adventurer/explorer, enduring physical challenges. As O'Reilly (2006: 1003) points out, he is pitted "(the ideal is generally a 'he') against the forces of nature, savage 'Others,' and his own physical and psychological limits.”

Because this story is influenced by and contributes to well-known discourses, telling it affords Francis considerable cultural capital. On the other hand, Alana, 
for whom the challenges of her journey were at times too terrifying to bear (she cut her trip to India short), expressed trouble communicating this to her friends and family, because "people only want to hear that you had a good time." This suggests that she felt pressured to make her experience into a story that confirmed her listeners' expectations of overseas travel. Lozanski (2011: 477) even found that backpackers whose travel experiences did not neatly fit with their expectations were reluctant to talk about this, "a reluctance undoubtedly infused by both representations of travel in popular culture and the consciously constructed narratives of other travellers." So, in retelling travel stories, travellers

[... select certain parts of their experience, cutting them up, exaggerating for effect, making connections among different places: in short using a whole host of narrative devices to communicate some kind of story to others. (Desforges, 2000:938)

The way in which in which travellers select and edit experiences for retelling, while others are left out or even forgotten, is influenced by dominant tourism discourses, which are in turn related to wider orientalising tropes. At the same time, those discourses structure the traveller gaze, to the point where objects which do not conform to the expected discourse about a region are rendered 'invisible.' As Cohen (cited in Phipps, 2002:84) has observed, travellers to Thailand visit the northern regions specifically to observe the "hill tribe" people, while the south is known exclusively for its beaches and party culture. In the southern areas, visitors demonstrate almost "complete indifference to the existence of 'exotic' and vibrant village life a hundred metres inland from the beaches that so captivate them." This compartmentalised gaze is no doubt influenced by a host of factors (the historic development of specific industries to profit from these different 'attractions'), but it also illustrates what (Alneng, 2002: 467) means by saying: "To successfully become tourists we dream on until our dreams come true; the world is called upon to live up to the phantasms of it." This is how backpackers experience the world, because that part of the world that seeks to profit from them eagerly shapes itself to their imagination. Thus, the 'banana pancake trail' becomes 
discursively solidified or frozen, and real (Agger, 1989), and backpacker discourse functions as ideology. However, if we now turn our analysis to backpackers' reflections on their practice, rather than discourse produced in storytelling or in guidebooks, and look at how this ideology is experienced from within, we find that backpacker's expressed ideals are at odds with this process.

\section{Contested Label, Shared Ideals: Backpacker Identity}

Tourists stay in Hiltons, travellers don't... The traveller wants to see the country at ground level, to breathe it, experience it - live it. This usually requires two things the tourist can't provide - more time and less money. (Tony Wheeler, Lonely Planet co-founder, cited in Welk, 2007: 84)

As discussed, independent long-term travel has become increasingly popular, institutionalised, and commercialised. At the same time, organised package tourism is more flexible and individually tailored than the modernist tourist 'hordes' were, reflecting a wider shift to post-Fordist consumption (Frow, 1997; Munt, 1994; Uriely, 1997; Urry, 1995; 2002b). This has led some theorists to question the empirical validity of the distinction between these two categories (Uriely et al., 2002; Sørensen, 2003). Despite this conflation in objective terms, backpacker or traveller remains a self-proclaimed identity, which "makes sense from an insider's point of view" (Sørensen 2003:852), and, as the quotation above indicates, is also perpetuated by the guidebook industry and other popular travel media.

This identity is primarily based on people's vehement self-distinction from tourists (Welk, 2004; Sørensen, 2003), although empirical observation suggests their behaviour resembles that of mass tourists, considerably more than they would like to admit (Cohen, 2004a; O'Reilly, 2006). Part of this distinction is a continued 
idealisation of the 'drifter's' attributes: long-term, low-budget travel, physical hardship, spontaneity (O'Reilly, 2006; Riley, 1988), an emphasis on freedom and open-mindedness (Welk, 2004: 80), seeking personal growth and cultural sensitivity in engagement with the Other (Lozanski, 2010). The degree to which people can claim to attain these badges enhances their "road status" as backpackers, not tourists (Riley, 1988). However, the mainstreaming, commercialisation, and institutionalisation of backpacking has not escaped these idealists, and those who see themselves as more alternative often prefer the words traveller, real traveller, or nomad (Noy, 2004; Sørensen, 2003), which Welk calls "post-backpacking” (2004: 89). Whatever the label, the distinction between 'vulgar' and 'noble' traveller remains.

Participants in this study reproduced the contestation found by other researchers in terms of their identification with the labels 'traveller,' 'tourist,' or 'backpacker,' and there was no agreement as to which term was more appropriate. Many laughed when I asked this question, and distanced themselves from the debate. However, it became clear that while there was little agreement over which label to choose, nearly all saw themselves as different and better than mainstream tourists, due to their willingness to engage responsibly with the real world. As Hannah explained, tourists are egotistical - it is their holiday, their relaxation, their fun whereas backpackers/travellers aim to learn about the world around them. Francis expressed the following 'post-backpacking' sentiment:

Not a tourist not a backpacker, no, definitely traveller [...]. Both those words to me imply a certain degree of aloofness from the culture of the country you're travelling in. You're just kind of seeing the sights. But I mean I was getting to know locals a bit more and also sort of getting off the beaten path and doing my own things a bit. I wasn't just seeing it on the gringo trail. I mean I did see [...] some of the major biggest attractions that everyone goes to [...]. But I did see a lot of little areas that not many people go to. 
Francis defines himself as a traveller because of the unique activities he undertook in addition to, not instead of, the 'gringo trail,' and he defines himself through this alternative activity, highlighting his investment in less commercialised, unique experiences and in achieving proximity with 'local' peoples and cultures. Dean's answer reveals a suspicion that there may be little objective difference between the labels, but that he chooses to call himself a traveller: "I think I fit into whatever definition there is of tourists, probably actually I fit into all three categories, but I'd probably call myself a traveller." Thus, Dean suggests that the difference between the labels is little more than symbolic, while still ascribing a normative value to different travelling styles. Throughout his narrative, Dean distanced himself from developed and commercialised tourism areas for two reasons. On the one hand, this enhanced his journey, as he experienced remote places as more authentic (see chapter two); and on the other hand, it stemmed from his concern about the impact of tourism (see chapter three). He continued: "I do fully try not to participate in the mainstream tourism that would have a strong impact." Instead, he made efforts to be environmentally and culturally sensitive.

According to Camille, travel style is irrelevant as long as one's attitude is open and engaged. For example, she said she thinks backpackers, travellers and tourists are "all the same thing," and criticised travellers who seem to compete to travel the furthest, with the smallest budget and the smallest pack. She said:

What does it matter, as long as you're open-minded to the experiences and like actually absorbing some information about where you are, then that's a positive thing.

She reflected the same concerns as Dean when she explained her aversion to flying:

Um it's because I'm really conscious of my environmental impact when I'm travelling and like [the carbon emissions from] flights just add up so quickly $[\ldots]$. And also I think like you get more of an authentic 
experience like taking the boat with the locals than, you know, flying with the white people.

Most participants reflected these twin ideals of engagement and responsibility, whether in their description of their own travel or their derision of other travellers. Isobel was critical of "tourists" who travelled more "superficially," "normally for two weeks, three weeks," and she criticised people who stayed in the hostel taking drugs or "had been there for a year and could barely say Hola." For her, learning the language and speaking with locals was part of travel:

And I guess, so that's more like backpacker level maybe versus hotel, you can, you're getting a bit more down and dirty, like you're not so much on the tour trail. [emphasis added]

Here she reflects Tony Wheeler's assertion, cited earlier, that travellers see the world at "ground level," indicating a willingness to go to considerable effort (learning the language) to do so. Chris criticised people who see travel in the developing world as a "chance $[. .$.$] to go and live like millionaires." The point of$ his trip, he said, was not to "just to blast through the Thai islands and go and ride an elephant and come home," but to slow down (18 months, 7 countries) to travel cheaply, very nearly fitting into Wheeler's 'more time, less money' definition. This meant thinking of it as "living as locals overseas," travelling with locals on the cheapest transport, learning as much of the local language as possible "so we could interact and barter in the market place." Living as cheaply as possible, and appearing poor through dress or behaviour has been discussed as a badge of road status (Riley, 1988), but it has also been identified as a factor through which backpackers attempt authenticity (Lozanski, 2010; Molz, 2006; Muzaini, 2006). In the context of seeing the country at "ground level," this relates to both of the main backpacker ideals, as it demonstrates willingness to dispense with the luxuries of the developed world and to renounce the hierarchies of (neo)colonial relationships between traveller and local. 
Although participants in this study did not uniformly identify with a particular tourist-label, and several rejected this debate altogether, ${ }^{13}$ most distanced themselves from the 'aloof' and superficial attitude associated with mass-tourists, and from hedonistic party-travellers considered characteristic of the mainstream backpacker. Or, they attempted to "overcome not only the neo-coloniality associated with mass tourism to the Third World [...], but also the neo-coloniality associated with the hedonistic travel (Lozanski, 2007: 298). Participants in this study shared investment in an ideal construction of 'noble' traveller, who demonstrates an engaged, responsible attitude in relation to the 'real' world.

Because authenticity, or the 'real world,' is negatively affected by commodification, as I will discuss in chapter two, backpackers eschew the tourist industry. Therefore, many attempt to achieve their ideals through activities that lie beyond 'typical' backpacker activities. Over half the participants in this study included more sedentary periods as a part of the trip they talked to me about, especially as volunteers. Initially, I saw these activities as separate from the backpacking journey, and focused on periods when participants were travelling. This distinction is also made by Mustonen (2006: 160), who argues that although volunteering is similar to backpacking in many respects, the altruism that motivates it makes volunteering a "clearly separate form of tourism," more a "postmodern pilgrimage." However, as my research progressed, it became clear that for many participants these activities were central, and it was largely through these activities that they spoke about the ideals of engagement and responsibility. Brian illustrated this through the following comments, which are indicative of the reflexivity and self-analysis backpackers undertake:

So backpackers are an incredibly um, pretentious bunch. Um, who I try and distance myself [from] as much as I possibly can because they're always after finding themselves and the authentic experience and they

\footnotetext{
${ }^{13}$ For example Adam, who is in his early thirties, said that while he felt passionate about this debate in his youth, now he does "not care what you call me."
} 
frown on tourists and, um... frown on the insincerity and ingenuine [sic] experiences of places.

In this passage, Brian appears scornful of backpacker desires for authenticity. It later became apparent he nonetheless valued engagement and responsibility, but achieved them through volunteering, and his scorn was related to the idea that these were attainable through backpacking:

I'd say [volunteering is] much better than backpacking, because you get to do something, you feel more worthwhile [...], because of what you're doing. You don't feel like a tourist, I mean that's probably why....um. You get to know people and it's a great introduction to the country as well. You get to know customs.

Brian is not unaware of the contradiction between these two statements, as he later addressed this by continuing his unfinished thought, "That's probably why..."

And that comes back to the whole ego trip about backpackers, trying to go to the most remote places. [...] But I'm definitely a part of that. Because maybe volunteering, maybe that was the reason for my volunteering, maybe it was just an ego trip, because I wanted to go to these remote places [...] but um, yeah, maybe that was just part of the ego trip [laughs], who knows.

Thus, he reflexively acknowledges his implication in the status-seeking culture of backpacking, and brings volunteering back into this scheme. Although it appears to be beyond the backpacker industry, Brian suggests volunteering is nevertheless mainly an avenue for achieving the backpacker or 'drifter' ideals, which (commercialised and mainstreamed) backpacking can no longer cater to. Thus, in this thesis the category of backpacking is heterogeneous and stretchy. Reflecting further, Brian said:

Backpackers, they're always thinkers at least. [...] They're trying to see the world [...] I mean they're there for a reason. They're not there just for their... I sound so pretentious [laughs] but um. I mean if you choose to go anywhere, I mean like there's people [in my hometown] that you chat to, they've never left $[\ldots]$, don't see the point. 
In Brian's story then, we see that trying to see the world, to get to know Other customs and to do something worthwhile is valued, even if backpacking is not a successful way of achieving this, or if attempting to achieve this is "just part of the ego trip." This is the closest to a generalisable statement about the participants in this study: engagement and responsibility are goals to strive for, but there is little certainty about how, or even whether, these ideals are achievable. Backpackers demonstrate their willingness to engage with the real world, not simply by looking beyond the comforts of the tourist 'bubble,' but by experiencing it, by living it at 'ground level.' In addition, they hope to contribute positively to the places they travel through, or at least minimise the negative impacts of their travel, taking some responsibility to address global inequality. Although backpacker discourses include at least as many stories where these ideals have failed, as where they have succeeded, the striving for them suggests utopian desire for a better world: a world in which hierarchies and inequalities melt away, and the differences between people are merely a matter of cultural curiosity. Analysing backpacker ideals as they are reflexively understood and experienced, 'from within,' highlights a level of awareness that challenges the view that backpackers are ideological dupes, and indicates reflexivity about, and discomfort at, the commodified nature of the 'tourable world.'

The backpacker ideals of engagement and responsibility are contrary to the postmodern emphasis on playfulness or the celebration of accelerated experiences of the simulational postmodern tourist. So I suggest backpackers fall into the category of 'other postmodern' tourists, whose behaviour Munt (1994: 104-105) suggests reflects,

the growth of interest in mass and minority (non-Western) cultures, religious traditions, ethnicity, and environment and ecology, all of which find special (though not exclusive) expression in Third and Fourth World 'otherness.' 
However, this categorisation is not entirely clear-cut, as many also mentioned the lighter, more hedonistic side of travel, staying on beaches, 'partying' with other travellers - in short, indulging in a freer and more luxurious lifestyle than they can afford at home. However, participants' near apologetic explanations for such activities (see chapter three, or consider Chris' comment: "we were going for the less touristy type stuff, but I do have a thing for beaches") suggests that these activities do not bear the same symbolic value. ${ }^{14}$ As Chris said, "You don't want to have that ' $t$ ' word, like you don't want to think of yourself as a tourist." The pronoun 'you' here appears to be a generalised: 'nobody' wants to be called a tourist. This again raises the question of the validity of categorisation by selfdifferentiation, or whether, as (Larsen et al., 2011) suggest, there may be a tendency among all tourism industry niches to distinguish from the mainstream, as they vie for middle class hegemony (Munt, 1994: 107; Noy, 2004; O'Reilly, 2006).

Thus, my study cannot confidently attest to the objective difference of backpackers, or even that their investment in difference is unique. However, one participant may be the exception that proves the rule (or tendency), as he overtly reflected 'post-tourist' predispositions, often prioritising the entertainment or aesthetic value of an experience over the 'deeper' concerns of the other participants. In fact, in every chapter of this thesis, I will cite Erik as exceptional in some way. As the only person who spoke about being in paid employment overseas, he could appear to be 'living like a local' but paradoxically, he said:

I love playing tourists, it's great. Um, even when I was working in places I purposely would leave work, get my shirt and everything off, put my shorts and everything on, just so I looked like a tourist.

When I said that he was the first person whom I had talked to who had wanted to appear as a tourist, he explained it like this:

\footnotetext{
${ }^{14}$ This may be context dependent - a conversation amongst friends may have a different emphasis to a research interview - I am conscious of this question, although the answer lies beyond the scope of this research.
} 
I would rather be a tourist sometimes because it's just a bit more fun. They're kind of like, 'ah he's just another stupid tourist. Let's make a leeway, we'll try and rip him off more, but basically we'll be friendly' [laughs]

Thus, while most were anxious to distance themselves from 'vulgar' tourists and present themselves as 'better,' this was not the case for Erik, who relished the 'fun,' or the ludic nature of post-tourism (Urry, 2002b). He preferred the friendliness offered by the tourism industry, even though he saw it as contrived by people who saw him as "just another stupid tourist," and who inflated the prices to suit. Thus, Erik did not invest in distinguishing himself from post-tourism to the same extent as most backpackers with whom I spoke. This lends some validity to the distinction in which the majority of participants invest - although they did not uniformly reproduce the contestation between the labels backpacker, traveller, and tourist, the majority invested in the ideals behind the 'noble traveller' distinction.

\section{Mobility as Capital}

Stepping back 'outside' of the experience in my analysis, I read the investment in the ideal of 'noble' traveller as symbolically important, as this is a consumption practice that functions as sign value (Baudrillard, 1981) or as cultural capital (Bourdieu, 1984). As Munt (1994: 106), explains, postmodern 'cultural' consumption is a key resource for the new middle class to construct a distinctive habitus "which provides the basis for class reproduction and differentiation." From this perspective, the anti-tourism sentiment is used by backpackers to assert their position by declaring themselves both more tasteful (sensitive, respectful, serious) than 'hedonistic' travellers, and more engaged and flexible than luxury or package tourists. Situated as they are among the young or aspiring new middle class, they do not have the economic capital to participate in either chic-or eco-tourism. 
Therefore, their differentiation is predicated on their travel style - slower, longerterm, low budget and authenticity-seeking (Kontogeorgopoulos, 2003: 197; Lozanski, 2010; Munt, 1994) and, I argue, their attitude - engaged and responsible. Bourdieu argues that this class faction particularly scorn categorisation, as they are "caught rather uneasily on the classificatory fence between the classes below and the bourgeoisie and upper classes above" (Munt, 1994: 107). Instead, they invest in activities considered 'alternative' by intellectualising and professionalising consumption practices. Intellectualisation occurs by travellers prioritising the educative, serious, rather than hedonistic aspects of travel in their discourse. And professionalisation of travel occurs in the reduced distinction between work and leisure travel, mentioned previously. But travel, even when it is 'time out' from work, often contributes to enhancing career prospects upon return. So when travel appears as a positive attribute on a $\mathrm{CV}$, cultural capital can be re-exchanged for enhanced financial capital (Cremin, 2007; O'Reilly, 2006; Simpson, 2005). Some employable attributes backpackers hope to gain are independence, self-reliance, coping under pressure and the acquisition of other languages. Such a reading of the backpacker industry also links back to my earlier argument about commodification: not only do apparently un-transactional experiences form part of the overall backpacker commodity, but this understanding of alternative forms of capital transforms travel itself into a commodity with exchange value (Munt, 1994: 109).

Reading travel through this literature suggests that mobility itself is an important aspect of this alternative capital. Through it, young people demonstrate their capacity to take up the 'freedom' late capitalism offers them. Under late capitalism, (financial) capital is highly mobile and employment is increasingly temporary, even for the service classes. Thus, the capacity for mobility or flexibility "has become a hot commodity" (Molz, 2006: 9). Participating in globalised work spaces, 
families, and social networks presumes a "compulsion," and a "right" to virtual and embodied mobility:

A modern person is one who is able to exercise those rights and who conceives of him or herself as a consumer of other cultures and places throughout the world. (Urry, 1995:165)

Through describing the spontaneity and serendipity which characterise their travel routes, backpackers demonstrate flexibility and mobility - their ability to take up the freedoms of globalisation. Very often, only a few sights or events are fixed in a pre-planned itinerary: for Eric it was the Great Wall of China; Gemma and Chloe pre-booked the 'Gibbeon Experience' (three nights staying in jungle tree-huts); and Megan planned around the carnival in Brazil. But, for many, only flights were pre-booked. This flexibility allows backpackers the freedom to never miss out, and to make the most of unexpected opportunities or friendships. It also means that if a place fails to satisfy, they will quickly move on to another, more promising, location:

So I plan a very broad route around a country maybe, and then find out what's good on that route, and if I'm bored in a place, I carry on quickly. (Brian)

I'd say if I find a place I like, I'll hang around until I feel like leaving. So, like in Bali we had mopeds and that was, that was perfect. So we could do whatever we wanted. And if we didn't like a place, we'd just leave the next day. If we, yeah, if we did like it, or if we got a deal on a hostel or something for staying extra nights, we'd probably do that. (Dean)

This flexibility shows the importance, not only of 'liking' places but of mobility itself. To reconsider Urry's (2002a: 262) suggestions that determining one's mobility "may well have become the most significant form of power," this spontaneity could be read as just such a demonstration of power. This is particularly pertinent in some instances, where it seems the aim was simply to be 
travelling, while destination itself was rather secondary. The point, it seemed, was not to go somewhere, but simply to go.

We were just both like, 'well, what shall we do?' It was like, 'well, let's jump on a plane and do something else.' So we basically just packed up and left. That was it [laughs]. No other motivation, other than just something different. (Erik)

I'd never really been interested in going to Indonesia, honestly [...], I actually wanted to go to Vietnam and it didn't work out, I didn't have the money, Bali was a lot cheaper. And [my friend had] been to Bali before so we decided 'yep, alright let's go to Bali' and we did. (Dean)

Thus, flexibility is an attribute which backpackers practise to demonstrate their 'fitness' as mobile 'global citizens' (Molz, 2006). By highlighting their mobility and flexibility, backpackers display their potential membership of (or aspiration to) the powerful "mobile class." Bauman (1998) has also theorised the tourist as a metaphor for all affluent world citizens, as they negotiate liquid modern flows. He argues that the frailty of all relationships under liquid modernity means that in order to survive, subjects must be "on the move before the ground moves [out from under their] feet, to be always ready for another run - this is the name of the game" (Bauman, cited in Franklin, 2003: 208). The following quotation shows how, for one participant, the physical mobility of travel has spilled over into 'real' life in the form of a 'mentality,' characterised by impermanence:

The whole travelling thing, it doesn't necessarily go away when you come home and get a job, like it's a mind-set [...]. And if you think of yourself as permanent in this place you get stuck in a rut or in a routine, it's easy to kind of get bogged down [...]. So it's kind of like keeping that 'life is a working holiday' type mentality [...] things are just blocks of time...And, they're just adventures, you know. (Chris)

For Chris, in this context, mobility is certainly positive, opening life up to endless opportunities and adventures; he relishes the fluidity and impermanence of postmodernity, rather than feeling helpless and lost in this tide of constant change. Permanence, on the other hand, being "stuck in a rut" or a routine, are negative, 
and nothing could be worse than being "bogged down" in a particular place or situation. Therefore travel can be seen to condition young people for the mobility required of them for their participation in late capitalism. This emphasis on mobility is in tension with the ideal of engagement, slowing down, and "living like a local."

\section{Solidarity of the Mobile Class}

The shared ideals of backpackers form the basis of a nascent imagined community or cultural group, albeit one which is inherently mobile, spatially unbounded, and whose membership is fluid (Sørensen, 2003: 855; O'Reilly, 2006). This bond is based upon distinction from other tourists, and from the cultural Other: the 'local.' Despite their professed interest in 'other' cultures, backpackers spend considerably more time with fellow Western travellers in backpacker enclaves, than with 'local' inhabitants (Enoch and Grossman, 2010; Kontogeorgopoulos, 2003; Lozanski, 2010). For many, meeting fellow travellers, was an important aspect of the trip. As Chris explains:

A lot of the walls you have when you're at home aren't there and so, you do find that, it doesn't take long before you can engage with someone quite deeply. And then just as soon split ways and find someone else and so there is this real kind of transient thing.

The bonds between travellers have been theorised as particularly meaningful because they occur in a liminoid space/time, which offers a sense of comunitas that Turner originally identified among pilgrims, where status markers and distinctions fall away (Wang, 2000). This kind of interaction offers "an unmediated, 'pure,' inter-personal relationship between pilgrims [or tourists] who confront each other as social equals based on their common humanity" (Wang, 2000:69). Among backpackers, however, it is not so much common humanity, as common 'Westerness' that forms the basis of bonds (Korpela, 2010). For example, Chris said, 
That's kind of what makes it so interesting, because you'll be able to sit around and have a beer with all these people from the other side of the world who are all in the same boat. You know, they're all in a foreign country and all travelling, and working things out, discussing the similarities and differences. [Emphasis added]

This illustrates interaction between people whose primary commonality is being Western in an-Other country and culture ("all in the same boat"), a case of collective identities being formed through distinction from Others. The difference between backpackers of different Western nationalities disappears when contrasted with the racialised Other (Korpela, 2010). Thus, travel contributes to the solidification of national identity (Bell, 2002), but also of a racialised Western imagined community or identity (Lozanski, 2011: 467).

This situation is exemplified when travellers experience conflict with or feel threatened by an Other. On a train in India, Gemma and Chloe felt threatened by the attention from Indian men. They found reassurance in speaking to Western male travellers, who, although complete strangers, seemed more familiar and trustworthy than the Indians. This indicates how cultural difference is exciting only as long as it is interesting and safe; in times of crisis, other Westerners offer a first point of reassurance. Camille described a similar sentiment:

Sometimes you would just want to hang out with Westerners just kind of like let your guard down, because we felt like around Asians we had to have so much more guard up. Because they'd be trying to rip us off [...] So sometimes you just want to hang out with Westerners and like have a bitch about the place and be like 'yeah they rip me off everywhere.'

This distinction demonstrates the limits of backpackers' desire to engage with the Other. Urry (1995) argues that the popular claim that travel 'broadens the mind' and fosters international understanding is dubious. Nonetheless (or instead), contemporary mobility fosters an aesthetic cosmopolitanism; this is not the same as the genuine world-citizenship the word implies. Aesthetic cosmopolitanism, 
whereby modern people become "connoisseurs of place," entails intellectual and aesthetic curiosity and openness to difference, and a rejection of hierarchy and uniformity (Urry, 1995: 166-167). Given backpackers' interest in local cultures and people, and in cultural sensitivity, they generally did not make overtly racist comments. The process of racialisation often became apparent more subtly, precisely in speaking about relationships with other travellers not locals. The following quotation about Columbia is an example of a figure of speech that occurred frequently:

We didn't see any tourists for the first three days, like we were the only people; nobody goes because everybody says it's so dangerous. (Isobel)

'Nobody' and 'people' both refer to Western tourists, as it is unlikely Isobel found Columbia to be unpopulated. Although Isobel probably would quickly correct this slip of tongue, were she aware of it, the thoughtlessness with which we make such statements demonstrates the strength of the assumption that underlies them. Somehow, other Westerners are more important than non-Westerners, 'locals,' who are sought precisely for their difference. Thus the primary bonds with other travellers are experienced quite differently to bonds with those Others who are, in more than one way, the 'object' of travel. Whether, in our analysis, we approach this as positive (at least backpackers engage in aesthetic cosmopolitanism), or whether we see this as a failing, (their cosmopolitanism is only aesthetic) depends on which mode of analysis, 'internal' or 'external', or which side of the dialectic we are looking through: ideology or utopia.

\section{Background of Stasis}

To return to the 'other' side of the Othering process, self-definition as mobile occurs against a background of stasis; backpackers travel through, over, and past landscapes and people. Although they imagine an ideal world of equality and 
freedom, in constructing themselves as hyper-mobile, they also emphasise the Other's immobility, or their rootedness to place, their localness. According to the Oxford Dictionary (2010), the word local means "related or restricted to a particular area," and for backpackers, this takes on a positive value as long as it is associated with the Other. As such it functions in its first meaning as related to an area, and thus affords authenticity and exoticism. However, in light of the cosmopolitanism and mobility mentioned above, the restrictive element of the word is negative, and backpackers distance themselves from it at the same time as they seek to engage with it. However, in analysing the interview transcripts I was surprised by the frequent use of the word, in some instances when it would not be strictly necessary, often as an adjective (rather than saying "the locals"), describing something which is already clearly 'local' in a literal, geographic sense. ${ }^{15}$ For example, "the local culture in India"; "the shitty transport because it's cheaper, because it's local"; "their local language"; "ten local guys, who lived in a local village"; "camping with the Bedouin at the local camps outside the local oasis." In these phrases, I understand the emphasis on 'local' as highlighting the object's or person's difference from the globalised, networked, fluid, tourist 'bubble' world, and, for a touristic object, this is a positive attribute.

However, the word local also helps to construct the dichotomy of mobility/immobility which enables backpackers to live and retell their freedom to mobility and the Other world's passive 'tourability.' This local world is indispensable scenery for the backpacker to travel through and to engage with. But it is also through this localness, constructed as Other to the Self, that backpackers reinforce their globalised mobility and 'Westerness' - thus, the localness of Others works as a resource to avoid, oneself, becoming "bogged down" (Chris).

\footnotetext{
${ }^{15}$ It is important to point out that I also used the word in my questions, e.g. 'Did you make local friends/meet local people/experience conflicts with locals?'
} 
However, it is untrue that local populations are static, passive objects of the gaze and untouched by modernity, and to ignore this merely reinforces the dichotomy within backpacker discourse (Ateljevic and Doorne, 2005). They are a part of complex life-worlds and political processes, and equally tied in to the modern and post-modern worlds of global capitalism. In addition, Zygmunt Bauman (1998: 8098) highlights that mobility is not the exclusive terrain of privilege, of the tourist, confronted by constant consumer choice, but that the most disenfranchised people, whom he describes as nomads, powerless in the face of global changes, are propelled from place to place as refugees and migrant labourers. Their travel trajectories may parallel those of tourists, but their presence is rarely acknowledged by the tourist world (Franklin, 2003).

\section{Conclusion: Guns and Cigarettes}

Although some danger and risk add flavour to any travel adventure, there is a point at which regard for personal safety will prompt backpackers to take their business elsewhere: they are, after all, pleasure seekers. In these interviews, stories of near drownings, muggings, and illnesses, were told with relish. Despite the mainstreaming and relative ease of travel, journeys are still adventurous, risky, uncomfortable, and fulfilling to participants (O'Reilly, 2006). Risk is particularly significant in traveller discourse, as it adds to 'road status' in backpacker culture (Riley, 1988), and cultural capital upon return (Elsrud, 2001). However, there was also considerable emphasis on safety precautions: taking out travel insurance, travelling with a guide in Africa, and using 'common sense.' This shows not only the pervasiveness of liberal individual-responsibility-for-safety messages (Lozanski, 2007), but also the level of safety that First-World inhabitants take for granted (and, usually, are granted), regardless of the 'local' situation. So if violence or other 
dangers become too extreme, measures to avoid or mitigate this are available. ${ }^{16}$ Adam described the scenes at Bangkok airport during the 2010 riots:

People had been sleeping there for like a day or two, just because they didn't have a flight, they couldn't get one, but they were willing to stay in the airport until they could. You know, everyone was just looking for the first flight out.

This means the social/political reasons behind violence, like the violence itself, can easily be sidestepped by tourists with the right kind of passport and travel insurance. The ability to do so is clearly the preserve of the 'mobile class.' In light of the valorisation of mobility discussed above, any impediment to mobility is seen as negative and states which attempt to restrict movement are considered in violation of human rights (Urry, 1995: 165). These areas lie outside of the tourist world. ${ }^{17}$

Although the freedom of movement is tipped in favour of affluent Westerners in terms of financial resources to travel, access to travel routes, visa regulations, and passing security checkpoints (Lozanski, 2011), ${ }^{18}$ backpackers are sometimes unsettled by encounters with the structural limits to their freedom of movement (Haverig, 2007). For example, Gemma said she was always nervous at border crossings: "once you hand over that passport you're in their hands." And when Alana experienced a fifteen hour layover in Saudi Arabia:

They just, they didn't know what to do with us. And they had people with guns on both sides of us, it was really horrible, I couldn't say

\footnotetext{
${ }^{16}$ As Alneng (2002) points out, violence in tourist destinations is often presented in terms of its potential threat to tourists or the industry by Western news media.

${ }^{17}$ However this "final frontier" is also being breached as tourists seek more extreme experiences, such as the travels depicted in the travel book Bad Lands: Tourist on the Axis of Evil (2007) by Tony Wheeler, co-founder of Lonely Planet Publications.

${ }^{18}$ For example, since 2010 New Zealand visitors to India are offered a 30 day visa-on-arrival at certain airports (See: www.nzembassy.com/india/news/visa-on-arrival-for-new-zealanders-visitingindia), whereas Indian visitors to New Zealand must apply for a tourist visa, which requires proof of good health, sufficient funds, and 'good character' (see: http://www.immigration.govt.nz/migrant/stream/visit/visitors/default.htm)
} 
anything because I was a female they wouldn't listen to me. And, and besides having guns, they were smoking and I was just thinking, this is horrible, why do you have guns and cigarettes?

Although Western democracies have stringent border controls, regulating "Other" people attempting to enter, when this type of restriction is applied to a Western 'free' traveller, it is represented as though the authorities are at fault. In the excerpt above, the regime is presented as irrational and authoritarian, patriarchal and violent (not to mention smoking). Most participants made some mention of the 'rife' corruption in developing countries, and Linda described the extreme circumstances which required her to pay a bribe to re-enter India from Nepal:

We caught the bus, it took about twelve hours from Kathmandu, and then we crossed into India on horse and cart. We had to bribe on the Nepal side, and then we got to the India side, and they said to us; 'we're not letting you back in.' And the thing is, we were in the middle of the border, so basically it was a tiny little bit of land and the border was closing in ten minutes [...] so we really didn't have much of a choice and they wouldn't stamp our passports unless we paid them.

The impediment, here, is the guards' greed, which is often attributed to nonrational non-Western corrupt bureaucracies. One reading of Linda's emphasis on 'not having a choice' in this situation is that it explains her discomfort at participating in this 'un-modern' exchange.

If unwilling border guards are an annoyance, Phipps (2004) argues that tourism meets its nemesis in the terrorist. As opposed to the tourist, the terrorist is considered as operating outside of globalisation and "functions to reinforce the tourist's innocence and political neutrality" (Bennett, 2007: 281). In opposition to the terrorist's fundamentalism, the tourist's peaceful mobility is seen as defending the "Western" way of life (Phipps, 2004). Encounters with resistances to their mobility, whether in the form of 'corrupt' border officials, terrorism, or other threats to safety, are uncomfortable for backpackers because they unsettle the picture of the world as 'tourable,' attractive and accessible. In such moments, the 
'dark' side of globalisation seeps into the backpacker experience. Such moments also illustrate the limits of late capitalist multiculturalism, to "the folklorist Other deprived of its substance - like the multitude of 'ethnic cuisines' in a contemporary metropolis," while any 'real' Other, who may resist the global-free-market utopia or ideology, is easily denounced as fundamentalist (Žižek, 1997: 37). In discourses of such experiences, the 'local' loses its appeal, and appears Other, in a negative threatening sense. According to this reading, backpackers' valorisation of interaction with the Other, is limited to terms determined by the backpacker, and people who resist this 'dream' are excluded from it. This challenges the universality of backpackers' utopian vision, and highlights its specificity to Western liberal values.

The picture of the world as 'tourable' is not an untruth - it is a partial truth, because the tourist world really does hide or remove unpleasant things. Apart from the 'ruptures' of backpacker ideals (which will be discussed), the world shapes itself to their ideals because backpackers have the purchasing power to ensure this, or to leave. Backpacker movement relies upon structural privilege and inequality, as budget travel would be impossible without the currency disparity that differentiates destination and home societies (Hutnyk, 1996: 214). This chapter has discussed how, in representing their experience of the tourable world, backpackers' discourse reinforces this 'tourability' and the dichotomies their travel relies upon. This division, however, is at odds with their 'dreams' of engaging in genuine, equitable interaction with Others and of taking responsibility for a better world. But at the same time, the global/local dualism works in their favour when it enhances their status as mobile global citizens. However, in their conscious reflection about their practise, backpackers distance themselves from these processes, revealing their utopian desires for a better world. 


\section{Chapter Two:}

\section{Engaging with the Real World}

In the previous chapter, I suggested that backpackers distinguish their travel style from that of 'vulgar' tourists and construct themselves as 'noble' travellers primarily by seeking depth. Depth for most backpackers entails engaging with 'real' or 'authentic' experiences beyond the tourist 'bubble.' Authenticity is here understood as socially constructed or as achieving a fit between an ideal or 'dream' and an experience, rather than as an objective attribute.

In the interviews conducted, two main dreams structure backpacker evaluations of the 'reality' through which they travel. The first is the romantic dream, where the 'real' is associated with the pre-modern and natural, and which informs orientalising discourses associated with both colonialism and tourism. Although this frames backpacker discourse, participants in this study often distanced themselves from this notion. The second, more overt way in which backpackers seek authenticity is by engaging in 'real life' beyond the tourist 'bubble.' This is attempted by 'fitting in' with difference, and by achieving genuine interpersonal exchanges. The underlying desire for this ideal is to transcend the coloniser/Other or tourist/local binaries and to construct a multicultural and egalitarian utopia. Both these 'dreams' also function ideologically, as they reify and conceal global inequalities. However, they are also fragile and easily ruptured by the social 
relations of tourism and capitalism. It is in such ruptures that I argue another kind of authenticity or 'utopian moment' lies.

\section{Authenticity in Tourism}

Debates around commodification and authenticity have been at the heart of tourism studies since Boorstin's (1964) critique of mass tourists as lacking interest in original cultures and failing to look beyond the comfort of the tourist 'bubble' and the experience of commercialised 'pseudo-events.' Turner and Ash (1975: 15) extend this perspective and see the increasingly global spread of the tourist "hordes" as "a device for the systematic destruction of everything that is beautiful in the world." MacCannell (1976) argues against these condemnations of tourists as superficial and destructive, interpreting tourism as a modern secular pilgrimage, or quest for authenticity. As modernity alienates people from their immediate communities, rendering lives less meaningful, people become interested in the "real life of others" (p. 91). However, they find "there is no salvation in tourism," because the tourist industry restricts tourists to "false backstage areas," constructed to protect local people from the intrusion of the tourist gaze (Cohen, 1988: 372). Despite their differing interpretations of tourist motivation, Boorstin and MacCannell ultimately agree that tourism "come[s] to constitute a closed off, selfperpetuating system of illusions" (Urry, 2002b: 9). However in MaCannell's work this is a result of the social relations of tourism, rather than lack of desire for the authentic.

Both sides of this polemic ascribe to the modernist distinction between reality and representation, using an objectivist concept of authenticity (Uriely, 1997). Approaching authenticity from a social constructivist perspective, Cohen (1988) focuses on the processes that render objects authentic, arguing that 'staged 
authenticity' may take on new meanings for locals and tourists alike. In addition, he argues that tourists have varying interpretations and expectations of authenticity. Building on this, he revises his 1972 tourist typology of travel styles ${ }^{19}$ to a phenomenological concern with various modes of experience, based on tourists' interest in cultural difference (Cohen, 2004b: chapter 5). This interest ranges from minimal, for the 'recreational' tourist, to complete for the 'existential' tourist, who is alienated from home and finds an elective centre by complete immersion in 'strangerhood.' Cohen argues that the tourist experience of authenticity is not uniform and categorises tourists accordingly.

As previously discussed, Urry (2002) suggests a postmodern shift in mainstream tourism. If the tourists Cohen identified as 'recreational' were indifferent to authenticity, post-tourists deliberately seek a heterotopic Disneyfied world. They celebrate postmodernity through intensified, highly mediated experiences such as adrenaline sports or tours with deliberately fragmented and hectic schedules, (Rojek, 1993: 213; Urry, 2002b: 92; Bell and Lyall, 2002). In contrast, 'other postmodern' tourists are concerned with 'real' experiences with cultural Others and nature (Munt, 1994). Often marketed as 'eco' or 'ethical' tourism, these ventures claim cultural sensitivity and environmental sustainability. Not only do they promise authentic sights, these tours claim to constitute an authentic or honest mode of travel themselves. This is particularly relevant to backpackers, who deeply invest in their travel style, which they differentiate from mainstream tourism as more engaged and responsible. Many writers have identified the search for authenticity as motivating backpackers' distaste for the tourist 'bubble,' their preference for the cheapest services, and their attempts to engage with the Other (Davidson, 2005; Korpela, 2010; Lozanski, 2010; Muzaini, 2006; Noy, 2004; O'Reilly, 2005).

\footnotetext{
${ }^{19}$ As discussed in chapter one.
} 
In this thesis I approach authenticity as a socially constructed concept, understanding it as structured by certain phantasms (Alneng, 2002), rumours (Hutnyk, 1996), discourses, or dreams. Thus, when the tourist gaze finds authenticity, it is in an object that acts as a sign of their pre-imagined expectation, so "authenticity does not reside in reality, but in an interpreted representation of reality" (Dann, 1996: 19). Or, as Hughes argues (1995: 783):

Tourists do not contrast the staging of authenticity against direct experience of the original, but rather against a mental image of that original which has already been "corrupted" by mediating influences.

Thus, experiences are evaluated in regards to various discourses, dreams, or desires that structure the tourist gaze. Most of the participants I interviewed ascribed to two main dreams. The first is the romantic dream, which seeks unspoiled nature and cultures untouched by modernity. The second and stronger dream is to achieve experiences that allowed them to transcend their subject positions as (neo) colonialists, tourists, and consumers. To begin with though, I will discuss an example of investment in objective authenticity, which, ironically, also serves to illustrate the social construction of authenticity, as well as a postmodern troubling of this concept, where a participant is aware of and nonchalant about the simulated origins of his ideal.

\section{Constructing the Real}

The traditional or objectivist understanding of authenticity, as it was originally used in museum contexts, relates to an artefact's veracity, or "whether objects are what they appear to be or claim to be" (Trilling, cited in Wang, 2000:47). In tourism, this tends to be understood as the extent to which objects or events are original to a local culture, assumed to be rooted to a particular place and people. This discourse is dominant in tourism media such as guidebooks, advertising, and 
travel writing, which stress the exotic and emphasise difference as diametrically opposed to and threatened by modernity (Bennett, 2007; 2008; Bhattacharyya, 1997; Tegelberg, 2010). Seeking this type of experience confirms McCannell's argument that tourists seek to compensate for a perceived lack in modernity. As such, this approach emphasises dichotomies between Western/Other, exotic/normal, modern/primitive, and global/local. While seeking such experiences underlies backpacker motivations in striking out beyond the beaten path, few spoke about it as overtly as Erik, who expressed a particular interest in pre-modern Chinese culture and artefacts. He said "the sights, the everything, the culture," in China were "incredible," but then highlighted that he means "the traditional culture, not the Western bullshit culture that we've sort of enforced, and that they're absolutely milking us for." This statement alone demonstrates how this discourse reinforces us/them binaries and devalues modernity as depthless ("bullshit culture"), while also affording it absolute power, as the modern stifles the traditional. Below, Erik describes the incorporation of historic sites into contemporary Chinese cities.

You can tell they've retained the moats and stuff because they were probably never that perfect before, but now they've got streets going down either side and bridges going across and parks on either side. But they're like, 'yep, that's the original moat,' um, now with a water fountain with coloured lights and shit coming out of it. God they love their neon crap. Um [laughs] it's amazing, they've just destroyed so much stuff with bright flashing lights. It's like, why, why did you do that?

On the face of it, this is an example of the authenticity of traditional artefacts being threatened by modernity, which is presented as destroying the artefact as well as the 'soul' of traditional peoples who are "milking us" for our culture. Interestingly, he explains that his love for Asian 'history' is from video games:

A lot of it is just from video games and bits and pieces. Um, but just the history and the wars and the way it works, and the ideas, like I'm huge into martial arts as well. So just, Asia to me, just everything about it is awesome. 
Erik's use of "everything" here is quite particular, as it excludes those aspects of Asia that do not conform to and confirm his expectations. Considering his expectations derive from the gaming industry, this is not a 'traditional' conception of authenticity in an archaeological sense after all. This highlights that regardless of the age of an artefact or practice we gaze upon, we view it through lenses that add additional meaning.

This is an overt example of what Alneng (2002: 467) argues is a widespread phenomenon: that tourist practices are structured by phantasms, or are "dreams put into practice." Contemporary backpackers to Vietnam, he argues, arrive infused with fantasies that conflate Vietnam the country and Vietnam the war (movie), to the point that experiences can only be interpreted in relation to prior film viewings. For example, when asked to describe his view of Saigon, a backpacker in Alneng's (2002: 468) study replied:

You know the opening line in Apocalypse Now - 'Saigon, shit! - it says everything about Saigon.

Thus, as Alneng (2002: 468) puts it, the "phantasies of film directors [...are...] dragged on to the physical landscape." Hutnyk similarly argues that tourists are implicated in the reification of 'rumours' of Calcutta as a place of poverty and decay. Because these rumours precede visitor experiences of the city (they have been perpetuated by several centuries of cultural representation by Westerners) they seem the 'real' Calcutta. Significant portions of Calcutta that do not conform to these rumours are experienced as secondary or somehow 'fake' (Hutnyk, 1996: 5). This means travellers' experience confirms the rumours they had heard before arriving, and their own stories contribute to further rumours. This illustrates the process by which the tourist gaze constructs its objects as signs of an imagined ideal (Urry, 2002b), and whereby sights which represent this ideal or 'dream' are considered meaningful and authentic or 'typical.' Thus satisfaction with a destination "corresponds largely to the degree to which a phantasm can be 
transformed into experience" (Alneng, 2002: 465), and Erik's search for 'traditional' Chinese-ness is an attempt to concretise his dreams of battle, which he has experienced virtually through games.

Erik is not unique in evaluating his experiences in relation to a desired ideal. However, he uses much stronger language than other participants in admitting his awareness of the mediatised origins of his particular phantasm, and in his dismissal of sights that do not conform. Consider Alana's description of her experience of Jamaica, which also did not match her preconceived notion:

I hadn't done any research. The only Jamaica that I knew was kind of a tropical [paradise], drinking rum on the beach, Bob Marley music, that was my impression of Jamaica, um and Cool Running's [...] that puts Jamaicans in a very good light. Um so that was my picture of Jamaica. And then when I got there [...] I got really scared about um, I just didn't feel safe, that's what it was.

Although the discrepancy between her experience and her expectation was disappointing, this led Alana to redefine her conception. In saying that the movie Cool Runnings "puts Jamaicans in a very good light," she questions the veracity of the movie and blames herself for basing her expectation on popular culture rather than 'research' (as her partner, who was less shocked, did). This is not to imply that her resulting redefinition of Jamaica (which she described as a "scary" place) is more correct in an objective sense, but to underline that her contrasting subjective experience somewhat troubled her preconception, rather than simply being dismissed. Nonetheless, my guess is that in those instances when she did find a peaceful beach and a glass of rum in her hand, she thought with relief, 'ah, now this is the real thing.'

Erik on the other hand is much more open and confident in his expectation of the world to live up to his dreams, and when it fails to, the discrepancy is dismissed, as in his description of neon-lighted China as "bullshit culture" (this is the illusion), 
despite not being concerned with the veracity of his version of history. Of 'modernised' Chinese cities, Erik said, "If I wanted this, I'd just go home." The trip for him is unashamedly about pleasure and entertainment. Thus, I argue Erik travels more as a 'post-tourist than the 'other postmodern' backpackers with whom I spoke. ${ }^{20}$ Like Erik, other backpackers also ascribed to the romantic dream of discovering 'typical,' 'traditional' peoples and cultures, untouched by modernity. And, like Erik, they were often disappointed on this quest. However, as we will see later in the chapter, their response to this was to adapt themselves to fit in with and experience difference, rather than simply expecting the world to 'fit' their dream.

\section{Utopia and Ideology in Guidebook Advice}

The dominant conception of authenticity that structures tourism advertising and guidebook advice emphasises difference from 'normal' home-life. It must, after all, justify the effort, expense, and time invested in corporeal travel. In addition, the emphasis on difference helps perpetuate a need for the guidance and mediation such publications provide (Bhattacharyya, 1997). Guidebooks frame the tourist gaze by selecting, recommending, and interpreting attractions worthy of tourists' attention. For example, the description of Lima in the Lonely Planet Guide to Peru (2001: 51) advises travellers to seek buildings dating from the pre-Columbian and colonial periods in amongst an otherwise dreary and 'modern' city:

On its surface Lima is no thing of beauty. A sprawling desert city it clings precariously to a set of dusty cliffs, and spends much of the year

\footnotetext{
${ }^{20}$ However, this distinction is not definitive, and it may be useful to think of tourists as potentially moving across different types of tourist experiences throughout their lives or even particular journeys (Feifer, cited in Uriely, 1997: 983), or, to think of these distinctions as differences in practice rather than people (Edensor, 2000). More contingently, I consider these distinctions primarily as different discursive practises, bearing in mind that travel narratives are constructed in context-specific ways (Desforges, 2001).
} 
covered in a perpetual fog [...] but peel back the foggy layers and you'll find pre-Columbian temples sitting among the high-rises and extravagant colonial mansions with Moorish-style balconies.

The allure of the "wonder that was," (Bhattacharyya, 1997: 381) as opposed to a destination's contemporary aspects is typical of guidebook discourse, which also presents natural sites devoid of people, and social life as typified by "the folk, the ethnic, the colourful, the traditional" (p. 381). In this discourse, 'local' is again a positive attribute - an Other to the backpacker's own 'global' identity. Given the authoritative and instructive voice of guidebooks, such representations come to construct a strong picture of typical or 'real' life, history, or nature, in the destination (Bhattacharyya, 1997: 388). This construction of the 'typical' is an image travellers bring with them, and when particular encounters match this, they are recognisable as authentic. While backpackers express ambivalence toward this form of authenticity, it nonetheless structured their narratives. The instances when the people or vistas they gazed upon matched the preconceived notions of 'real' or 'typical' local scenes were often cited as highlights, and became stories worth telling (see chapter one). Isobel provides an example of an experience that is authentic for fitting into stereotypical notions of hospitality and culture:

Stopping off, we'd read some old lady rented out rooms. So we're just knocking round [on doors] and we're like [...] 'Are you Maria? Are you?' And they're like, 'no no she's up there,' in this town of like four streets or whatever. And she was lovely and we had the best coffee in South America in her house, and she ground the beans. And [there was a] picture of the pope above our beds, [laughs], and she cooked for us every day and it was just really cool.

The picture of the pope speaks of tradition, the small town of simplicity, and the coffee and home cooked meals of hospitality and sincerity. Isobel also stresses the informal organisation, indicating this experience was off the beaten path and beyond tourist infrastructure. Several participants mentioned the regenerative or transcendental power of 'unpeopled' nature. For example, in the Peruvian cloud forest, Francis experienced 
this moment of Zen-like clarity and inner peace and everything just went quite for like five seconds, and then I had this thought, 'isn't it amazing how everything in this forest is interconnected?'

This illustrates the power nature is endowed with by the romanticist discourse (Wang, 2000), here teamed with the ecological and spiritual concerns of postmodern backpackers. Travel to remote locations to experience the sublime power of nature or to undergo an extreme physical challenge, epitomises the romantic trope of self against an uncontrolled nature. In backpacker discourse, this is often linked to narratives of profound self-transformation or discovery of the 'true self' (Noy, 2004; Elsrud, 2001). Such experiences function as a balm for the ills of modernity. As Oakes (2006: 232) puts it, the search for authenticity represents

an attempt to negotiate the paradox of modernity, to repair modernity's polarising and paralysing dualism, to absolve the anxiety and ambivalence of the modern experience, and to recover a sense of one's self in the modern world.

As the main emphasis of the romanticist discourse is its contrast to modernity, it can be seen as an expression of discontent with rationalised, industrialised modernity, and of utopian longing for authentic community relations (Wang, 2000: 63). In this sense, backpacker yearnings overlap with Marxism in their idealisation of non-fetishised relations. In this dominant guidebook form, however, this 'simple life' refers to an ideal imagined to predate modernity, so this is a nostalgic and past-oriented yearning. In this discourse money tends to be seen as a homogenising, 'globalising' force, harmful to 'local' community life and difference (Desforges, 2001). Consequently, authenticity is often aligned with poverty (Kontogeorgopoulos, 2003; Scheyvens, 2011).This allows the tourism industry to whisper that this 'authentic' life persists in un(der)developed countries, not (yet) ${ }^{21}$ corrupted by modernity.

${ }^{21}$ This 'yet' is quite important for the tourism industry, as it lends an air of urgency to the touristic quest. 
This alignment with poverty, history, tradition, and exoticism means this dream can more readily be criticised as ideological, than as utopian. As discussed previously, this version of authenticity is an extension of the colonial discourses which constructed territories as primitive, romantic and unclaimed (Curthoys, 2008). For example, Tegelberg (2010) analyses exclusion of people from photographs of Angkor Wat, in Lonely Planet Cambodia, as similar to the practice of editing humans out of colonial drawings of these ruins. Similarly, Lonely Planet India omits contemporary Indians from representations of authenticity, and confines its discussion of local inhabitants to service providers (who are represented in evaluative tones) or scenic 'tourees' (Bhattacharyya, 1997). As tourees, local inhabitants become objectified by a gaze, which, in seeking difference, often focuses on the most disenfranchised ethnic minorities. In this way, guidebooks contribute to the silencing of local perspectives from tourism discourse (Bennett, 2008a). Ultimately, as a discourse that objectifies people, and objectifies them specifically as Other, poor and of purely cultural interest, this romantic dream functions primarily ideologically despite being motivated by a utopian longing. Considering the authoritative and 'circulatory' influence of guidebook texts, discussed in chapter one, this is certainly influential in shaping the backpacker gaze, and it has wider consequences as backpacker experiences are shaped into traveller tales, which in turn contribute to further discourses about the Other. However, shifting the analysis to backpackers' own interpretations of authenticity reveals a level of contestation and ambivalence towards such discourses. 


\section{Backpacker Ambivalence: The Abyss of Authenticity}

Turning now to focus on backpackers' reflections about and experiences of authenticity suggests considerable ambivalence towards the idea that the real world is something that can be found through travel. This indicates that backpackers, although influenced by guidebook discourse, do not blindly follow its advice. Backpacker discourse cannot be 'read' by exclusively analysing guidebooks, as it appears backpackers engage with them in variable ways. The first way in which participants were sceptical that backpacking could deliver on its promise of 'romantic' authenticity was in the perception that leaving the beaten track to find the 'vanishing world' of diverse traditional cultures is considered increasingly difficult. The proliferation of backpackers throughout (much of) the world has led to the development of backpacker 'bubbles' or ghettos (Sørensen, 2003). These spaces often feature cafes, nightclubs, bookshops and western-style restaurants (frequently with televisions tuned to American TV shows). Although these areas are more heterogeneous than the highly regulated private 'tourist' enclaves Edensor (2000) describes, these are spaces of "Western cultural domination" (Hottola, cited in Lozanski 2010:751). Bennett (2008b: 9) describes them as apolitical, though infused by the exotic Other: a "safe and exciting world full of pleasurable, educational and new attractions for the global tourist.” But to most travellers I spoke with, these places are too safe, too developed, too 'global,' and too commercial; they cater to exactly the hedonistic, mainstream backpacker my interviewees aimed to avoid. Again, this study cannot attest to the extent to which backpackers really avoided these areas. However, it certainly highlights that these places are considered less worthy or meaningful. ${ }^{22}$ Dean's description of Bali's

22 Empirical ethnographic studies of backpackers in destination countries (for example Kontogeogpoulos (2003), on Thailand, and Lozanski (2010), on India) suggest that they spend much of their time in such areas, despite recognising them as modernised and therefore less authentic. 
'resort town' Kuta is typical of the derision participants in this study reserved for such areas:

It's a pretty ugly place in my opinion. It's, I don't know it could be any, any club town in the world, you know, and it's just built around it's nightlife and around it's crappy surf and around it's cheap products and it's just not attractive to me at all. I wanted to get out of there as soon as I possibly could.

He was "put off" these kinds of places because of their "lack of authenticity," and said, "I guess it just doesn't seem like it's really the country that I want to see if I go to a tourist area." Luckily, for him, he found that

it was possible also to find places that were more untouched, at least to a small degree. But then. [...] So um, Lombok seemed like what Bali used to be, I don't know, thirty years ago. So I really want to go to Lombok and my mate found out about Sumbawa which is the next island over which is huge and there's absolutely nothing there and I was even more intrigued to go [laughs]. [Emphasis added]

Josie, on the other hand, found that in Southeast Asia it was already too late:

Southeast Asia's been done to death, so it's not like, I don't know it's not like, so exotic because like a lot of people have been there already.

According to Josie, destinations lose their allure the more people (i.e. Western tourists) travel there. In part, this distaste is due to backpackers' desire to distance themselves from 'vulgar' mass tourists, in order to highlight their distinction, as discussed in chapter one. However, they also wish to avoid the homogenising effects of tourism development, demonstrating that their ultimate "fantasy is to visit lands and people free from the blight of other tourists and modernity" (Phipps, 2004: 84). For Chris this fantasy seemed always just out of reach:

There is this kind of mentality like 'ah it's ruined now, there's too many tourists.' So backpackers are the ones that are kind of always looking for the [places] where there's no one around [...] And so it's kind of um, I've heard so many people say, 'oh this was so much better five years ago, you should have been here ten years ago.' [Emphasis added] 
Both Chris's and Dean's quotations (and several others besides) highlight how the non-touristic world is characterised as no-where ("there was nothing there") and non-tourists are 'no one.' While this is not deliberate, and would likely be quickly corrected by participants, were they made aware of it; it is significant, given the frequency and precisely the thoughtlessness with which it occurs. This suggests these are prevalent, taken-for-granted, ways of speaking. Earlier I discussed this to demonstrate the bonds that exist between tourists as opposed to 'locals.' In the context of the 'romantic gaze,' it highlights emphasis on being a 'lone explorer' in terra nullius. However, in Chris' passage he speaks of backpackers in the third person. This creates a slightly ambiguous distance between his practice and his reflection upon it: it is not quite clear to which extent he counts himself amongst the "too many tourists" who "ruin" destinations. This linguistic device possibly creates a little critical or ironic space for reflection upon the paradox between his ideals and his practice.

The desire for this romantic dream is mired in a rather obvious paradox: that "tourism destroys (in the very process by which it constructs) the authenticity of the tourist object" (Frow, cited in Alneng, 2002: 466). Because tourism is seen as a harbinger of modernity and capitalist economic exchange, so it is seen to destroy the traditional cultures and the uncorrupted communities it seeks. While in another backpacker dream, that of tourism's purported development effect, this very function of tourism is a positive quality (see chapter four), in terms of authenticity it creates a "paradox" or "abyss" of authenticity; it is a "dream that can never be realised" (Oakes, 2006: 233). Thus, avoiding the presence of other tourists and contesting their own touristic identity is partly an effort to avoid the traces (or mirror image) of their own destructive presence. Backpackers - who (as opposed to mass tourists) care about authenticity, but lack the financial resources to participate in more expensive eco-tourism (Lozanski, 2010) - find themselves caught in this paradox. Their painful reflexivity about this can be called 'touristic 
shame' (Frow, cited in Phipps, 2004; Alneng, 2002). As Dean said of his search for the most remote island:

I know that no matter, just my mere presence there is changing in some way their... I don't know, their settlement, their society. I mean, especially when you go to really small places, you know, it's, it may not even be negative but in some way you're changing it.

The conundrum for individual backpackers is they are not alone in their idealisation of the non-touristic and their differentiation from every other tourist. Phipps (2004: 85) sees this as more than touristic shame, and identifies "abject selfloathing, almost to the point of homicidal fantasy" in backpacker ideology. However, in my study, this was expressed more reservedly in the realisation that 'simply' travelling to the least explored places was insufficient to experience authenticity: the tourist 'bubble' is stretchy and sticky; it will not burst. This leads one participant to reject the possibility of discovering the 'real,' saying, "The real Africa, that's a classic backpacker slogan, if I've ever heard one."

Well where's the real Africa, who knows? I've no idea. I mean everyone sees it whenever they go to Africa, or, you see it on the news, when, I mean, everything's real [...]. Um, yeah, I think it's completely made-up jargon, actually [laughs], well pretentious jargon by backpackers trying to elevate their kind of, trying to legitimise their trip to something more than it is, ah. Yeah, the real Africa, I think it's all bullshit. (Brian)

Lozanksi (2010) argues that some backpackers refuse the idea of authenticity overtly, but nonetheless reveal unconscious investment in discourses of authenticity through their travel narratives. I could make a similar argument about Brian, as he subsequently showed that he also ascribes to notions of authenticity. However, with Brian, it became clear that his scepticism related considerably to the ability of backpacking to deliver such experiences.

In hindsight, with comparing, ah, volunteering with backpacking, I'd argue that volunteering is actually much more rewarding in terms of getting to know a local community. [...] I mean you get, I've still got 
some mates, $[\ldots]$ if I saw them again, you know they'd still be really good, I'd count them as good friends.

Consequently, while he is cynical of the concept of 'real' Africa as something to be found through travel, he nonetheless considers "getting to know a local community" and friendships with locals rewarding. These, he explained, are achievable through volunteering. The difficulty for many travellers is that the romantic trope emphasises difference and distance - this is something they want to reject, in efforts to construct an equilateral pluralistic world. Erik's statement illustrates the dream of authenticity that backpackers favour more overtly, that of achieving proximity to, and intimacy with difference.

\section{Engaging With Difference: Fitting in With Utopia}

The type of authenticity backpackers in this study discussed more readily and confidently, is experiential: it entails a desire to engage with and experience, rather than view, something real. Instead of 'simply' finding areas that fit their dream, backpackers consider authenticity something that requires work by fitting themselves in with the dream. Thus, they try to blend in, create as little disturbance as possible, and 'become one' with difference: ultimately aiming to be acknowledged by Others as a friend. This is an existential authenticity (Wang 2000), sought in relation to the cultural Other, both intra-personally (by adapting to difference) and interpersonally (by achieving non-instrumental relationships with the Other). Such interactions allow people to forget they are tourists, the cultural descendants of former colonisers. This represents a desire to eliminate the inequalities between traveller and host, and stems from the backpacker dream of experiencing the world as an open, liberal space in which diverse individuals enjoy equal freedom. In this way backpackers construct themselves as representatives of such a world (the West), travelling through places which are not (yet) so. Here, 
difference is still central, but the aim is to overcome it; the greater the difference that is eliminated/obscured, the better the achievement.

Some ways in which people experienced this was by following informal travel advice from 'locals' (Adam), playing with children (nearly all of the female participants mentioned this), speaking about cricket in India (Adam), and being invited to learn a traditional dance at a family reunion (Megan). As mentioned in chapter one, several participants asserted that travelling slowly, using 'local,' cheaper transportation and accommodation, allowed them to think of themselves "as living as locals overseas" (Chris). This idea that cheaper services are more authentic and 'local,' is based on the assumption that money renders "places placeless” and more globalised or 'Western' (Desforges, 2001: 362). Although frugality counts as 'road status,' it also represents a desire to experience, rather than simply view (imagined) local ways of life, and make real connections with 'local' people (Molz, 2006; Kontogeorgopoulos, 2003; Muzaini, 2006; Buddhabhumbhitak, 2010). This is again based on the association of authenticity with poverty. However, this time, rather than simply view poverty, backpackers wish to (temporarily) experience it, and this is accompanied by a willingness to forego the physical comforts of Western privilege, and to disavow the attendant social hierarchy.

However, for many participants, slow and cheap travel was not enough. In the previous chapter, I described Camille's claim to authenticity by boat travel instead of by "flying with the White people." But in general, she did not achieve many satisfying interactions on her trip in Southeast Asia. However, she said she was not surprised by this as she doubted it was possible to have those "meaningful local cultural connections that I think a lot of people think they have," by "just backpacking through a Third World country.” Instead, this required volunteering, which provided: 
[...] a really different way of seeing the culture. Like, you're kind of observing when you're backpacking, and actually being in it when you're volunteering.

All participants who undertook volunteering valued it for the opportunity to "be in' culture, and share in the local sense of community. This is quite a different trope than the one which emphasises mobility: now local embeddedness is a positive thing, which is (temporarily) emulated. When I asked Francis whether he felt he had experienced the real Ecuador, he said "yes," but only by volunteering and "living with locals" for seven weeks. Rather than (or as well as) transcending tourism geographically by outrunning tourism development, these experiences seem to transcend the industry metaphorically, by escaping the capitalist system. For Chris, volunteering on a farm in Northern Thailand offered a "good insight into village culture":

And that was like get up in the morning; go get your water from the well, and like, real community living [...]. Like, everyone in the community uses the same kind of wells and stuff, and, seeing that kind of local mentality, playing soccer with the school kids after school.

Chris indicated his inclusion in village life through narrating the act of getting his water from the same well as everyone else. He went on to emphasise that this was not a 'voluntourism' project. Such projects are pre-booked through external organisations, and often charge fees exceeding the cost of regional tourist accommodation (Simpson, 2004). While the participants who volunteered on such projects still found them fulfilling, those who did not, were rather critical of them. Chris, in particular, pointed out that such a project did not appeal to him. So instead of pre-booking from home, he decided to "go with the flow": he 'discovered' the farm mentioned above informally, by overhearing a conversation between other backpackers. In addition, the atmosphere there was affective rather than commercial and the host looked after the international volunteers as though they were family: "We all had to call her Mum. That was her mentality." This differentiated his experience from others he had heard about, where "it's kind of 
just, like, a transactional experience, where it's like, come in, do your thing, get out."

In telling this story, Chris demonstrates his success at escaping the tourist bubble, the cash nexus, and colonial/racist hierarchies, by achieving affective familial relations and experiencing authentic community life. Throughout all the previous versions of authenticity, non-commodification is important, highlighting the modern dichotomy between the public sphere of work and finances and the private realm of the family and of emotions. Because intimacy is part of the private sphere it is seen to constitute 'real life.' Seeking to share 'real life' with cultural Others and to imagine the possibility of being loved by the Other reveals a desire to reject colonial power differentials (Conran, cited in Lozanski, 2010: 747). In their distinction from 'vulgar' mass tourists and from 'closed minded' people who stay at home, backpackers claim to ascribe to a postcolonial imagination which views the Other as equal (Korpela, 2010), and to construct a world where differences are simply cultural and therefore a cause for celebration. This represents a postmodern multicultural and pluralistic utopia.

\section{Utopia and Ideology: The Fragility of the Dream}

This dream of achieving a multicultural and egalitarian utopia through interaction can be citicised as ideological on two fronts. First, it can be seen as inherently contradictory, as backpackers value such interaction primarily with 'really' different 'locals,' and thus attempt to "objectify the world while, paradoxically, subjectively experiencing it at the same time" (Oakes, 2006: 238). The second critique suggests that this utopia is a liberal discourse of tolerance that works in conjunction with neoliberal capitalism, which "inncoculates" backpackers from awareness of the exploitative relations they reproduce (Lozanski, 2011: 470). I will 
explore these arguments before returning to a more utopian possible reading of backpacker desires.

To illustrate the first critique, I explore a tension between intimacy and difference, or familiarity and exoticism, in Linda's story. Linda described staying with families in India and Turkey as a privilege because "it's so much more authentic." In her description of the Indian village she stayed in, she highlights the 'traditional' ('primitive?') aspects of her experience as dangerous and opposed to modern bureaucratic rationality. She describes this area as "probably one of the most conservative parts of the world [where] female infanticide is extremely high," and said,

There were no police where I was and corruption was very high, basically in the village everyone [...] looks after themselves. So if there's any crime, it's [...] revenge, you do what you want and no one stops you.

Yet despite this situation being "very different" from her accustomed life,

[When] I talked to my parents, they'd say, 'what are you doing?' I'd be like, 'well I'm going home and I'm washing my hair.' You know when you're there for so long it's just everyday life, and often I had to sort of kick myself and be like [...] 'I'm very close to Pakistan, you know, nowhere.'

In this passage she stresses her adaptability and said, "I love places that are different, like I feel very comfortable there." In fact, she adapted so well to the family's culture that they loved her: "I wouldn't fight it, and I would help with the cleaning and they, they loved me." This type of authenticity is not about seeing the exotic and different, but about becoming different. However, to 'truly' become different would normalise difference and require taking on a 'local' subject position: being close to Pakistan would no longer be "nowhere," but "home," rendering the exercise pointless. As discussed in chapter one, 'localness' is diametrically opposed to the backpackers' mobile and globalised identity, so there 
is a tension between demonstrating one's adaptability and acceptance of and by the Other, while still retaining a construction of exotic Otherness to comment on.

The desire to achieve this intimacy only with the most different, or 'real' locals has been empirically observed on the backpacker trail in India, where travellers bemoaned the difficulty of meeting 'real' Indians while ignoring opportunities to speak to middle class English speakers in their train carriages (Lozanski, 2010). This is a result of the investment in discourses of authenticity which renders 'modernised' local inhabitants 'fake' (Kontogeorgopoulos, 2003), 'invisible' (Bhattacharyya, 1997), or even considered to "disrupt the [picturesque] landscape" (Lozanski, 2010: 751). Intimacy and engagement operate within a "broad infrastructure that imposes difference - and distance - through discrepancies of racialization, class, nationality, and mobility” (Lozanski, 2010: 747). Backpackers necessarily cannot hear the 'authentic' subaltern voice, because they approach it from a Eurocentric subject position (Korpela, 2010). The greater the difference that is overcome, the more the experience is valued, and this leads to a necessarily fragile situation, where backpacker efforts to avoid objectifying the Other do so nonetheless.

Although Linda is not alone in idealising 'genuine' interactions with the Other, another event from her story to illustrates the second critique of the multicultural egalitarian 'backpacker utopia.' When I asked Linda to describe experiences that stand out as particularly meaningful for her, she described the following moment at the Taj Mahal:

There was $[\ldots]$ one moment where this woman was very very poor and [...] I said 'Namaste,' and I sort of [bowed]. And she was so taken aback, because, you know, I was seen as such a high [...] status, and she was very, you know, obviously very poor. And she was just so moved and she took my hand $[\ldots]$ and it was a really nice moment, and it was things like that that I remember. 
This momentary exchange between a Western backpacker and an apparently disenfranchised Other is particularly memorable and moving for Linda, because it allowed her to transcend both the (neo) colonial relations of domination and the alienating forces of financial transaction. In this exchange, Linda described her own liberalism and tolerance as affirmed in the other woman's pleasantly surprised reaction. Quintessential this moment may have been, but it was also fleeting, and only obscured or suspended, rather than overcame, international class inequalities between Western traveller and 'Third World local.' Thus, this moment affirms the self-construction as liberal and tolerant, which works as a "strategy of innocence" whereby travellers absolve themselves from the inherently exploitative aspect of their journey (including volunteering), which reinforces and relies on the very structural inequality they disavow (Lozanski, 2011: 470; see also Bennett, 2008b; Hutnyk, 1996). Thus, Lozanski argues that backpackers are "inoculated" from and incapable of seeing the unpleasant realities of the "exploitative relations between coloniser and colonised" (p.470).

But if we shift the focus of analysis, and read the desire for non-commercialised experience and non-transactional exchanges primarily as a desire to escape the 'cash nexus,' rather than the cultural divide, it reveals another utopian strand in backpacker discourse. Although backpackers especially valued interaction with Others who were most different from them, in this study, the main emphasis was on non-commodification of relationships, as in several cases 'genuine' exchanges with 'Westernised' 'locals' were also valued. Thus, in addition to escaping their role as 'colonisers,' backpackers sought to escape their role as consumers. The notion that non-commercial interactions are more meaningful stems from the modern perception that commercialisation and rationalisation have destroyed authentic human connections (Mazlish, 1989; Wang, 2000). This notion also relates to the Marxian description of human relations as fetishised or reified by capitalism. By attempting to construct relationships with people independently of 
their 'market' function, backpackers demonstrate a utopian desire for more 'authentic' human relations. Or, as Jameson might read it, backpacker ideology "figures for the ultimate concrete collective life of an achieved Utopian or classless society" (1982: 291). So focusing on the economic aspect suggests backpackers share Marx's unease at fetishisation of human relations under capitalism, although they seek temporary escape rather than systemic change.

If we understand backpacker desires for an egalitarian and diverse world as utopian as well as ideological, their efforts to bypass exploitation and evade their own position as exploiters is not a result of blindness to this position, but the result of awareness and discomfort at these very inequalities. I agree with Lozanksi (2011) that when backpackers claim to have successfully overcome inequality, they ideologically inoculate themselves from the structural inequalities that their practice rests upon and exacerbates. However, such claims are relatively rare, and when made, often only fleeting, as demonstrated in Linda's experience above. More often, this is a desired and imagined, rather than an achieved ideal, which is frequently spoken about in terms of its fragility and failure.

\section{Rupture: Confronted With the Self}

While I have presented several examples of situations where participants felt their desire for genuine interaction was achieved, this version of authenticity is just as evident in its failure as in its success. As Dean said about connections with local people,

It's never as much as I'd like, and it's always, it is really hard to know whether they're being genuine or whether they're wanting something from you. And I can't blame them for that. 
As Dean's statement indicates, backpackers often feel their good intentions are thwarted by Others who refuse the subject positions projected by backpackers and instead reveal the backpackers' position as First World tourists (Korpela, 2010; Lozanski, 2010). This is another instance during which of the "abyss" of authenticity can "abruptly reveal itself" (Oakes, 2006: 233). He observed this amongst tourists who had brought seeds to donate to a Chinese village they were visiting:

That being tourists weighed heavily upon them was clear [...] they wanted to think of themselves more as ambassadors of friendship and development (2006: 234).

However, the villagers concluded the visit with a "frenzy of hawking, until the tourists beat a hasty retreat to the safe confines of their minivan," to look for a more authentic village elsewhere. In this moment the tourists were confronted with the shocking realisation that they were "a group of tourists, fantasising about becoming something else" (p.236). In such moments of failure lies the 'truth' of the backpacker's position (Lozanski, 2010; Oakes, 2006). As

The only authentic experience to be had is the experience of the outsider, the experience one has as the tourist - rather than as a local and this only reinforces the distance that authenticity-seeking tourists seek to overcome (Oakes, 2006: 237).

Backpackers I spoke to experienced this in a variety of situations: for example, when 'locals' returned their gaze, treating them as an oddity to be stared at or even photographed, or when Erik suspected he was invited to Chinese people's homes to contribute to their cultural capital. In these instances, backpackers see their 'outsider' status reflected back to them in the Other's actions. Interestingly, this is one instance where the Other's agency is stressed, as in Erik's story about porters who took his luggage against his will and then charged "horrendous amounts." 
You have no choice. [...]. And this is where it gets really bad [... there's not much else you can say because they just don't understand, but you start swearing at them, because they understand the key word 'fuck off' [...] But it was just an awful feeling to have to put yourself in that situation. But then they put it on you.

Although Erik used the pronoun 'you' here to distance himself from his actions or to imply that this is how anyone would react (after all there was no choice), no other participants revealed this level of aggression. However, all participants in this study found street hawkers and beggars challenging and confrontational, and presented this situation as beyond their control. For example,

[You] kind of always felt, not threatened, but you knew people were always out to get you and rip you off and it's hard to know who to trust. [...] like in Varanasi you walk down the street to get your breakfast, and literally you'll have five people come up and break hash under your nose and be like 'hash hash,' 'silk silk, buy,' and they just assume you're a tourist so you've got money to buy silk.

In these passages, the 'local' returns to a negative connotation: that of a relentless, hounding entrepreneur. This is not the 'real local' whom backpackers wish to interact with, nor is it the 'real' interaction they were hoping for: both have been tainted by capitalism (Kontogeorgopoulos, 2003). According to Lozanski (2010: 741), these are instances when "so-called Others articulate their subjectivity in a way that is inconsistent with travellers' expectations." Therefore, this could be an example of the Other articulating their agency by refusing or contesting the tourists' objectification. In this sense, such moments of rupture could be an instance of "authentic subaltern voice" (Korpela, 2010: 1302), which is disappointingly not asking for friendship, but asking for cash.

Ateljevic and Doorne (2005), advocate attention to these voices and stress local entrepreneurs' active participation in the tourist exchange. In a challenge to “traditional [tourism theory's] arguments of cultural producers as passive victims commodified by the globalised tourism complex" (2005: 14), they argue that 
entrepreneurs willingly tailor their services to backpackers' desires (rather than simply being an object of the gaze), demonstrating "their ability to re-interpret their own cultural contexts through the eyes of [...] travellers visiting the area" (Ateljevic and Doorne, 2005: 18). While this study reveals important proactivity on the part of the producer, it does not demonstrate an equitable relationship between producer and consumer, as the subaltern here still must envisage her/himself through the eyes of the consumer, internalising (or pretending to) the tourist's orientalist expectations. Thus, the 'locals' backpackers engage with “operate both their businesses and their 'host' role as active agents, responding to the opportunities available to them" within the limits of a nonetheless unequal exchange relationship (Lozanski 2010: 751). As I see it, both parties are implicated in the commodity exchange system, and the Other can only thwart their own objectification in negative proportion to their dependence on tourist dollars. I agree that there is a moment of authenticity in these ruptures, where backpackers become aware of their position as consumers; however, I suggest that this is so uncomfortable because it merely confirms something backpackers already know. After all, it is their imagined reflection as global consumer they see in the eyes of the Other.

\section{Utopian Kernel in the Rupture}

The disillusionment and disappointment backpackers reveal in discussing their inability to transcend their position as consumers, culminates in a feeling of objectification as money. Several participants spoke about the apparently incessant attempts by street vendors or beggars to extract money from them. This thwarts their efforts to be perceived as 'equal' human beings. For example,

Basically we are walking money machines. That's it, as far as they're concerned we have got millions of dollars to spend, and we're stupid and we'll give it to them. (Erik) 
Because I think, fair enough, there's kind of an assumption from them that here's some cash walking around, that is out to literally spend cash. (Chris)

People are just seen as money. (Chris)

This failure to escape the alienating power of money highlights their very desire to escape. In these passages money is certainly negative, and to feel reduced to money is dehumanising and denies travellers of their individuality. As Camille said, when backpacking, "you're just like a dollar sign sometimes." This is another reason she prefers volunteering, "because you're actually, the locals get to know you more as a person.” Although this objectification appears to originate in the Others' disappointing action, I suggest that it originates at least as much in backpackers' awareness of their role as affluent global consumers, and their desire, but inability to imagine a different subject position. Thus, travellers imagine their own reflection in the eyes of Others as money. This awareness is also suggested by the frequent follow-up of this money metaphor with, "I can't blame them" (Dean), and, "fair enough" (Chris). ${ }^{23}$ Camille explained this in more detail, saying, she "totally" understands this:

Because when [...] you're a poor country and you just have all these tourists coming through, of course you're going to want to make as much money from them as you can. Because they have so much more than you, and like I totally understand that. But after a couple of months of it you're just like 'oh' there's just no, you know no real human interaction any more, other than your travel partner.

Despite the alienating and dehumanising subjective experience, backpackers "totally understand" their own objectification as money, because they are painfully aware of global inequality, and if not their exploitation of this, then certainly their "luckiness" in this regard (see chapter four). So money is the self-image

${ }^{23}$ This is also a result of the conflicting backpacker dream: the ability to contribute to local development. See chapter four. 
backpackers see reflected back in the eyes of the Other. This is painful, not only because it ruptures the utopian dream of friendly relations with 'authentic' Others, but because backpackers know it is 'true': they see themselves as nothing but money in relation to the Other, and this is uncomfortable because it inherently contradicts their desire to be human to the Other.

Thus, I read another kind of utopia in these paradoxical ruptures of 'authentic' relations: Jameson's (2004: 46) notion that in the failure of the utopian imagination, one can find some truth. Here lies, he suggests, our "utter incapacity" to imagine a utopian future and the "ideological closure of the system in which we are now trapped." In this way, utopia is an "operation calculated to disclose the limits of our own imagination of the future" (2010: 413). The discomfort backpackers experience in these 'moments of rupture,' where they perceive their own reification as money, highlights a utopian longing for a better reality, as well as the ideological impossibility of articulating or imagining this utopia. Although backpackers wish to escape the alienation of capitalism, they cannot imagine an alternative. This is not an individual failing but is symptomatic of the postmodern impossibility of utopia.

One participant, Brian, mentioned the 'truth' of this moment in 'vulgar' tourists, who do not share, what he called backpackers' "pretentions" to authenticity:

Tourists know what they're doing, they're cash, they're flying in, they fly out, they don't want to get any nasty diseases. But, I mean, if backpackers got a nasty disease, they'd brag about it, you know? [emphasis added]

In Oakes' account (2006: 233), when travellers are confronted with the "abyss" of authenticity they all "gingerly step away from the edge $[\ldots]$, convincing [themselves] to look elsewhere," unwilling to admit the impossibility of authenticity. In my interviews, there was considerable mention of and frustration at the fragility and frequent failure of the backpacker dream of fitting in with 
difference (although responsibility for this failure was usually attributed to the Other). It is this awareness of failure that contains the possibility for a utopian moment, a moment that, paradoxically, reveals the ideological limits of the imagination.

\section{Conclusion: Back to the 'Bubble'}

When seeking the 'real' world and 'real' connections become too challenging, and hagglers or beggars rupture the dream, backpackers have the option of recuperating in the nearest backpacker 'bubble.' This offers opportunities to relax and re-connect with Westerners and Western culture, or, as I cited Camille in the previous chapter, to let their "guard down." As discussed there, backpackers approach risk in developing countries with the power of knowing they have travel insurance and return-tickets home. Likewise, they approach the Other in the knowledge they can retreat to the 'bubble' at any time. Hottola (cited in Lozanski 2010) found all travellers spent significant time in spaces where the locus of control is with Westerners. Backpackers in this study did not discuss their time in such places at length, but when they did, it was often in an apologetic register, as a guilty pleasure that needed justification.

When we got to Thailand, my God that was wonderful [laughs], they just treated us so well [laughs]. It felt like a break from the hassles of India (Adam)

And it does get quite tiring after a while as well, like, how much, you know you need a break from that [...] just giving out a lot of stuff all the time. And so it seems odd but you do need a holiday from travelling sometimes. You need three or four days to go and hang out on a beach and do nothing. I know it sounds ridiculous (Chris)

Camille said that while her partner was hospitalised in Vietnam she, 
watched a lot of HBO in the air-conditioned [laughs] guesthouse. Wasn't too bothered to go out and see, but that was like the end of our trip and I was like 'oh I don't care about Asia anymore, I just want pizza and cheese and bread.'

This suggests the 'bubble' is a welcome choice when difference and exoticism become exhausting. Although engaging with 'reality' beyond the tourist world is more morally acceptable to people only too aware of their own privilege, this is only attractive to a degree - as long as it is safe, entertaining, and confirms their construction of self as liberal and tolerant. These periods in areas that provide the comforts of home can be seen as both a 'powerful' and a 'defeated' retreat; it is a response to the failure of backpackers' dreams of engagement and friendship, but also a source of pleasure: a comfortable return to the globalised consumer utopia. This provides respite from efforts to 'fit in' with Others, and an opportunity to enjoy being served by Others. As Lozanski (2010: 748) puts it,

Distance and desire operate in tandem as a means through which to know and be known by the Other without compromising the structurally embedded colonial status that makes this knowledge and desire the purview of travellers.

Authenticity is constructed according to various discourses, and sometimes achieved when experiences fit preconceived notions from guidebooks or other sources. The most pervasive form of authenticity lies in backpackers' desire to transcend their own position as tourist consumers by engaging in noncommodified interchanges and relations of friendship with the Other. One way of doing this is through volunteering, as this appears to be a non-commodified opportunity for immersion in local communities. The other is through transcendental moments of interpersonal exchange. Both these methods can be critiqued as ideological as they entail objectification of Others and obscure, rather than address, global class inequalities. However, this ideal of engagement also contains utopian moments, both in its desire and in its failure, when tourists' subject position as tourists rather than friends is confirmed to them. The benefit of 
looking at the utopian content of the dream rather than simply its ideological function is that it highlights an implicit critique of capitalism in the desire for transcendence, but also reveals the limits to this desire. 


\section{Chapter Three:}

\section{Responsible Backpacking for a Better World}

In this chapter, I address two questions. The first is how do backpackers understand the broader effect of their travels on the world through which they are travelling? The second is what impact does travel have on backpackers' imagining of global capitalism, or "cognitive mapping," and does their discourse include possibilities for thinking beyond this system (Jameson, 1991)? To address the first question I explore how wider tourism discourses, whether from a 'free-market,' development, critical, or guidebook perspective, are flavoured by utopian impulses. These contested but hopeful impulses are mirrored in backpacker discourse, which presents the practice as uncomfortably suspended between the contradictory facets of the 'globalisation dialectic,' which is seen as a force of homogenising domination and a force for pluralistic freedom, simultaneously (Jameson, 2010). Thus 'other postmodern' backpackers present the effects of backpacking as neither categorically positive nor negative, but rarely as neutral, agreeing that it should be 'good.' Some backpackers undertake eco-tourism, which addresses their twin concern of engagement and responsibility. This concern can be criticised as ideological for its subsumption of political concerns into the private, individualised realm of consumer choice. However, seeking the 'utopian moment' within this ideological practice reveals considerable reflexivity amongst the backpackers in 
this study about how their positive contribution is limited. Thus, backpacker discourses seem to settle on the suggestion that the most they can do is care, and be respectful: they take responsibility for the contradictions of the world they travel through in the only ways they can. These limits are not the result of a lack of desire for change, but are the result of a structural limitation on the imagining of alternatives.

My discussion of the second question leads on from these limits, where I suggest that systemic cognitive mapping is not greatly facilitated by backpacking, as the physical immediacy of personal experience eclipses broader analyses. Physically travelling along globalisation's infrastructure to experiences of difference, means backpacker discourse focuses on the connective and cultural aspects of globalisation. Confronting global inequality through interpersonal encounters is often framed by understandings of difference as primarily cultural - something to be 'experienced.' But those encounters which refuse this interpretation prompt intense emotional individualised responses. In these cases, backpackers feel a sense of responsibility towards the Other. Given their individualised and cultural understanding of inequality, backpackers express this responsibility through discourses of guilt, luck, and risk, and they attempt to address it through responsible consumption practices, rather than through the imagining of alternatives to capitalism. This failing of the utopian imagination is not the failing of individual backpackers, but reflects wider resistance to utopianism under late capitalist postmodernism (Jameson, 1991).

\section{Tourism and Responsibility}

Tourism has been described as "the largest voluntary transfer of resources from the rich to the poor in history" (Lelei LeLaulu, cited in Scheyvens, 2011: 1), but it is 
more than a transfer of resources, as the corporeal travel of passengers from the developed to the lesser developed nations produces a complex and paradoxical relationship between tourism and poverty. Because tourism, especially backpacker tourism, draws people to places marked by their difference from home life, poverty is an attraction in itself (Frow, 1997; Munt, 1994; Scheyvens, 2011). This leads to a tension between the aesthetic and romantic consumption of poverty and the liberal ideals of equality and prosperity through development to which many tourism discourses ascribe. While tourism is criticised as economically, environmentally, and socially exploitative by many scholars (Bennett, 2008a; Britton, 1982; Hutnyk, 1996; Mowforth and Munt, 2003), others argue that in its eco or even backpacking varieties, it has the potential to address some of these very concerns (Higgins-Desbiolles, 2006; Scheyvens, 2002; 2011). This contestation alone indicates that tourism theorists, like tourists, are motivated in various ways by a utopian longing for a better way of living, and, whether critical or hopeful, suggest that tourism should ideally be a positive force (see for example HigginsDesbiolles, 2006).

Modernisation theory of the 1950 s saw tourism as a potential modernising strategy, through which 'Third World' countries could gain revenue and create industries, ultimately following their former colonisers to prosperity (Scheyvens, 2011: 1). By the 1970s, dependency theorists started to question the local benefits of tourism, as the dominance of foreign 'First World' ownership, profit leakage, and poor local employment conditions came under critique. Britton (1982) for example, highlights the correlation between colonialism and tourism, arguing that the industry flourishes in countries where prior foreign domination has established the infrastructure for contemporary capitalist foreign domination. Tourism from this perspective is an economic neo-colonialism that benefits corporations based in (or across) the metropolitan countries. Despite this critique, the United Nation's Millennium Goals of eradicating extreme poverty by 2015 have essentially 
prompted a return to the ideals of modernisation theory amongst the development industry (Scheyvens, 2011: 2). Following this, the United Nations World Tourism Organisation (UNWTO) has made poverty alleviation one of its guiding principles. It is argued that tourism has a "special position" from which to achieve this, as the primary source of foreign earnings for forty-eight of the least developed countries (UNWTO, 2011a). As such, tourism offers local employment and "represents fertile ground for private initiative," while also serving "as a foothold for the development of a market economy where small and medium-sized enterprises can expand and flourish" (UNWTO, nd). This discourse employs wholesome terminology such as "fertile ground" to imply universal and inherent benefits of developing a market economy.

However, elements of the 1970s critique, as well as contemporary environmental concerns, have been incorporated into dominant economic discourse (Boltanski and Chiapello, 2005), and tourism is no longer considered inherently or automatically beneficial. Although described as an "engine for development," tourism "should not be seen on its own as 'the answer' to the elimination of poverty, only as a powerful contributor, if managed correctly" (UNWTO, 2011a). Thus, qualifiers such as 'sustainable' or 'responsible' are used to bridle relentless market growth, and tourism destinations are required to be "both competitive and sustainable" (UNWTO, 2011a). The UNNWTO also attributes responsibility to the individual traveller in its brochure Tips for Responsible Travellers (2005). This injunction to responsibility reflects a wider turn to ethical consumption as concern with sustainability, human rights, and equitability are slipping from the realm of politics to the domain of consumerism (Lewis and Potter, 2011). Ethical consumption also lends individual consumers responsibility and moral worth as they are frequently served with a 'side' of ethics, meaning consumption practises are morally as well as symbolically loaded. That many consumers take up this responsibility is indicated by the successful proliferation of products that claim to 
facilitate it. In tourism, this has resulted in a rise of 'alternative tourisms' and enterprises which are marketed as 'ethical' and claim to promote environmental responsibility, local ownership, and cultural respect (Munt, 1994). This alternative tourism industry is accompanied by non-government organisations such as Tourism Concern, which lobbies against human rights abuses and exploitative practises in the industry. Simultaneously they advise individual travellers on how to "Avoid Guilt Trips," again suggesting that some responsibility and opportunity to be virtuous lies with consumers. ${ }^{24}$

Tourism Concern (1999) has dedicated an issue of its magazine to backpacking. Overall, the publication was critical of backpackers as culturally disrespectful, hedonistic, egotistical, and as a forerunner of mass tourism, which is generally understood to be worse in its exploitation of local resources and labour. Many governments of developing countries, however, prefer to invest in luxury tourism than encouraging backpackers who are seen as a negative cultural influence whose economic contribution is minimal (Scheyvens, 2002). This runs contrary to backpackers' subjective claims of being 'better' and is a viewpoint which Scheyvens questions, arguing that the backpacking industry has the potential (again with qualifiers, especially concerning the "self-centred" attitudes of some backpackers) to challenge the foreign domination of the tourism industry. She argues that backpacking creates significant opportunities for grassroots economic development, because backpackers stay longer, buy local products from informal providers, visit places bypassed by luxury tourists, and have less of an environmental impact than resort tourism.

This perspective also features in guidebook discourse, which makes a point of addressing its readers as being more responsible than the 'masses' and is underscored by a proclaimed ethos of cultural respect, environmental

\footnotetext{
${ }^{24}$ See: http://www.tourismconcern.org.uk/
} 
sustainability, and ethical, especially 'local' consumption. For example, The Rough Guide to First Time Around the World (Lansky, 2010: 167) suggests that,

With good reason, travel publications have long asserted that mass tourism destroys the very things [...] that attracted visitors in the first place. Truth be known, we independent budget travellers contribute to this as well, probably more than we'd care to admit. Simply by being aware of your impact, though, you'll probably make more thoughtful decisions about where you spend your money and how you interact with people.

Although suggesting that backpackers also have a negative effect on destinations, the subtext in this extract reinforces the 'vulgar' tourist / 'noble' traveller divide, by assuming that travellers care about their impact. In addition, such awareness alone is presented as potentially addressing the problem. Tegelberg (2010) suggests a disconnect between the values guidebooks proclaim in such passages, their simultaneous avoidance of their own implication in adverse tourism development, and their silencing of resistant perspectives. He argues that such passages, are a little more than a "highly effective marketing strategy," as they target the audience who already wish to distance themselves from the tourist hordes (Tegelberg, 2010: 505). Thus, guidebooks consciously tap into the concerns around which 'other postmodern' tourists construct their identities as 'alternative' consumers (Munt, 1994). Throughout this chapter, I will suggest that backpackers reproduce this discourse and attempt to both ascribe and take responsibility for the exploitation they encounter in ways that emphasise individualisation, culture, and consumption. While this works ideologically as a panacea for the ills of capitalism and as a block to structural critique, it also represents backpackers' utopian yearnings. As discussed in the previous chapter, analysing these yearnings can lead to discussion of the limitations to utopian imagination (Jameson, 2004). 


\section{Dialectics of Development in Backpacker Discourse}

In response to my question about the general effect of tourism on their destinations, most participants initially presented tourism as a positive force in its links to economic development, modernisation, and creating a better, more harmonious world. In economic terms, this was often described as a dehumanised, mechanised process, as "pumping huge amounts of money into those poor communities" (Francis), or as an "injection of cash" (Brian). This depersonalised way of speaking about money uses metaphors similar those used by the UNWTO in describing tourism as an "engine for development" (2011a). These phrases reinforce 'globalism,' or dominant globalisation ideology, which implies free market globalisation is inevitable, irreversible, benefits everyone, and is beyond anyone's control (Fairclough, 2006: 46). This mechanisation metaphor alludes to these automatic and beneficial aspects, and this is an interesting counterpoint to the negative objectification of tourists as "walking money machines" explored in the previous chapter. Now the cash nexus is portrayed as positive, because tourism is "really a lifeline for people" and even the "lifeblood" of certain cities (Francis). Camille presented a more personal way of speaking about this:

I see like, well I could be spending my money on beer at home, or I could be spending it, you know, with this tuk-tuk driver. And at least this tuk-tuk driver, you know, saved up his money to buy his tuk-tuk and he's feeding his family with it.

In this excerpt, Camille speaks of a local entrepreneur in quite a different register to the statements in the previous chapters about local people "trying to rip us off." Here, the tuk-tuk driver is virtuous for having invested in a slice of the tourism industry market in order to sustain his family. This is an idealisation of the traveller's individual input, and the directness of the transaction seems to bypass corporate capitalism and 'corrupt' local governments. However, the overall message of liberation via participation in capitalism is essentially linked to a vision 
of the free market as utopian (Jameson, 2010). Thus, tourism is not a neutral product but an activity charged with sustaining underdeveloped areas (in an abstract 'macro' way) and, more personally, offers the opportunity for individual tourists to help change individual lives.

Culturally, tourism is seen as fostering exchange, understanding, and respect, and contributing to the pluralistic, multicultural 'global village' vision of globalisation. Francis, for example, said that tourism promotes "awareness of other cultures for both people; tourists learnt about Ecuadorian culture and locals learnt about foreign culture." Several others also stressed the two-way nature of this exchange, with Brian saying that tourism helps break down "barriers" between Others and tourists, meaning, "you're more human to each other, I think, rather than being completely different." Again, this contradicts the discourses cited in the previous chapter, where backpackers described their own objectification as money, and participated in objectifying the 'other' as precisely "completely different." This is a reminder that backpacker journeys are multifaceted and individual backpackers encounter a variety of experiences that they may interpret in contradictory ways, depending on the context.

However, not all were certain of this equitability. Isobel said travel raises awareness of social issues in other countries, "but it's not necessarily helping at a bigger level, it's probably more helping me," because the opportunity is one-sided: "The poor person [only] gets to see those wealthy [laughs] coming in." She also mentioned the development of sex-tourism and a drug culture related to tourism in South America - concerns other participants shared about India and Southeast Asia. In this way, tourism brings modern vices to the very people and places it sustains economically. In a similar vein, after spending two months immersed in 'traditional' culture, volunteering in a Thai national park, Hanna experienced more "culture shock" at a backpacker Full Moon Party than she previously had. She was 
particularly critical of the creation of a 'globalised' subculture amongst Thai youth. This experience prompted Hanna to redefine her travel priories: rather than seeking the most remote, 'traditional' areas, as planned she decided to stay on the beaten path, where the 'damage' was already done. Hanna voices reservations about the benefits of drawing 'unspoilt' places and peoples into global capitalism and culture. Thus, we return to (post)modern ambivalence about modernity, especially in relation to an idealised, more 'real' community life. Hannah struck me as unusual in letting the strength of her conviction deny herself from experiencing these more 'authentic' areas. Nevertheless, it later became clear that this self-derival occurred only in her capacity as tourist, because she continued to visit such communities as a volunteer, which she described as a "privilege." It is specifically touristic behaviour or consumption that she considered to have a harmful effect. Although Hannah acted out of sensitivity, Desforges (2001: 360) suggests that backpackers sometimes exercise their consumer power to preserve the aesthetic tourist pleasure of poverty. He thus observed backpackers refusing to purchase in 'authentic' villages and spending in established souvenir shops instead. This is in order to preserve the villages from the "modernising force of money," which is understood to destroy "traditional human relations, partly through their replacement with calculating relationships, and partly through the power which money offers to those who are able to accumulate" (Desforges, 2001: 360).

If tourism development corrupts 'pure' community relations, it is also considered environmentally harmful, especially in developing countries where development is often presented as proceeding irrationally or "just exploding," leaving the basic infrastructure struggling, while also leading to "gentrification" (Chris). This is contrary to the ideals of authenticity-seeking backpackers, although it may provide a comfortable recuperation space. This is also why development is 'regrettable' for Dean: 
You know, for Kuta to become this city that it has, I'm really sad about, because I'm sure it was beautiful thirty years ago when there [were only] a few people that knew about how nice Bali was. And the Kuta beach this amazing beach, but now it's just, it's got a wall built around it, it's covered in rubbish and there's a mall, and right on the other side of the wall there's this huge esplanade with all the clubs and everything, and like it'll never be the same again.

Dean demonstrates nostalgia for a time he never experienced, before people, their rubbish, and their commerce despoiled this beautiful place. Dean's reaction to this was the opposite of Hanna's: he wanted to "get out of there" and head for the more remote islands, although, as I will discuss, he was not un-self-critical. Thus, for Dean, as for many travellers, poverty adds adventure, authenticity and favourable exchange rates which is particularly important for backpackers who aim to travel for as long as possible (Riley, 1988; Scheyvens, 2011).

This idealisation of 'pure' human relations, environments, and cultures against the corrupting influence of economic exchange again implies the romantic nostalgic and utopian critique of Western and capitalist dominance (Desforges, 2001; Wang, 2000). However, it is a critique that simultaneously reinforces this dominance by presenting the Other as helpless and needing protection (sometimes protection from the backpacker themselves). It also serves to reify the Other as different, if not even to preserve poverty through backpackers excessive frugality (Desforges, 2001; Riley, 1988). Because of the contradiction in backpacker ideals, of experiencing and alleviating poverty, backpacker discourse is uncomfortably suspended between extolling and deploring modernisation and development. Where, on the one hand, they ascribe to the utopia of unfetishised human relations, on the other, they see the globalisation of capitalism as ushering in its own utopia: that of the free-market for individual opportunity and 'empty' multiculturalism (Jameson, 2010: chapter 17; Žižek, 1997). 


\section{Backpacking for a Better World}

The twin but contradictory backpacker ideals of responsibility and engagement find perfect expression in eco-tourism and volunteering. These activities provide the opportunity to experience poverty while providing the sense that one is alleviating it. While budget-conscious independent backpackers do not undertake entire trips with eco-tourism providers, they invest in the same values, and several participants mentioned instances where they chose 'eco' services. For example, Adam said,

In Tanzania, I'd say the effects of the tourism that we did felt really positive. Because we, we chose the company that gave half of their profits to local charities [...] and they sponsor a local school. [...] And we went and visited the school that, that we were helping to pay for.

The allure of fair-trade lies in its revelation of the relations of production, which mainstream commodification disguises. Thus, products appear less fetishised. In 'fair' tourism, the direct contact between the consumer and the producer, or recipient of the fairness, can be particularly rewarding for the customer. Adam's visit to the school he was "helping pay for" highlighted the "beneficial consequences that consumption of the product has on the particular community that produced the goods" (Cravatte and Chabloz, 2008: 234). This, however, is a process of re-fetishisation or 'enchantment' that is in some cases carefully constructed to create "solidarity links between consumer and producer" (p. 234). In the project Cravatte and Chabloz studied (an extended stay in a village, with organised 'ethical' activities, such as learning from craftspeople), this solidarity was consciously "constructed in contrast to an aestheticized exotic approach and to the humanitarian representation of the Other as being in need" (p. 244). This demonstrates the considerable complexity of appealing to highly reflective consumers who distance themselves from conventional tourism, and somewhat ironically, suggests that this most 'honest' form of tourist product requires 
additional levels of enchantment. Adam's experience of the benefactor role was further validated by the impression that,

they actually rely on western visitors to come through and give them new ideas and help them teach the students [...] Because when we arrived, he said 'oh, thank goodness you've come, I've been, I've been wanting a westerner to come and help me understand this textbook.'

He then made a point of explaining that the teacher was very educated and the course material "way beyond any science I'd ever learnt at school." Thus, Adam is careful not to present the teacher as inferior, while still being able to point to the value of his visit to the school. Megan and her partner also participated in specific eco-tourism, and chose the most expensive Amazonian eco lodge they could find, which they would not "generally have done because we were on quite a tight budget."

Half of the price that you pay went back into the lodge to make sure that it was kept modern and help train guides and things like that, and half went back into the village that they'd come from. [...] that was really cool because it felt like you were kind of able to give something back.

Like Adam, she valued seeing the beneficial effects of her contribution, presented in a video of improvements in the village since the project's inception. While staying at an eco-lodge offers guests tangible proof of their positive contribution, it also offers a particular type of experience: Megan pointed out that this lodge was the deepest in the Amazon, as well as being quite modern. Staying with an ecoprovider justifies enjoying a touch of luxury and organised group activities, which most backpackers would probably scorn in an urban environment. The symbolic value of "community run" is such that it endows a relatively expensive experience with enough authenticity to encourage this backpacker to break her tight budget. As she explained, on walks through the jungle, guides would intermittently leave the track, 
[...] and come back with like a leaf, and say 'rub this between your fingers' and it goes a bright purple. And he's like 'this is the kind of dye that we use to colour our clothing.' [And he would bring other] bits and pieces and show you how they used different resources within the jungle.

This experience was more luxurious and 'packaged' or 'staged' (e.g., the guided walks and other organised group activities such as piranha fishing), than typical backpacker activities. But for Megan, its commodified aspects were offset by 'backstage' experience of 'traditional' life in the jungle (MacCannell, 1976), and by the numerous positive development effects of the project. Thus, eco-tourism combines the twin backpacker concerns of engagement and responsibility, allowing backpackers to strive for their ideals when the opportunity is presented.

\section{Ideology: Consumption as Critique}

In tourism, the utopian longing for a diverse, equitable and sustainable world, which attracts backpackers to this form of consumption, is ideological not in its content, but in the way it reifies and obscures (or attempts to) global inequalities (as discussed in the previous two chapters). The concern with ethical consumption is its relationship to individualisation of responsibility (and risk) in society, whereby political questions have come to be a part of everyday domestic rather than public life (Lewis and Potter, 2011: 10). In a study of eco-tourism in the Caribbean, Duffy (2002: xi) critiques this niche industry as "green greed.” Profits are still the bottom line for producers, and the consumers are less concerned about the environment than with "journeys of self-development; their decisions to deny themselves the luxuries of other forms of tourism just reflect the roles they play within their peer groups." This reflects the argument that alternative tourism counts as a marker of distinction or cultural capital for the new middle classes. In fact, conservation concerns are an "ultimate justification for natural exclusiveness," 
articulated through limits on carrying capacity (emphasis in original, Munt, 1994: 119). Other theorists critique ethical consumption as "greenwash" or "superficial platitude," which simply encourages us to keep consuming, but with more 'care,' (Lewis and Potter, 2011: 17). To the extent that ethical consumerism claims to offer solutions to the largely capitalist problems of global inequality and environmental degradation through capitalism, it functions ideologically. Subsuming backpackers' utopian dreams of a better world back into consumerism commodifies critique itself. My earlier citation from Jameson (2010: 413), that the luxuries and pleasures of consumerism have eclipsed utopian desires because consumer society "needs no further supplement" could be extended: through ethical consumerism, consumption itself appears as a utopian force.

However, alternative tourisms do not substantially challenge global power imbalances or the class structures of capitalism. And, rather than fundamentally contesting the processes and institutions of the tourist industry, they continue to aestheticise poverty and nature, and to profit from global inequality and the unequal exchange rates which render tourist dollars so attractive and powerful (Mowforth and Munt, cited in Cravatte and Chabloz, 2008: 232; see also Hutnyk, 1996). In addition, the sustainable tourism industry can be analysed as sustaining capitalism itself by easing its internal contradictions and directly contributing to the fixing of crises of overproduction in capitalism. Fletcher (2011) suggests that tourism fulfils Harvey's concept of spatial (geographic expansion) and temporal (through investment in future projects) displacement of excess capital. With ecotourism, this industry may also help to forestall capitalism's 'second contradiction,' where the depletion of finite resources leads to price increases and market stagnation. Fletcher (2011: 453) argues that because nature tourism does not specifically require the extraction of primary resources, it abets this second threat to capitalism. Thus, neo-liberal capitalism "is able to exploit crises it has helped to create," and if, 
[...] sustainable tourism has become the dominant paradigm within the global tourism industry as a whole, then this may be due in part to the need to sustain capitalism as well. (Fletcher 2011: 457)

This argument suggests that capitalism has subsumed tourists' utopian investment in sustainability in order to sustain itself, rendering this utopia ideological. By presenting the 'ethical consumer choice' as providing solutions to global problems, this link remains hidden from view, contributing to "sustaining an ideological commitment to the notion that capitalism can address its own crises on the behalf of its victims" (Cremin, 2007: 535). In this way, capitalism has incorporated and adapted to some of the critiques made of it (Boltanski and Chiapello, 2005), rendering it softer or more "frictionless" (Žižek, 1997), and less susceptible to critique.

This is not to negate the value of ethical considerations within capitalism, or to suggest that development strategies do not offer poverty alleviation and should be abandoned in favour of more blatantly exploitative practises. I would not want to contribute to the "otherness machine" of the tourism brochure and critical tourism studies (Aitchison, 2001: 143) by denying subjects of developing countries the agency to participate in capitalism in ways they deem most beneficial. As Scheyvens (2011: 82) suggests, "fundamentally it seems that communities that have tourism development, want tourism development"; what they seek is greater control and greater access to benefits. She cites Rangan:

it seems ironic that scholarly debates should clamour for a postdevelopment era, just when voices from the margins - so celebrated in discourses of difference and alternative culture- are demanding their rights to greater access to a more generous idea of development. (p.82)

This is true within the bounds of capitalism. However, as opposed to several of even the most critical studies I have drawn on throughout this thesis (for example Bennett, 2007; Lozanski, 2011; Simpson, 2004; Higgins-Desbiolles, 2006), my aim is not to find solutions for tourism, to make it more inclusive or equitable, 
although those are valid ideals. Instead, I am interested in the possibilities and limitations to understanding or 'mapping' capitalism as a totality, and even of thinking beyond it. In these terms, mobilising consumption against the negative effects of capitalism is limited.

\section{Utopia: Reflexivity and Limitations}

It is precisely to reveal such limitations and iniquities that Lewis and Potter (2011) argue that ethical consumption should be theorised as more than just an ideological trend or status marker. The very fact that concern with the fairer distribution of resources can enhance our status and can ease our conscience demonstrates the social importance of these values. Cravatte and Chabloz (2008: 18) put it this way:

What the practises and politics of ethical consumption at its most radical can bring us to then is a rethinking of the "good life" and of ethical living in ways that fundamentally challenge the logics of consumer culture itself.

This suggestion clearly aims to identify the utopian element contained within (and expressed by) ethical consumption and, as Levitas (2007) argues, it is by laying bare the utopian undertones in ideology that they can be properly analysed and their limitations considered. With this aim in mind, listening to backpacker reflexivity reveals that while some backpackers in this study saw their travels as having positive impacts, as above, many others highlighted the limited and contradictory effectiveness or even failure of their ideals in this respect.

Efforts to mitigate environmental impact were spoken about with particular hesitance and reflexivity. Dean tried to find soap that "didn't contain any harmful toxins or anything like that," on his Amazon trip, but said: "It's pretty, probably pretty useless actually when you think about how much the Amazon's actually 
been polluted." This suggests reflexivity about the value of his efforts, and he sums it up like this: "I don't know. I'm not sure that I'd do anything very substantial to mitigate my impact." With much more certainty, he distances himself from types of tourism he considers more harmful, saying: "But I do fully try not to participate in the mainstream tourism that would have a strong impact." Later, he again reflects more deeply on his disapproval of this type of tourism, saying:

I think part of my repulsion [laughs] of touristic areas, is that I'm quite conscious that I'm probably part of creating that, um,... yeah it's a bit of a conflict, I think.

This demonstrates the considerable reflexivity and self-analysis that postmodern individuals subject themselves to and the awareness that, despite his good intentions, his actions do not satisfy his ideals and in some cases even contradict them. This is another instance of 'touristic shame.' Backpackers experience "selfloathing" towards their own mirror image in other tourists, for their environmental destructiveness, as well as for spoiling the authenticity discussed in chapter two (Phipps, 2004: 85).

Another way in which backpackers take responsibility for the world they are engaging with is through volunteering. Seven out of the fourteen people I interviewed spoke to me about volunteering projects they were involved in as part of their travels. These activities included biological research, conservation work, permaculture farming, teaching English, health campaigning, and construction work. Volunteering can also be critiqued as ideological, as it is seen as part of the professionalisation of travel and helps volunteers' self-construction as liberal and engaged (Cremin, 2007; Simpson, 2005). In addition, it functions as a form of cultural imperialism that contributes to the construction of the developing world as 'in need' of Western help (Hutnyk, 1996). Particularly problematic are commercial 'voluntourism' operations, which capitalise on backpackers' altruism but do not undergo the same level of regulation and consideration as development 
organisations (Simpson, 2004; Scheyvens, 2011). Thus, volunteers or charity workers can be critiqued as complicit with the problems they hope to alleviate.

However, in this study, very few participants raised their volunteer work when speaking about the ethical choices that shaped their trip. Most put surprisingly little emphasis on volunteering as a way of improving the world, and none made grandiose pronouncements about their altruism or the positive impact their actions had. Although most saw their volunteering as one of the most worthwhile of their experiences, they openly disclosed that this was of value for them personally. Francis, for example said that the "actual volunteering" was a "bit of a disappointment":

I mean, I was working in a little organic garden [...] there wasn't a lot going on there, sort of composting and growing some crops, but it, yeah, it wasn't really a great project. [...]I'd come there with the intention of making a difference and helping to save the rainforest.

When he spoke of these intentions to one of the other volunteers on his first day,

She just laughed and said, 'ah yeah we all want to do that, but it's like, you'll kind of see we don't really do a lot.'

Nonetheless, the experience was worthwhile and enjoyable for other reasons:

Just because the people, both the volunteers and the locals we met, and also because of just the amazing scenery. It sort of cast a spell on many of the volunteers, a lot of us sort of like still think about it a lot and sort of really love the place.

Hanna also described volunteering as a privilege, and Megan only considered it when she thought her boyfriend would not join her trip. In that case, her "focus would have been on [...] trying to get more out of one or two places," rather than trying to see "all of" South America. As already discussed, Brian more cynically and self reflexively suggested that volunteering adds prestige to the backpacking experience. 
It seems from these interviews that although the relationships and experiences from volunteering are considered as a 'special' part of the trip (as more authentic because they are not experienced as part of the cash nexus), the volunteering is nonetheless a part of backpacking and motivated by the same desires. This is in contrast to Moustonen (2006) who describes volunteering as postmodern pilgrimage, because of participants' altruistic motivation and desire to distinguish themselves from 'mainstream' backpackers. However, in my study, all (bar one) backpackers ascribed to this distinction, and volunteering was not the only way of attempting it. While I concur that volunteers are altruistically motivated to a degree, this is not necessarily unique to those travellers who volunteer, as it seems much tourism discourse includes altruistic or utopian elements.

To continue the analysis of the reflexivity and hesitations in backpacker discourse regarding the attainability of 'responsible' travel, it appears that perhaps the only certainty is backpackers' desire for this ideal. This reflects Hutnyk's (1996: 11) observation that backpackers vindicate themselves by saying, "Yes I recognise the contradictions but I try to avoid them myself." This aids the construction of self as 'innocent' against 'vulgar' tourists who do not 'even' try, while nonetheless still being able to enjoy similar privileges as they do. For example, Isobel said she had "more philosophical discussions" on the ethics of tourism, such as buying finger puppets made by children in Peru, but did not clearly make up her mind:

I don't know if I ever made, we did buy finger puppets, and I still don't know whether I would think... I'd say, yeah, there are issues about it, but it's not black or white. You know, like, no, they shouldn't be having to knit finger puppets and sell them, but if you don't buy them, then what happens, you know?

She also said, "like, it would be really nice if I could say yeah, 'I helped people,' but I don't know." However, she points out that "other people would be, like, I don't even give a shit," suggesting it is better to 'care,' even though caring did not affect the outcome of her actions. Adam justified his 'not making a difference' quite 
differently. First, he spoke of his admiration for the Peace Corps' principles because the first is to facilitate cultural exchange "and then their third is maybe they can do some work that's actually useful to the community." He explains as follows:

And, I just really respect that as a view of what you do in another country, you know. We weren't here to work; we weren't there to dig ditches or to pay someone to. You know, we were there to be on holiday, and, and experience that cultural exchange, so...

This statement constructs tourism as an a-political practise firmly in the realm of pleasure and leisure (Bennett, 2008b), rather than ditch digging. This allows Adam to feel quite justified in not having made a tangible difference to the countries he visited. However, this statement followed his discussion of the 'ethical' school visit discussed above, and he quickly followed it up by explaining that he also felt guilty for burning "the world's precious oil by flying." However, his absolution comes in his work as an energy researcher, which allows him to "spend three, five, however many years [trying] to overcome that." Contrast this to the following statement by Erik, whom I described as more of a 'post-tourist,' and who appears less invested in the self-construction as responsibly engaged. Speaking about his attitude to the civil unrest in Bangkok during his Thailand holiday, he said, "we had no idea, we were like 'whatever, we don't care, we're sitting on a beach [laughs] it's not going to affect us." Erik did not feel the need to follow this up with any justification, as 'other postmodern' backpackers may have.

As discussed earlier, Oakes (2006: 234) observed tourists in China desperately attempting to supersede their status as tourists and to "think of themselves more as ambassadors of friendship and development." Oakes read real anxiety and guilt in their expressions: "they wanted to believe that the village's Faustian bargain with tourism" would be for the best, despite what they saw as "disturbing cultural corruption required by such a bargain" (p.230). This and the other examples discussed here demonstrate the tension tourists experience between their ideals of 
contributing to the development of a diverse, egalitarian, and sustainable world, and their inability to do so, at least through tourism. While they experience genuine concern for the (imagined) wellbeing of others, in a sense this very act of caring is a "strategy of innocence" (Lozanski, 2010: 742). Caring, emotionally or "philosophically," absolves tourists of political involvement. The suggestion that the cultural positives and environmental moderations of tourism are more important than the structural inequality that allows it, is another way of obscuring this contradiction. The postmodern and liberal celebration of difference in cultural terms can come at the cost of recognising the economic factors involved in this difference. Thus, "alternative travel [...] can be criticised as an illusion of 'nice' cottage capitalism, soothing ideological anxieties, while extending commercialisation and the tourism industry" (Hutnyk, 1996: x), although Hutnyk considers this "inadequate," he suggests that it is "not surprising, given the difficulty of identifying and understanding the complexities of life within late twentieth century capitalism" (p. 11). I will presently discuss this difficulty through Jameson's concept of “cognitive mapping” (Jameson, 1991).

In this section, I have identified reflexivity in backpacker discourse regarding the limitations and failures of their ideals of changing the world through responsible travel. I interpret this reflexivity as traces of utopianism itself, by returning to Jameson's $(2004 ; 2010)$ suggestion that the utopian imagination is sometimes most evident in its failure. Thus, I do not approach the backpackers in this study as travelling under 'false consciousness,' in believing that their travels, or even their volunteering, significantly improve the world, but instead highlight the awareness that their desire to do so is thwarted. My study cannot address to which extent backpackers reflect upon how or why this thwarting occurs, but I suggest it is through the paradox of attempting to address the ills of capitalism, through capitalism, rather than thinking to alternatives beyond it. This occurs as the political seeps into individual consumer practises, and the economic structure is 
seen in cultural and environmental terms, channelling attempts to address these into liberalism and ethical consumerism.

\section{Globalisation: Mapping the World through Travel}

The difficulty of imagining possibilities beyond capitalism or of "mapping the totality" (Jameson, 1991: 46) can also be read into the interview participants' comments on globalisation. At the outset of this research, one of my questions was whether the embodied experience of global inequality that backpacking offers leads participants to a more systemic analysis of the global system and their place within it. Does physical travel along the infrastructure of globalisation prompt contemplation or critique of the world as a unified and stratified 'world system' (Wallerstein, 1990)? I asked participants to explain their understanding of globalisation, and whether travel had affected this. Several spoke about globalisation as culturally homogenising and destructive of the cultural distinctiveness that motivates travel, in ways I have already discussed. Two participants said this was not something they had thought about and declined to answer. The other responses indicate an emphasis on the positive cultural connectivity of globalisation, although this was presented against economic negatives that seemed too difficult or perhaps simply too obvious to bother discussing.

For example, Adam said he had recently revised his opinion of globalisation and that he now saw it as "quite a positive force" of information and cultural exchange, necessary for resolving global crises, such as impending energy shortages. Although he still also feels "some bitterness" about "the big corporations that most people talk about when they discuss globalisation," in general, his main concern is that "we won't keep doing it [laughs]." Alana said that she "unfortunately" looks at 
it from a business perspective, which entails "breaking barriers to bring people closer together and making things easier and supposedly easier." As her use of "unfortunately" and "supposedly easier" suggested some critique, I asked her whether travel had prompted her to think about it differently. However, she again focused on how technology smooths accessibility and connectivity: "while I was traveling, one thing I did think about was, I can't even imagine how people travelled before the internet." Camille also first mentioned the "terrible practices" of corporations and the International Monetary Fund who "go in and [... bankrupt countries," and then said,

But then there's also globalisation, like, it's easier to have information and to get to places. I think there'll be a lot less cultural misunderstandings the more, the quicker information can pass between places. So I think it's good in that way. And I think it's good that people can travel easier, but of course, you know, I like to travel, so I'm going to say that [laughs].

Here she pre-empts my possible critique that this is a self-serving justification and highlights her reflexivity and awareness. Similarly, Chris said: “There's definitely some issues with [...] a whole bunch of tourists coming in and that whole exploitative, cashing in on [inequality]," but then quickly turned to the positives of globalisation, and especially travel. In particular, he suggested that it creates empathy:

And it's sad but true, but the only way to kind of really experience empathy is to be there and to actually directly have the experience of being somewhere completely different.

In general, answers to my questions on globalisation allowed backpackers to demonstrate their awareness of the unequal global stratification that underlies it, and then to turn to speak about it in ways that justified their travel, presenting the aspect of globalisation they are most obviously involved in, as primarily positive. This suggests that the abstract 'reality' of the global system that facilitates their passage through the world is either too complex or disturbing to contemplate at 
length; it is easier or more palatable to turn to their own experience of it. Considering backpackers' position in the 'mobile class,' and their access to the technologies of connectivity and mobility, this experience is likely primarily positive, and offers little direct experience of the 'dark' side of globalisation (Bauman, 1998).

Despite this lack of attention to the structural workings of capitalism in globalisation, backpacker discourse can be read as an attempt at "cognitive mapping" (Jameson, 1991: 51). Based on the Althusserian redefinition of ideology as the "the representation of the subjects' Imaginary relationship to his or her Real conditions of existence" (cited in Jameson, 1991: 51), this is a process:

to enable a situational representation on the part of the individual subject to that vaster and properly unrepresentable totality which is the ensemble of society's structures as a whole. (Jameson, 1991: 51)

As this quotation points out, the complexity of late capitalism means the totality is currently unrepresentable. Under postmodern culture, attempts at cognitive mapping necessarily fail, neutralised by our "spatial as well as our social confusion" (Jameson, 2000: 232). Jameson is referring primarily to the disorienting effects of postmodern architecture, but it seems the pleasure itineraries of backpackers function similarly. Despite their desire to engage and to take responsibility for the 'real' world, backpackers are distracted by the intensity of their personal experiences along the trail. Much like the suggested routes traced onto maps in the introductory pages of guidebooks, backpacker's imagined maps of the geographical and social world seem to be structured around highlights. These may be memorable attractions, such as those moments when experiences conform to a particular backpacker ideal, or they may be moments of crisis or rupture in these dreams: either way, they are personal and individual souvenirs. These experiences and even their gaze are structured by the self-perpetuating, cyclical backpacker discourses that I discussed in previous chapters. Thus, rather than imagining new 
possibilities, backpacking tends towards confirming prior expectations, or, where this fails, leads to intensely personal, emotional responses. I will now explore this through backpacker responses to 'poverty.'

In terms of poverty, participants were quite uncomfortable with describing inhabitants of the countries they visited as poor in what they saw as a reductive manner. Instead, they understood 'local' lives as fulfilling in other, non-economic ways and emphasised people's happiness:

You know, I didn't see anyone starving to death. I saw kids selling souvenirs on the street, but they were still really happy kids who unfortunately weren't in school, but they were still, like, really happy kids that had really loving families.

This is a reiteration of the romantic idealisation of the pre-modern, and of the utopia of authentic, un-commodified community and familial relations. As we have already seen, this may be an extension of the orientalising, naive trope stemming from colonial times, here supplemented by the assumption that the Other is untouched by the anguish and desires of modernity, or is somehow inured to suffering through their religious or spiritual beliefs (O'Reilly, 2006: 1003). Camille contrasted this with her description of modern alienation:

I think a lot of us have, you know, we feel so secluded or so removed from social connections. We're so individualistic that there's a lot more depression and mental disorders, I think, in Western countries than there. They seemed a lot happier.

However, Camille's grounds for making this judgement are dubious. As she pointed out earlier, she had few intimate exchanges with local people. However, she did mention one highlight of the trip was talking with a temple guard who told her he earned twenty dollars a month. She described this as "kind of an awakening," because it was interesting to see "how much we pay as tourists but it doesn't really go to the locals at all." However, she said that he was not "feeling sorry for himself," because in relative terms it was "probably a really good wage." 
However, basing such a judgement on this one interchange is an example of turning a "rhetoric of 'poor but happy' into an experience of 'poor but happy,' [and] presenting few questions about the nature of, or reasons for that poverty." (Simpson, 2004: 688).

Backpacking sells poverty, not only as a sight, but also as a 'cultural experience' backpackers can experiment with for themselves. As such, it does not encourage analysis of the structural aspects that underlie it. Nevertheless, experiences of living in a 'poor' community do allow precisely what Chris values about tourism: empathy. Although his volunteering experience led to a "redefinition" of poverty, and this "was not a word that I would use to describe [the people] at all." But reflecting on this statement, he realised that he was idealising a situation that was very different for people who live there permanently:

But in saying that there is no opportunity and they are stuck there [...] there's also a lot of idealism, because it's kind of like, you're only there for a week and it's actually really fucking hard to get up at five o'clock every morning and do all that stuff.

If engaging with poverty can generate some empathy, it is also linked to emotions of guilt. This particularly comes to the fore with stories of beggars or haggling, instances where, as we have seen, the economic inequality between tourist and host cannot easily be bridged, and backpackers are startlingly confronted with their position as relatively affluent consumers. When asked about making connections with local people, Dean said some were "kind of bad," such as the time he bought a painting for his dad and bargained until the artist reduced the price "to a fraction of the price just because he needed to sell the painting":

And that gave me this huge conflict inside. You know, like, I didn't want to be taking advantage of him but I couldn't, I was honest with him, I couldn't pay the money that he wanted, and I did like the painting, so if he even didn't want to sell it to me I just took it.

The guilt, though, has followed him home as he still thinks that 
Someday I'll send him a letter and, I don't know, ask for another painting and give him the amount of money for it but that's never come to... [laughter]

In contrast, Eric, the 'post-tourist,' enjoyed bargaining, completely unperturbed by Dean's dilemmas, and described it as a "huge game," saying that he was quite happy to spend an hour arguing over twenty cents, because he knew he was already paying "probably three dollars more" than he "should be." Thus, the sense of responsibility backpackers feel towards the people they encounter seems to be another attribute specific to 'other postmodern' tourists, rather than backpackers in general.

Adam also described a story of emotional torment in response to being confronted with global inequality: he described feeling "hot and bothered" and stepping out of his "basic" but "lovely, nice hotel which had a rooftop garden and [...] a view of the Red Fort." Walking down the busy, noisy street he saw

[..] this man sitting in the gutter, completely naked, and he, he was actually pooing in the gutter, and he reached out and held my hand, grabbed my hand looked up at me with the saddest eyes, and said, 'please help'... and I wanted to hit him.

Adam was so "bothered" by this very physical confrontation with economic inequality and pre-modern sanitation, and by the contrast to his comfortable, 'hotel-bubble', as well as by his helplessness, that he was "angry in a way that I don't normally get. But I didn't hit him. I just, I let go of his hand and I just carried on walking." This incident was significant and Adam was clearly still tortured by the memory:

And you know, I, I've told this story so many times trying to figure out what I was thinking, and still don't know, but I was just anger [sic].

Lana likewise described her encounters with what she calls "real India" (everything outside of Goa) as "very emotional" because "you just want to, oh you 
just want to do something, you can't do a thing." She then described being 'swarmed' by children in the street:

I pretty much just froze because, one, they were children and so I just wanted to give them whatever they wanted. But I wasn't ready for that. [...] I didn't, I don't know, I didn't react well to it, I got kind of upset about it. [...] so eventually we got to a taxi we just got in the taxi, and I think I was crying by the time we got into the taxi.

This experience resulted in Lana and her partner leaving India for Thailand earlier than expected, and she regrets this, saying "if you can look beyond the initial poverty, you'd get a lot more out of India," but added, "I would rather have not seen it."

This is the privilege of the mobile classes: their proximity to danger, discomfort, poverty, and difference is a consumer choice. Moreover, a safe passage home, or to a more palatable or 'safer' destination, is usually at hand. Lana's was the clearest 'escape' narrative but several participants rolled reactions to poverty into safety concerns, or had 'guilty' emotional responses such as Adam's. When poverty does not provide the cultural experience or interpersonal exchange that appears to foreclose critique, it tends to be understood in terms of individual guilt at the inability to "do something," or as a threat. However, it is not for a lack of desire for a more equitable world that backpackers find thinking about poverty difficult. But under late capitalism, this utopian desire fails, due to the individualised and culturalised understanding of the problem. Backpackers are left with feelings of responsibility and guilt at their own 'luck' of being born into the affluent part of the world, rather than encouraging systemic analysis (Simpson, 2004). The clash between our inability to imagine alternatives, let alone implement them, and our desire to do so is one factor of what Jameson calls the postmodern fear of or anxiety about utopia (Hardt and Weeks, 2000: 5). 
As Žižek (2000: 1) argues, contemporary capitalism operates under such an allure of certainty that it is easier to imagine the end of the world, than the end of capitalism. It has come to seem so 'natural' and 'real' that it "will somehow survive even under conditions of a global ecological catastrophe" (2000:1). This explains how, in backpacker discourse, economic poverty collapses into individual narratives of luck, guilt, and responsibility, and how economic stratification collapses into cultural difference and environmental degradation. As such, rather than lying outside of capitalism, the imagined solutions are to reform and enhance capitalism's sustainability, in order, at all costs, to forestall the imagined horror of its annihilation. The prospect of total systemic change is frightening, according to Jameson (2004: 51) because it would require a re-formulation of our very subjectivities, and efface the need for "all previously existing utopian impulses." This means that we cannot envisage losing the suffering of this world without also losing the pleasures of this world (Jameson, 2004: 51). For backpackers, the personal pleasures of this world are considerable, despite moments of rupture.

\section{Conclusion: Better Backpackers, a Better World}

Backpacking does not appear to facilitate systemic analysis or successful cognitive mapping. It does, however, present an avenue for becoming a 'better person,' through 'taking' responsibility for the guilt experienced. The possible avenues for doing so are consistent with the a-political understandings of inequality and the attendant 'solution' of sustainability. Many participants mentioned their subsequent interest in 'fair trade,' with Brian describing himself as a "more conscientious consumer," and Francis being involved in the promotion of fair trade Ecuadorian bananas, since his return:

Because in the context of getting to know Ecuadorians, local Ecuadorians [...], just seeing kind of what warm and friendly people they were, $[. .$.$] made me interested in doing something to help them.$ 
Gemma now sponsors a child from an orphanage she visited in Vietnam, and Brian is more sensitive to news reports of Africa, because "it's no longer just a starving kid on the news, it's a starving kid you might have met on the news." Thus, the personal confrontation with global inequality through backpacking has led these individuals to do what they can in the personal realm of consumerism. Thus, backpackers' individualised and culturalised understanding leads them to attempt to shoulder responsibility individually, which necessarily fails, and finds its only outlet in 'utopian' consumer practises, which have already been critiqued as primarily ideological in function.

In this thesis I have sought to contest Bennett's (2007: 31) argument that individuals must shoulder more responsibility for globalisation. She argues that anti-globalisation critics frequently blame iconic corporations such as McDonalds, obscuring the fact that anyone "caught in [globalisation's] flows plays a part however small - in its dominant shape." She identifies a lack of reflexivity in politically sanitised backpacker discourse, and promotes "critical literacy" in tourism discourse to "prevent globally advantaged citizens from losing faith in their relative political agency and ability to help less advantaged Others" (p. 32). I have attempted to show that individual reflexivity is not missing from backpacker discourse; in fact, backpackers are troubled by the disconnect between their utopian ideals and their inability to put them into practise. What is missing is systemic reflexivity: attempts to 'map' the totality, and to think beyond it. Again, this is not an individual failing or short sightedness on the part of backpackers, but is related to a wider postmodern turn against utopianism and the contemporary "necessary failure" of cognitive mapping (Jameson, 1991; Jameson, 2004). Moreover, in this failure lies a 'truth' or 'utopian moment' of postmodernism - its inability to represent the totality or to imagine alternatives. 


\section{Conclusion:}

\section{Ideology and Utopia along the Backpacker Trail}

The backpacker trail leads travellers through a complex interweaving of utopia and ideology as they exercise their freedom to seek responsible engagement with the 'real' world. These ideals of freedom, engagement, and responsibility suggest backpackers share a utopian dream for a world that is more open, diverse, and egalitarian. However, these ideals are beset by contradictions, which often render them ideological in that they serve to sustain domination and to limit the utopian imagination. Nonetheless, listening to backpacker interpretations and reflexivities about their practice reveals contestation about the attainment of these ideals. In fact, much backpacker discourse focuses on the fragility, failure, or rupture of attempts at authentic engagement and responsible travel. It is within these discourses of failure that the value of utopian analysis lies, as they reveal the ideological limits to the utopian imagination.

Freedom: As a mobile and flexible form of consumption, backpacking relies on technological, bureaucratic, and economic infrastructures that enable access to the 'banana-pancake trail.' In addition, backpacker narratives contribute to the discursive construction of the world as 'tourable.' In doing so, backpacker discourse exacerbates the dichotomy and inequality between the 'mobile classes' 
and the 'static' Others they travel past, who are constructed as rooted to the 'local.' Through their travels, backpackers demonstrate their freedom of choice as global consumers, emphasise their flexibility, and assume the right to mobility. Under late capitalism, these attributes count as cultural capital and function ideologically as signs of power. Nonetheless, this discourse of freedom and mobility contains a 'utopian moment' in that it reflects backpackers' experience of the world: their 'tourable' world really is open, multicultural, and consumable. However, this dream sometimes ruptures, allowing unsettling awareness of threatening or resistant aspects from beyond this world to seep into the backpacker experience.

Engagement: Backpackers interviewed for this thesis distinguished themselves from other tourists by their willingness to engage with the 'real world.' Although the backpacker gaze is structured by romantic and neo-colonialist Othering discourses, most travellers seek to experience difference by fitting into local communities, and seeking 'authentic' interaction with Others. Through this, backpackers idealise utopian 'unfestishised' human relations, aim to escape their status as colonial tourist-consumers, and hope to suspend the economic and power differentials which structure their relationship to 'local' Others. However, this dream is notably fragile and frequently fails; intimacy is in constant tension with difference, and any transcendence of inequality is merely a temporary masking, often thwarted by the Other's refusal of objectification. Such moments in which the 'abyss' of authenticity (Oakes, 2006) is experienced, reveal a utopian 'moment of truth' - that both backpackers' positions as global consumers and capitalist relations more generally, are inescapable.

Responsibility: both academic and popular discourses about tourism contain utopian suggestions that tourism could and should be economically, culturally, and environmentally favourable. Backpackers I spoke with reflect this desire that their practice be beneficial. However, their discourse is fraught by the contradiction 
between their desires of engagement with a non-capitalist world and responsibility through development. Although eco-tourism addresses these twin ideals, this form of consumption necessarily reinforces the ideology of consumer capitalism by commodifying critique. Nonetheless, close listening to backpacker discourse reveals considerable ambivalence regarding their ability to have positive impacts; ultimately, backpackers settle on demonstrating that they care by wishing their practice were beneficial. This constructs them as 'responsible' global consumers, while absolving and blocking them from considering political or systemic alternatives. In addition, confrontations with poverty are either reduced to interesting cultural difference, or result in intense emotional responses, which frame global inequality through individualised discourses of luck and guilt. Again, this can only be assuaged through further ethical consumption. Rather than facilitating systemic critique or 'cognitive mapping' of global capitalism (Jameson, 1991), backpacker experiences and understandings of difference are structured around individualised encounters and itineraries.

Overall, these three ideals are symptomatic of postmodern consumerism, in which concern with environmental sustainability and tolerance of cultural diversity count towards social distinction for the new middle class (Munt, 1994). Simultaneously, they reflect a utopian desire for an open world in which individuals have a right to mobility, cultural diversity is celebrated, and all enjoy equal rights and opportunities. Through these ideals, backpackers have a contradictory relationship to capitalism (trying to achieve authenticity beyond it, and attempting to assist development through 'sustainable' versions of it). This demonstrates the ambivalence felt towards the globalisation of capitalism, which is seen as economically exploitative and culturally homogenising, while also leading to pluralism and freedom (Jameson, 2010). Backpacker practice and discourse are suspended between these contradictory facets of globalisation, and backpackers are left feeling stranded as they attempt to escape the ills of capitalism, via capitalism. 
My theoretical approach throughout has been to highlight, rather than resolve these tensions, by using the conflicting but intertwined concepts of ideology and utopia. Utopia here is not understood as a place backpackers seek, but as a desire for a better way of living (Levitas, 1990), which underlies their ideals. However, these ideals also function to reify existing inequalities, to further entrench free market capitalism, and to obscure the structure of global inequality, and so, function as ideologies, despite containing utopian impulses (Jameson, 2004; 2010). Backpackers are not oblivious to these contradictions, and experience difficulty and uncertainty in achieving their ideals. It is in momentary confrontations with the abyss of authenticity or with their inability to improve the world, that the limits to utopian thought under late capitalism are revealed (Jameson, 1991; 2004). However, backpacker responses to this failure of their ideals (retreat to the 'bubble,' individually shouldering responsibility for global inequality, and attempting to redress this through consumption) represent another return to ideology. This is not due to individual failings on the part of backpackers, but is a bind that is symptomatic of the difficulty, during the postmodern period, to 'map' the totality, or to imagine utopian alternatives to capitalism.

As this project originated from reflections on my own experiences of backpacking, one of the problems it grapples with is attempting to reconcile critical sociology with a more 'descriptive' sociology of the critique social actors undertake (Boltanski, 2011). I have attempted this by switching between analysis 'from within,' which recognises actors' understandings and meaning-making (Reed, 2007), and a process of historicising or totalisation that seeks to reveal or uncover the traces of capitalism within the discourse (Jameson, 2010). I suggest that reading discourse through Jameson's (2004) approach may allow this: it is an approach which is sensitive to the possibilities as well as the limits of participants' imaginations and desires. 
In terms of backpacking literature, this thesis contributes to discourse and cultural critiques of the phenomenon. Undertaking qualitative interviews with backpackers allowed me to engage with their subjective interpretations, and to hear considerable self-reflexivity about their ideals. Many of the other critical studies that I have drawn upon are less sensitive to this, as they tend to be based on textual data (for example, Bennett, 2007; Bhattacharyya, 1997; Cremin, 2007; Enoch and Grossman, 2010; Tegelberg, 2010), although there are also some useful exceptions to this (Korpela, 2010; Lozanski, 2007; 2010; 2011; Simpson, 2004). In addition, the framing of the critical angle in my work by Jameson's Marxian approach differentiates it from more post-structurally informed critiques, as I finally analyse culture in terms of its links to the economic sphere. By focusing on travellers from (or currently residing in) Aotearoa/New Zealand, my work contributes both to wider work on backpacking in developing countries (none of which focus specifically on New Zealanders), and to work on the experiences of New Zealand tourists, most of which are concerned with the 'OE' to the United Kingdom and Europe (Haverig, 2007; Bell, 2002).

Sitting as it does at the intersection of several perspectives and schools, this thesis risks criticism from multiple angles. For example, theorists approaching backpacking from post-structural, postcolonial, or feminist perspectives may find it economically reductive. However, I chose primarily to focus on the ways ideology is shaped by capitalism, precisely to address what I see as a gap in backpacker critique, which generally focuses on colonial legacies and processes of racialisation. I hope this work begins to fill this gap without undermining the importance of other facets of domination and inequality.

On the other hand, more traditional Marxists might find my linkages to the structural workings of tourism as a global form of class exploitation weak. They 
would perhaps also be concerned that underlining the utopian kernel of ideology amounts to validating bourgeois ideology and consumer panaceas, while detracting from the formation of class consciousness or antagonism. They may also point to another contradiction: that I criticise backpackers for failing to undertake systemic analysis of their practice and their social position, while myself offering scant analysis of the material effects of backpacking. As such, my project is firmly a cultural/discursive analysis; however, I follow Jameson in treating culture as intricately intertwined with the mode of production from which it originates.

Perhaps this is another moment in which to return to the reflexive origins of this project. I have already identified some parallels between the utopian impulses contained within the travel stories I listened to, and those contained within my research approach. Yet it seems there is also a parallel limit to our imaginations, as it turns out, my ability to definitively 'represent the totality' is as limited as a researcher as when I was a backpacker myself. As Jameson (1991) reminds us, the totality is at present un-representable in its complexity and heterogeneity. As Hardt and Weeks (2000: 25) explain of Jameson's perspective,

Once we train ourselves to look for [utopia] we can find throughout the world of cultural objects expressions of utopian desire, just as we can find too attempts to understand the totality, however partial, deformed, or unconscious they may be.

Thus, this thesis itself contains a utopian impulse and only a "partial," if not a "deformed" attempt to understand the totality. Backpacker dreams and ideals represent a utopian desire for a better way of living, which mirrors the Marxian desire for a world where human relations are not fetishised by the capitalist labour market. However, under capitalism these ideals are contradictory and frequently rupture, and no amount of engagement or responsibility on the part of backpackers, or ideology critique on the part of academics, will address the systemic global inequalities that both backpacking and capitalism perpetuate and thrive on. While backpacking can perhaps be practised more ethically, sustainably, 
and equitably, and indeed it should be, this will not realise the utopian backpacker vision of an open, diverse and egalitarian world. Only through broader social transformation may backpackers one day travel in a world that matches their ideals. However, despite their limitations, recognising these ideals is important because although the utopian imagination is not political in itself, "it is hard to see how any durable or effective political action could come into being without it" (Jameson, 2009: 434). While engaged and responsible backpacking is far from a challenge to the social order, it represents a desire for (temporary) escape, and perhaps that is all the current social system allows. 


\title{
Appendix A: Participant Information Sheet
}

\author{
VICTORIA UNIVERSITY OF WELLINGTON \\ Te Whare Wananga o te Upoko o te Ika a Maui
}

Researcher: Sonja Bohn,

School of Social and Cultural Studies,

Victoria University of Wellington

Ph: 044635233 ext: 6710

email: sonja.bohn@vuw.ac.nz

\section{Participant Information Sheet for 'Backpacking in the Developing World'}

You are invited to participate in the research project "Backpacking in the Developing World', a study which explores New Zealanders' backpacking experiences in developing countries.

I am a Masters student in Sociology at Victoria University of Wellington, and this research will form the basis of my thesis. If you have recently been backpacking in developing countries for a minimum of two months, I would like to talk to you for about an hour about your experiences. I am interested in the hopes you had for this trip before leaving and how your experiences matched these expectations. I will ask you to discuss how you felt about being a traveller, and whether you feel your worldview has changed as a result of your trip.

This research has been approved by the School of Social and Cultural Studies Human Ethics Committee. Findings from the interviews will be included in my MA thesis, which will be submitted for marking to the School of Social and Cultural Studies and deposited in the University Library. This research may also lead to a journal article or conference paper. You may be assured of confidentiality; your identity will not be made public and no real names will be mentioned in the final write-up. No other person besides me and my supervisors, Dr Chamsy el-Ojeili and Dr Patricia Nickel, will see the full interview transcripts, and all information collected will be kept in a secure place. 
You will be given an opportunity to review the transcripts. If you are interested, you will be given a summary of findings at the conclusion of the project, and recordings will be returned to you or destroyed. You will have the right to withdraw yourself and any information you have provided from the research within three weeks of reviewing the transcripts or six weeks of the interview, whichever is later.

If you have any questions or would like to receive further information about the project, please do not hesitate to contact me or my supervisor, Dr Chamsy elOjeili, at the School of Social and Cultural Studies at Victoria University, phone: (04) 463-6740 or email: chamsy.el-ojeili@vuw.ac.nz

Sonja Bohn 


\title{
Appendix B: Consent Form
}

\author{
VICTORIA UNIVERSITY OF WELLINGTON \\ Te Whare Wananga o te Upoko o te Ika a Maui
}

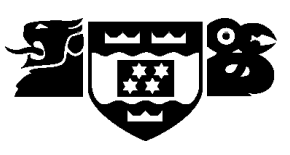

Researcher: Sonja Bohn,

School of Social and Cultural Studies,

Victoria University of Wellington

Ph: 044635233 ext. 6710

Email: sonja.bohn@vuw.ac.nz

\section{CONSENT TO PARTICIPATE IN RESEARCH \\ Backpacking in the Developing World}

I have read and understood the description of this research project, and have had an opportunity to ask questions.

I agree to be interviewed for this project on the understanding that the published results will not use my name, and all efforts will be made to present findings in ways that do not identify me.

I agree to having the interview audio recorded and I understand that the recordings will be electronically wiped at the end of the project unless I indicate that I would like them returned to me.

I wish to check the transcripts of the interview before publication.

Yes

No

I wish to receive a summary of the results of this research when it is completed.

Yes

No $\square$

I wish to receive the audio recording at the conclusion of the research.

Yes

No 
I understand that I may withdraw any information I have provided without explanation within three weeks after viewing the transcripts or within six weeks of the interview, whichever is later.

I agree to take part in this research

NAME (please print):

SIGNATURE

DATE: 


\section{Appendix C: Interview Schedule}

Please tell me the story of your trip...

Which experiences stand out as particularly meaningful for you?

Urban/rural/historical/cultural?

Do some experiences stand out as unique? That most other travellers wouldn't experience?

Can you describe some low points in the trip?

Interacting with locals - are there any particular connections that stand out in your mind?

How did this feel for you?

Conflicts?

Culture shock? Your reaction to seeing poverty?

Tell me about when you first started thinking about this trip - what were your thoughts?

Motivations Hopes Interests

What were you mainly interested in experiencing?

Describe your travel style?

Organisation accommodation? Transport? Interests?

Use of guidebook? Traveller advice etc?

Why travel like this? (Conscious decision?)

Did you spend much time in Tourist/backpacker areas? 
Interactions with other travellers?

\section{Politics}

Local politics or current affairs/history

Moral and political considerations?

Effects of Tourism

After - Do you often tell your travel stories? Photos etc?

Did you experience the real country?

Which of these do you identify with the most - traveller, tourist, backpacker?

Globalisation, what does it mean to you?

Is there anything you would like to add? Anything I haven't asked about that I should have?

Demographics:

Gender:

Age:

Ethnicity:

Current occupation:

Highest educational qualification:

Travelled to:

Date:

Interview date:

Nationality: 


\section{References}

AGGER, B. 1989. Fast capitalism: a critical theory of significance, Urbana, University of Illinois Press.

AITCHISON, C. 2001. 'Theorizing other discourses of tourism, gender and culture: can the subaltern speak (in tourism)?,' Tourist Studies, vol.1, no.2, pp. 133-147.

ALNENG, V. 2002. ' "What the fuck is a Vietnam?": touristic phantasms and the popcolonization of (the) Vietnam (war),' Critique of Anthropology, vol.22, no.4, pp. 461-489.

ATELJEVIC, I. \& DOORNE, S. 2005. 'Dialectics of authentication: performing "exotic Otherness" in a backpacker enclave of Dali, China,' Journal of Tourism and Cultural Change, vol.3, no.1, pp. 1-17.

BALIBAR, E. 2007. The philosophy of Marx, London Verso.

BAUDRILLARD, J. 1981. For a critique of the political economy of the sign, New York, Telos Press.

BAUMAN, Z. 1998. Globalization: the human consequences, New York, Columbia University Press.

BAUMAN, Z. 1999. 'Postmodernity or living with ambivalence,' in: ELLIOTT, A. (ed.) The Blackwell reader in contemporary social theory, Oxford, Polity Press.

BAUMAN, Z. 2000. Liquid modernity, Cambridge, Polity Press. 
BAUMAN, Z. 2003. 'Utopia with no topos,' History of the Human Sciences, vol.16, no.1, pp. 11-25.

BELL, C. 2002. 'The big "OE": young New Zealand travellers as secular pilgrims,' Tourist Studies, vol.2, no.2, pp. 143-158.

BELL, C. \& LYALL, J. 2002. The accelerated sublime: landscape, tourism and identity, Wesport, Praeger Publishers.

BENNETT, R. 2007. Moving off the beaten track: developing a critical literacy in backpacker discourse. PhD Thesis, Perth, Murdoch University.

BENNETT, R. 2008a. 'Entering the global margin: setting the "Other" scene in indepenent travel,' in: BURNS, P. M. \& NOVELLI, M. (eds.) Tourism and mobilities: local-global connections, Wallingford, CAB International.

BENNETT, R. 2008b. 'Exploring the liquid politics of tourism: developing reflexivity in backpacker discourse,' Fast Capitalism [Online], vol. 4, no.1, Available: http://www.uta.deu/huma/agger/fastcapitalism/4_1rjbennett.html [Accessed 15/09/08].

BHATTACHARYYA, D. P. 1997. 'Mediating India: an analysis of a guidebook,' Annals of Tourism Research, vol.24, no.2, pp. 371-389.

BIANCHI, R. V. 2009. 'The "critical turn" in tourism studies: a radical critique,' Tourism Geographies, vol.11, no.4, pp. 484-504.

BOLTANSKI, L. 2011. On critique: a sociology of emancipation, Cambridge, Polity Press.

BOLTANSKI, L. \& CHIAPELLO, E. 2005. The new spirit of capitalism, London, Verso.

BOORSTIN, D. 1964. The image: a guide to pseudo-events in America, New York, Harper \& Row. 
BOURDIEU, P. 1984. Distinction: a social critique of the judgement of taste, London, Routledge \& Kegan Paul.

BRITTON, S. 1982. 'The political economy of tourism in the Third World,' Annals of Tourism Research, vol.9, no.3, pp. 331-358.

BUDDHABHUMBHITAK, K. 2010. 'Tourist immersion or tourist gaze: the backpacker experience,' in: BURNS, P., PALMER, C. \& LESTER, J. (eds.) Tourism and visual culture, volume one: theories and concepts, Wallingford, Oxfordshire, CAB International.

CHIAPELLO, E. 2003. 'Reconciling the two principal meanings of the notion of ideology,' European Journal of Social Theory, vol.6, no.2, pp. 155-171.

COHEN, E. 1973. 'Nomads from affluence: notes on the phenomenon of driftertourism,' International Journal of Comparative Sociology, vol.14, no.1-2, pp. 89103.

COHEN, E. 1988. 'Authenticity and commoditization in tourism,' Annals of Tourism Research, vol.15, no.3, pp. 371-386.

COHEN, E. 2004a. 'Backpacking: diversity and change,' in: RICHARDS, G. \& WILSON, J. (eds.) The global nomad: backpacker travel in theory and practice, Clevedon, Channel View Publications.

COHEN, E. 2004b. Contemporary tourism: diversity and change., Oxford, Elsevier.

CRAVATTE, C. \& CHABLOZ, N. 2008. 'Enchantment and solidarity,' Tourist Studies, vol.8, no.2, pp. 231-247.

CREMIN, C. 2007. 'Living and really living: the gap year and the commodificcation of the contingent,' Ephemera: Theory and Politics in Organization, vol.7, no.4, pp. 526-542.

CURTHOYS, A. 2008. 'Indigenous subjects,' in: SCHREUDER, D. M. \& WARD, S. (eds.) Australia's Empire, Oxford, Oxford University Press. 
DANN, G. 1996. The language of tourism: a socioloinguistic perspective, Wallingford, CAB International.

DANN, G. \& COHEN, E. 1991. 'Sociology and tourism,' Annals of Tourism Research, vol.18, no.1, pp. 155-169.

DAVIDSON, K. 2005. 'Alternative India: transgressive spaces,' in: JAWORSKI, A. \& PRITCHARD, A. (eds.) Discourse, communication and tourism, Clevedon, Channel View Publications.

DESFORGES, L. 2000. 'Traveling the world: identity and travel biography,' Annals of Tourism Research, vol.27, no.4, pp. 926-945.

DESFORGES, L. 2001. 'Tourism consumption and the imagination of money,' Transactions of the Institute of British Geographers, vol.26, no.3, pp. 353-364.

DUFFY, R. 2002. A trip too far: ecotourism, politics and exploitation, Sterling, VA, Earthscan.

EAGLETON, T. 2007. Ideology: an introduction, London, Verso.

EDENSOR, T. 2000. 'Staging tourism: tourists as performers,' Annals of Tourism Research, vol.27, no.2, pp. 322-344.

EL-OJEILI, C. 2010. 'Post-Marxist trajectories: diagnosis, crtiticism, utopia,' Sociological Inquiry, vol.80, no.2, pp. 261-282.

ELSRUD, T. 2001. 'Risk creation in traveling: backpacker adventure narration [electronic version],' Annals of Tourism Research, vol.28, no.3, pp. 597-617.

ENOCH, Y. \& GROSSMAN, R. 2010. 'Blogs of Israeli and Danish backpackers to India,' Annals of Tourism Research, vol.37, no.2, pp. 520-536. 
FAIRCLOUGH, N. 2001. 'Critical discourse analysis as a method in social scientific research,' in: WODAK, R. \& MEYER, M. (eds.) Methods of critical discourse analysis, London, Thousand Oaks.

FAIRCLOUGH, N. 2003. Analysing discourse: texutal analysis for social research, London, New York, Routledge.

FAIRCLOUGH, N. 2006. Language and globalisation, London, New York, Routledge.

FAIRCLOUGH, N. \& WODAK, R. 1997. 'Critical discourse analysis,' in: VAN DIJK, T. A. (ed.) Discourse as social interaction, London, Thousand Oaks.

FLETCHER, R. 2011. 'Sustaining tourism, sustaining capitalism? The tourism industry's role in global capitalist expansion,' Tourism Geographies, vol.13, no.3, pp. 443-461.

FRANKLIN, A. 2003. 'The tourist syndrome: an interview with Zygmunt Bauman,' Tourist Studies, vol.3, no.2, pp. 205-217.

FROW, J. 1997. Time and commodity culture: essays on cultural theory and postmodernity, Oxford, Clarendon Press.

HANNAM, K. \& ATELJEVIC, I. (eds.) 2008. Backpacker tourism: concepts and profiles, Clevedon, UK; Buffalo [N.Y.] Channel View.

HANNAM, K. \& DIEKMANN, A. (eds.) 2010. Beyond backpacker tourism: mobilities and experiences, Bristol; Buffalo; Toronto, Channel View.

HARDT, M. \& WEEKS, K. 2000. 'Introduction,' in: HARDT, M. \& WEEKS, K. (eds.) The Jameson reader, Malden, Blackwell.

HARVEY, D. 1989. The condition of postmodernity: an inquiry into the origins of cultural change, Oxford, Basil Blackwell. 
HAVERIG, A. 2007. Should I stay or should I go?: the pushes and pulls around the $O E$ in New Zealand. MA Thesis, Christchurch, University of Canterbury.

HIGGINS-DESBIOLLES, F. 2006. 'More than an "industry": the forgotten power of tourism as a social force,' Tourism Management, vol.27, no.6, pp. 1192-1208.

HOWARTH, D. 2000. Discourse, Buckinghamshire, England; Philadelphia, Open University Press.

HUGHES, G. 1995. 'Authenticity in tourism,' Annals of Tourism Research, vol.22, no.4, pp. 781-803.

HUTNYK, J. 1996. The rumour of Calcutta: tourism, charity, and the poverty of representation, London; New Jersey, Zed Books.

JAMESON, F. 1982. The political unconscious, New York, Cornell University Press.

JAMESON, F. 1989. 'Marxism and Postmodernism,' New Left Review, vol.176, no.6, pp. 31-45.

JAMESON, F. 1991. Postmodernism, or, the cultural logic of late capitalism, Durham, Duke University Press.

JAMESON, F. 1996. 'Five theses on actually existing Marxism,' Monthly Review, vol.47, no.11, pp. 1-10.

JAMESON, F. 2000. 'Postmodernism, or the cultural logic of late capitalism,' in: HARDT, M. \& WEEKS, K. (eds.) The Jameson Reader, Malden, Massachusetts, Blackwell.

JAMESON, F. 2004. 'The politics of utopia,' New Left Review, vol.25pp. 35-54.

JAMESON, F. 2007. Archaeologies of the future: the desire called utopia and other science fictions, London, Verso. 
JAMESON, F. 2010. Valences of the dialectic, London, Verso.

KONTOGEORGOPOULOS, N. 2003. 'Keeping up with the Joneses: tourists, travellers, and the quest for cultural authenticity in Southern Thailand,' Tourist Studies, vol.3, no.2, pp. 171-203.

KORPELA, M. 2010. 'A postcolonial imagination? Westerners searching for authenticity in India,' Journal of Ethnic and Migration Studies, vol.36, no.8, pp. 1299-1315.

LANSKY, D. 2010. The rough guide to first-time around the world: a trip planner for the ultimate journey, London, Rough Guides.

LARRAIN, J. 1994. 'The postmodern critique of ideology,' The Sociological Review, vol.42, no.2, pp. 289-314.

LARSEN, S., ØGAARD, T. \& BRUN, W. 2011. 'Backpackers and mainstreamers: Realities and Myths,' Annals of Tourism Research, vol.38, no.2, pp. 690-707.

LASH, S. \& URRY, J. 1987. The end of organised capitalism, Oxford, Polity.

LEVITAS, R. 1990. The concept of utopia, Syracuse NY, Syracuse University Press.

LEVITAS, R. 2005. 'The imaginary reconstitution of society, or why sociologists and others should take utopia more seriously.' Inaugural Lecture. University of Bristol.

LEVITAS, R. 2007. 'Looking for the blue: the necessity of utopia,' Journal of Political Ideologies, vol.12, no.3, pp. 289 - 306.

LEWIS, T. \& POTTER, E. 2011. 'Introducing ethical consumption,' in: LEWIS, T. \& POTTER, E. (eds.) Ethical consumption: a crticial introduction, Milton Park, Abingdon, Oxon ; New York, Routledge. 
LOZANSKI, K. 2007. 'Violence in independent travel to India,' Tourist Studies, vol.7, no.3, pp. 295-315.

LOZANSKI, K. 2010. 'Defining "real India": representations of authenticity in independent travel,' Social Identities: Journal for the Study of Race, Nation and Culture, vol.16, no.6, pp. 741 - 762.

LOZANSKI, K. 2011. 'Independent travel: colonialism, liberalism and the self,' Critical Sociology, vol.37, no.4, pp. 465-482.

MACCANNELL, D. 1976. The tourist: a new theory of the leisure class, New York, Schoken Books.

MANNHEIM, K. 1936. Ideology and utopia: an introduction to the sociology of knowledge, London, Trubner \& co.

MAY, T. 1997. Social research: issues, methods and process, Buckingham, Open University Press.

MAZLISH, B. 1989. A new science: the breakdown of connections and the birth of sociology, New York, Oxford University Press.

MCLENNAN, G. 1996. 'Post-Marxism and the "four sins" of modernist theorising,' New Left Review, vol.218, no.2, pp. 53-74.

MIRANDA, C., DOWL, A., SHORTHOUSE, K., WATERSON, L. \& WILLIAMS, B. 2001. Discover Peru: experience the best of Peru, Footscray, Lonely Planet Publications.

MOLZ, J. G. 2006. 'Cosmopolitan bodies: fit to travel and travelling to fit,' Body \& Society, vol.12, no.3, pp. 1-21.

MOWFORTH, M. \& MUNT, I. 2003. Tourism and sustainability: new tourism in the Third World (2nd Edition), Florence, KY, USA, Routledge. 
MUNT, I. 1994. 'The 'other' postmodern tourism: culture, travel and the new middle classes,' Theory, Culture \& Society, vol.11, no.3, pp. 101-123.

MUSTONEN, P. 2006. 'Volunteer tourism: postmodern pilgrimage?,' Journal of Tourism and Cultural Change, vol.3, no.3, pp. 160 - 177.

MUZAINI, H. 2006. 'Backpacking Southeast Asia: strategies of "looking local",' Annals of Tourism Research, vol.33, no.1, pp. 144-161.

NOY, C. 2004. 'This trip really changed me: backpackers' narratives of selfchange,' Annals of Tourism Research, vol.31, no.1, pp. 78-102.

O'REILLY, C. 2005. 'Tourist or traveller? Narrating backpacker identity,' in: JAWORSKI, A. \& PRITCHARD, A. (eds.) Discourse, communication and tourism, Clevedon [England], Channel View Publications.

O'REILLY, C. 2006. 'From drifter to gap year tourist: mainstreaming backpacker travel,' Annals of Tourism Research, vol.33, no.4, pp. 998-1017.

OAKES, T. 2006. 'Get real! On being yourself and being a tourist,' in: MINCA, C. \& OAKES, T. (eds.) Travels in paradox: remapping tourism, Lanham, Rowman and Littlefield.

PHIPPS, P. 2004. 'Tourism and terrorism: an intimate equivalence,' in: BOHNGMELCH, S. (ed.) Tourists and tourism: a reader, Long Grove, Waveland.

REED, I. 2007. 'Cultural sociology and the democratic imperative,' in: REED, I. \& ALEXANDER, J. (eds.) Culture, society, and democracy: the interpretive approach, Boulder, Paradigm Publishers.

RICHARDS, G. \& WILSON, J. (eds.) 2004. The global nomad: backpacker travel in theory and practice, Clevedon, Channel View Publications.

RILEY, P. J. 1988. 'Road culture of international long-term budget travellers,' Annals of Tourism Research, vol.15, no.3, pp. 313-328. 
ROJEK, C. 1993. Ways of Escape: modern transformations in leisure and travel, Basingstoke, Macmillan.

SAID, E. 2003. Orientalism, London, Penguin.

SCHEYVENS, R. 2002. 'Backpacker tourism and Third World development,' Annals of Tourism Research, vol.29, no.1, pp. 144-164.

SCHEYVENS, R. 2011. Tourism and poverty, New York, Routledge.

SIMPSON, K. 2004. ' "Doing development": the gap year, volunteer-tourists and a popular practice of development,' Journal of International Development, vol.16, no.5, pp. 681-692.

SIMPSON, K. 2005. 'Dropping out or signing up? The professionalisation of youth travel,' Antipode, vol.37, no.3, pp. 447-469.

SØRENSEN, A. 2003. 'Backpacker ethnography ' Annals of Tourism Research, vol.30, no.4, pp. 847-867.

SPEED, C. 2008. 'Are backpackers ethical toursits?,' in: HANNAM, K. \& ATEJEVIC, I. (eds.) Backpacker tourism: conceps and profiles, Clevedon, Channel View Publications.

STATISTICS NEW ZEALAND. 2011. International Travel and Migration [Online]. Available:

http://www.stats.govt.nz/browse_for_stats/population/Migration/internationaltravel-and-migration-info-releases.aspx [Accessed 14/02/12].

TEGELBERG, M. 2010. 'Hidden sights: tourism, representation and Lonely Planet Cambodia,' International Journal of Cultural Studies, vol.13, no.5, pp. 491-509.

THOMPSON, J. B. 1990. Ideology and modern culture: critical social theory in the era of mass communication, Cambridge, Polity Press. 
TOLICH, M. \& DAVIDSON, C. 1999. Starting fieldwork: an introduction to qualitative research in New Zealand, Auckland, Oxford University Press.

TORMEY, S. \& TOWNSHEND, J. 2006. Key thinkers from critical theory to postMarxism, London, Sage.

TOURISM CONCERN. 1999. Tourism in focus: backpacking, Spring, no. 31, London, Tourism Concern

TURNER, L. \& ASH, J. 1975. The golden hordes, London, Constable.

UNWTO. 2005. Global code of ethics for tourism [Online]. Dakar. Available: http://www.unwto.org/ethics/responsible/en/responsible.php?subop=7 [Accessed 01/12/11].

UNWTO. 2011a. Toursim and poverty alleviation [Online]. Available: http://step.unwto.org/en/content/tourism-and-poverty-alleviation-1 [Accessed 22/11/11].

UNWTO. 2011b. World Tourism Organisation [Online]. Available: http://www.unwto.org/aboutwto/why/en/why.php?op=1 [Accessed 14/06/11].

UNWTO. nd. Toursim will contribute to solutions for global climate change and poverty challanges [Online]. Available:

http://www.unwto.org/media/key/en/str_messg.php?op=4\&subop=7 [Accessed $1 / 07 / 11]$.

URIELY, N. 1997. 'Theories of modern and postmodern tourism,' Annals of Tourism Research, vol.24, no.4, pp. 982-985.

URIELY, N., YONAY, Y. \& SIMCHAI, D. 2002. 'Backpacking experiences: a type and form analysis,' Annals of Tourism Research, vol.29, no.2, pp. 520-538.

URRY, J. 1995. Consuming places, London; New York, Routledge. 
URRY, J. 2002a. 'Mobility and proximity,' Sociology, vol.36, no.2, pp. 255-274.

URRY, J. 2002b. The tourist gaze, London, Sage.

URRY, J. \& LARSEN, J. 2011. The tourist gaze 3.0, London, Sage.

WALLERSTEIN, I. 1990. The modern world-system, New York, Academic Press.

WANG, N. 2000. Tourism and modernity: a sociological analysis, Oxford, Elsevier Science.

WELK, P. 2004. 'The beaten track: anti-tourism as an element of backpacker identity construction,' in: RICHARDS, G. \& WILSON, J. (eds.) The global nomad: backpacker travel in theory and practice Clevedon, Channel View Publications.

WELK, P. 2007. 'The Lonely Planet myth: backpacker bible and travel survival kit?,' in: HANNAM, K. \& ATELJEVIC, I. (eds.) Backpacker tourism: concepts and profiles, Clevedon, Channel View Publications.

WHEELER, T. 2007. Bad lands: tourist on the axis of evil, Footscray, Lonely Planet.

ŽIŽEK, S. 1997. 'Multiculturalism, or, the cultural logic of multinational capitalism,' New Left Review, vol.225, no.3, pp. 28-51.

ŽIŽEK, S. 2000. 'How did Marx invent the symptom?,' in: ŽIŽEK, S. (ed.) Mapping Ideology, London, Verso. 